PERFORMANCE OF GEOTEXTILE-REINFORCED BASES FOR PAVED ROADS

by

MILAD SAGHEBFAR

M.S. Amirkabir University of Technology, 2009

AN ABSTRACT OF A DISSERTATION

submitted in partial fulfillment of the requirements for the degree

DOCTOR OF PHILOSOPHY

Department of Civil Engineering

College of Engineering

KANSAS STATE UNIVERSITY

Manhattan, Kansas

2014 


\begin{abstract}
Geotextiles have been widely promoted for pavement structure over the past 30 years. However, there is a lack of well-instrumented, full-scale experiments to investigate the effect of geotextile reinforcement on the pavement design. In this study, full-scale accelerated tests were conducted on eight lanes of pavement test sections. Six out of these eight sections had granular bases reinforced with different types of woven geotextiles. The reinforced base sections and the control sections (with unreinforced base) were paved with Superpave hot-mix asphalt. Base and subgrade materials were the same for all sections while the test sections had different asphalt and base layer thicknesses. Each section was instrumented with two pressure cells on top of the subgrade, six strain gages on the geotextile body, six H-bar strain gages at the bottom of the asphalt layer, two thermocouples and one Time Domain Reflectometer (TDR) sensor. The sections were loaded to 250,000 to 500,000 repetitions of an $80-\mathrm{kN}$ (18-kip) single axle load of the accelerated pavement testing machine. The mechanistic response of each section was monitored and analyzed at selected number of wheel passes. Results indicate that properly selected and designed geotextile-reinforced bases improve pavement performance in term of rutting and reduced pressure at the top of the subgrade. Finite element (FE) models were developed and verified using results from the full-scale accelerated pavement tests. The calibrated model was used to investigate the effects of geotextile properties on the pavement responses. FE analysis shows that benefits of reinforcement are more evident when stiffer geotextile is used.
\end{abstract}




\title{
PERFORMANCE OF GEOTEXTILE-REINFORCED BASES FOR PAVED ROADS
}

by

MILAD SAGHEBFAR

M.S. Amirkabir University of Technology, 2009

A DISSERTATION

submitted in partial fulfillment of the requirements for the degree

DOCTOR OF PHILOSOPHY

Department of Civil Engineering

College of Engineering

\author{
KANSAS STATE UNIVERSITY \\ Manhattan, Kansas
}

2014

Approved by:

Major Professor

Mustaque Hossain 


\begin{abstract}
Geotextiles have been widely promoted for pavement structure over the past 30 years. However, there is a lack of well-instrumented, full-scale experiments to investigate the effect of geotextile reinforcement on the pavement design. In this study, full-scale accelerated tests were conducted on eight lanes of pavement test sections. Six out of these eight sections had granular bases reinforced with different types of woven geotextiles. The reinforced base sections and the control sections (with unreinforced base) were paved with Superpave hot-mix asphalt. Base and subgrade materials were the same for all sections while the test sections had different asphalt and base layer thicknesses. Each section was instrumented with two pressure cells on top of the subgrade, six strain gages on the geotextile, six H-bar strain gages at the bottom of the asphalt layer, two thermocouples and one Time Domain Reflectometer (TDR) sensor. The sections were loaded to 250,000 to 500,000 repetitions of an $80-\mathrm{kN}$ single axle load of the accelerated pavement testing machine. The mechanistic response of each section was monitored and analyzed at selected number of wheel passes. Results indicate that properly selected and designed geotextile-reinforced bases improve pavement performance in term of rutting and reduced pressure at the top of the subgrade. Finite element (FE) models were developed and verified using results from the full-scale accelerated pavement tests. The calibrated model was used to investigate the effects of geotextile properties on the pavement responses. FE analysis shows that benefits of reinforcement are more evident when stiffer geotextile is used.
\end{abstract}




\begin{abstract}
ACKNOWLEDGMENTS
I wish to express my sincere appreciation to Professor Mustaque Hossain for giving me the opportunity to conduct this research. I am deeply appreciative of his guidance, encouragement and steady support during my time at Kansas State University. Also, I would like to thank my committee members, Dr. Esmaeily, Dr. Dissanayake, and Dr. Xin for their valuable guidance, assistance and help throughout this research. Thanks are also extended to Dr. Datta, external chair of my committee. Financial support provided by TENCATE Geosynthetics is gratefully acknowledged. I also wish to thank all my colleagues and friends for their help and friendship, which made my studies at Kansas State University more pleasing.

Finally, words cannot adequately express my gratitude toward my father, mother, fiancé and my sisters for their ongoing support, understanding, help and sacrifice throughout this period of study and being a constant source of inspiration.
\end{abstract}




\section{Table of Contents}

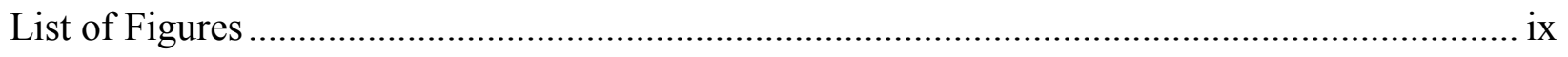

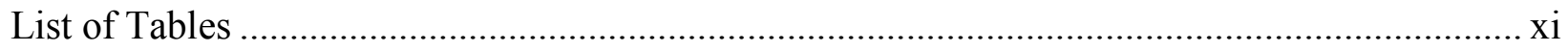

Chapter 1 - Introduction ................................................................................................. 1

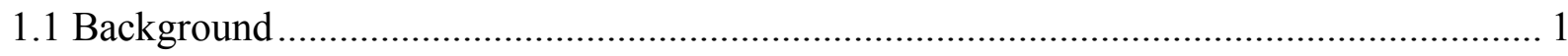

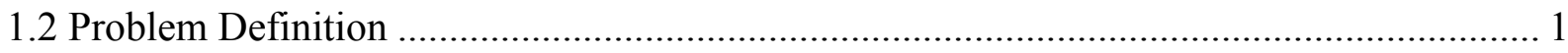

1.3 Objective

1.4 Synopsis of Research Plan ...................................................................................... 3

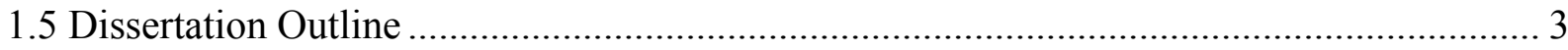

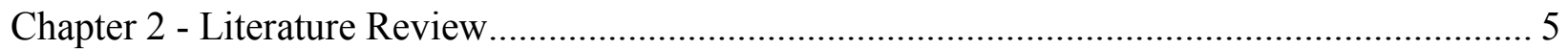

2.1. Mechanism of Geosynthetic Reinforcement in Pavements ............................................... 5

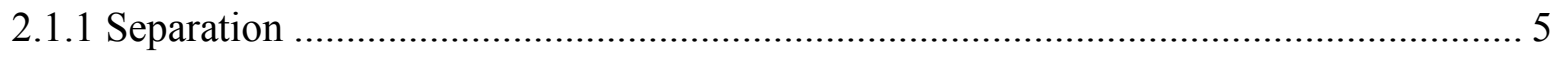

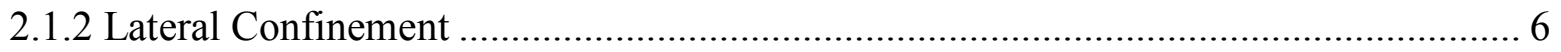

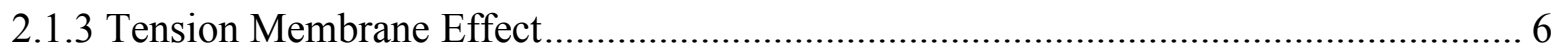

2.2 Previous Studies on Geosynthetic-Reinforced Pavement................................................. 7

2.3 Numerical Modeling of Pavements .............................................................................. 9

2.3.1Numerical Modeling of Geosynthetic-Reinforced Pavements ................................... 10

2.3.2 Soil/Aggregate-Geosynthetic Rnterface Model ........................................................... 11

2.3.3 Material Modeling of Geosynthetics ........................................................................... 12

Chapter 3 - Accelerated Pavement Testing of Geotextile-Reinforced Paved Roads.................... 13

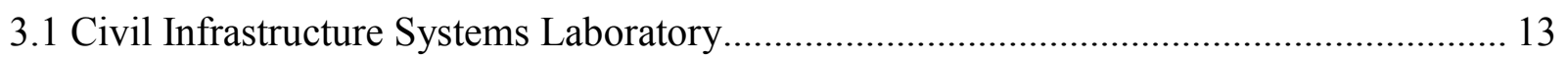

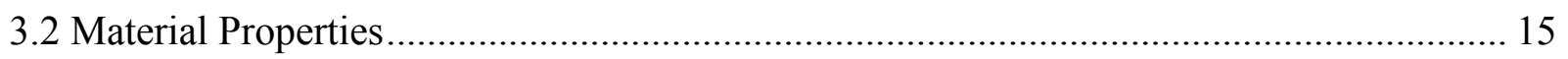

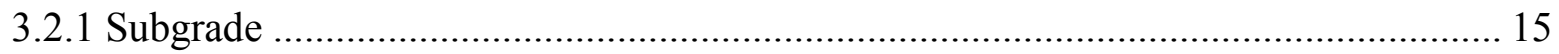

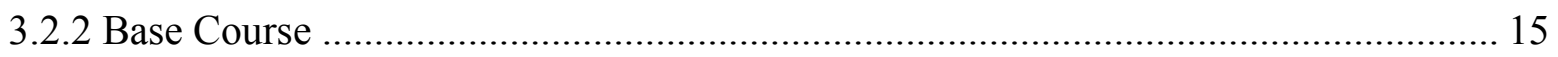

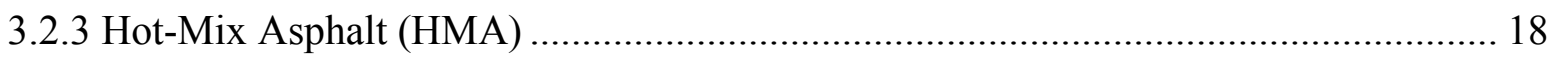

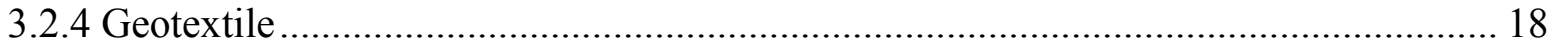

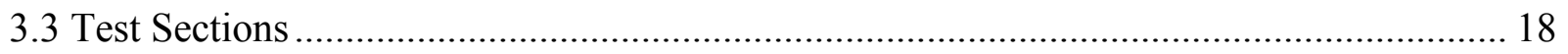

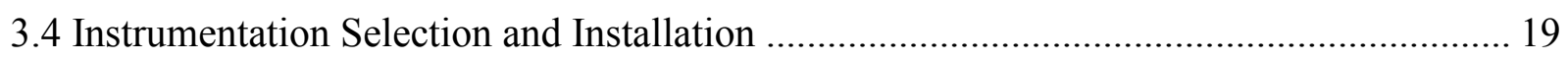

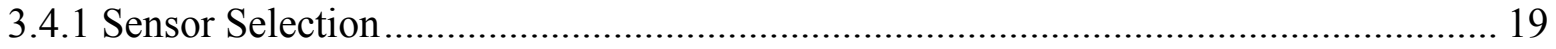




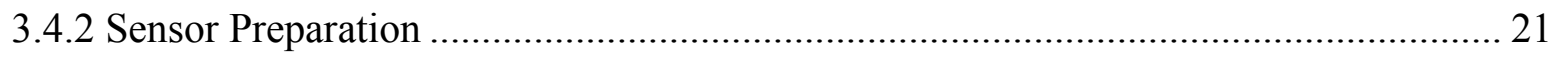

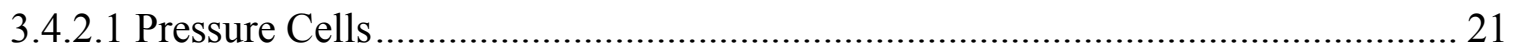

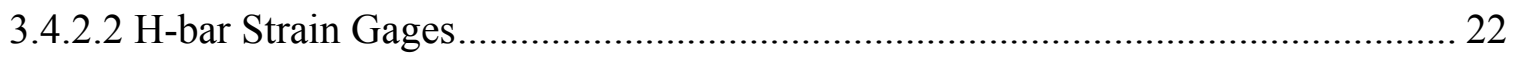

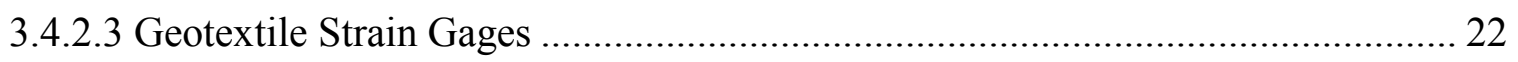

3.5 Data Acquisition Hardware .......................................................................................... 24

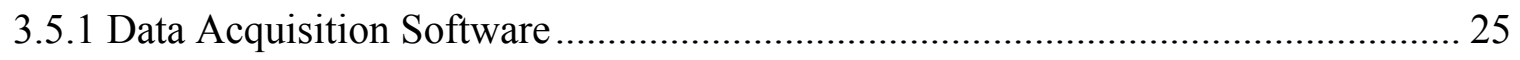

Chapter 4 - Full-Scale Accelerated Pavement Testing Results ................................................... 28

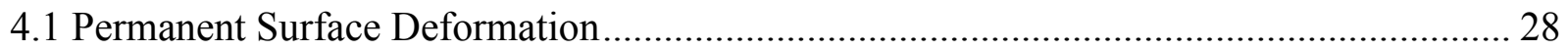

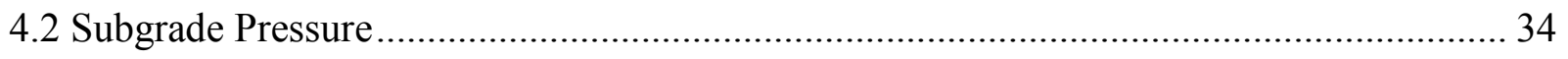

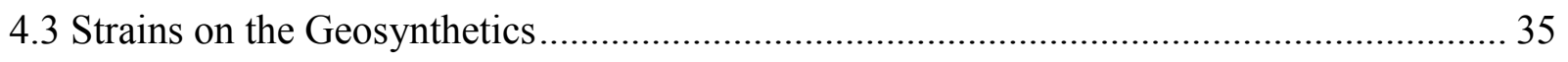

4.4 Strain at the Bottom of HMA Layer ............................................................................ 38

4.5 Back-Calculated Layer Moduli.................................................................................... 40

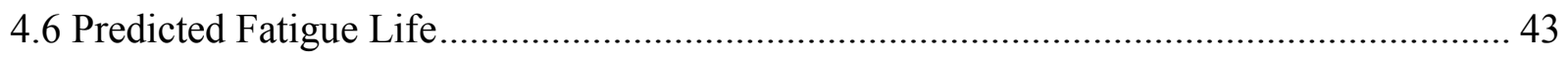

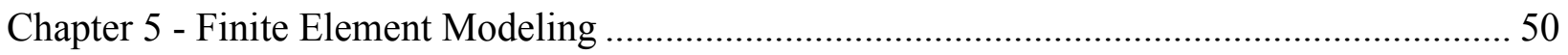

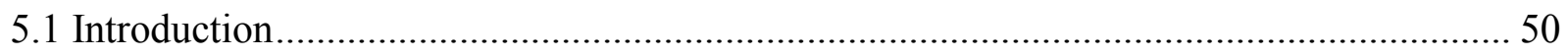

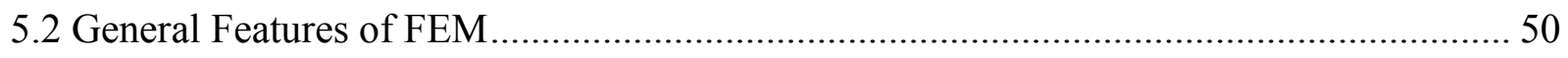

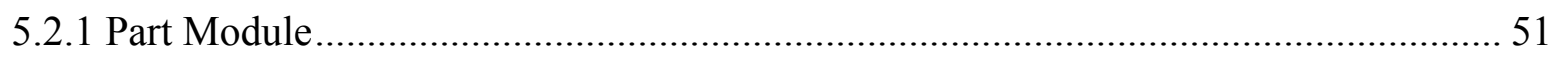

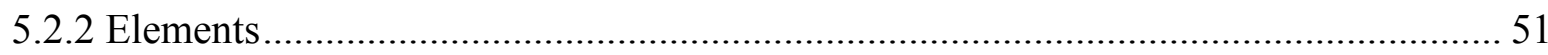

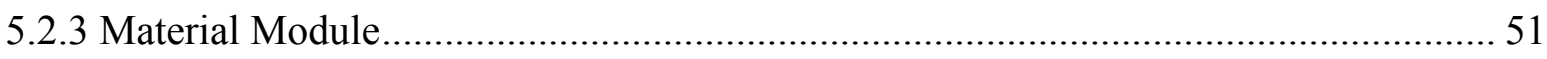

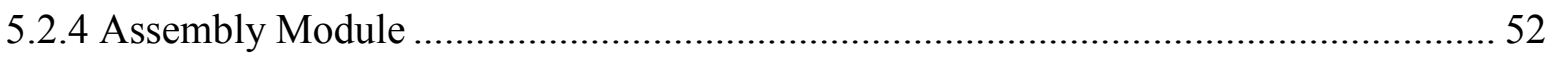

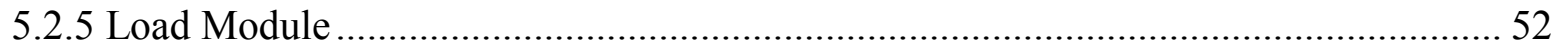

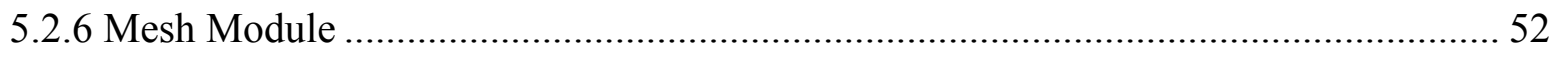

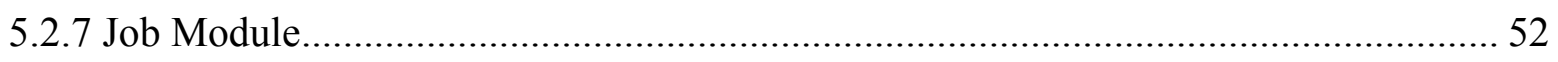

5.3 Pavement Layer Material Models ................................................................................... 53

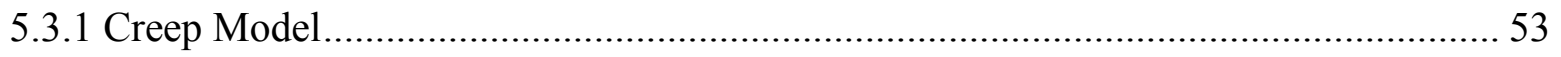

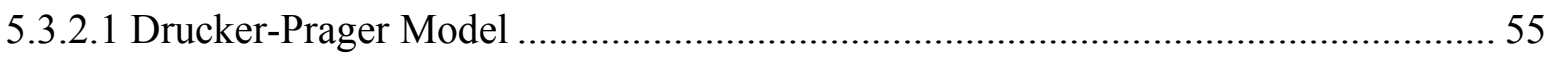

Chapter 6 - Finite Element Modeling of APT Sections ............................................................ 57

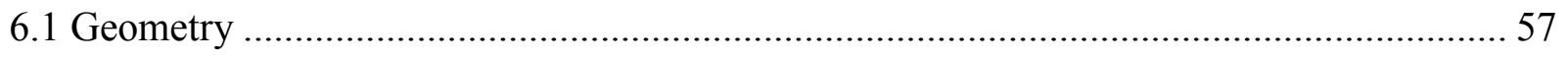

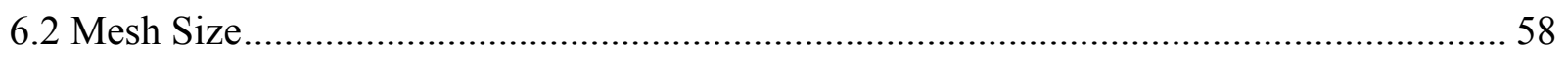

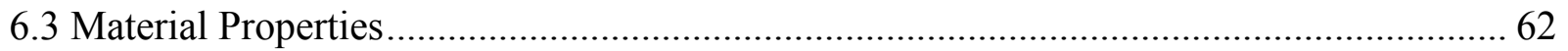

6.3.1 HMA Layer Properties....................................................................................... 62 


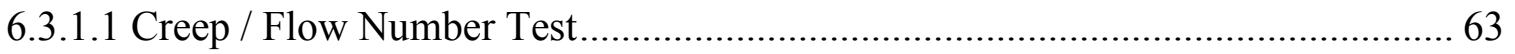

6.3.2 Base and Subgrade Layer Properties ....................................................................... 68

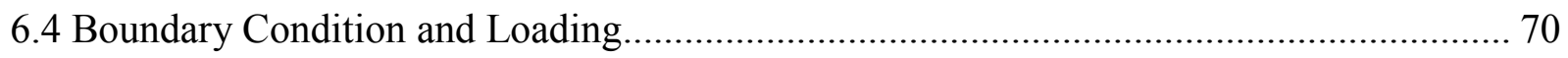

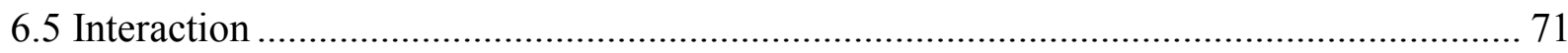

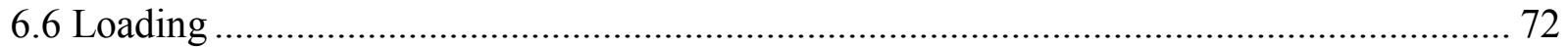

6.7 Sensitivity Analysis on Loading Mode and Material Model ............................................. 74

Chapter 7 - Finite Element Model Analysis Results............................................................... 78

7.1 Comparison of the FE Model Results with Full-scale Test Results ................................... 78

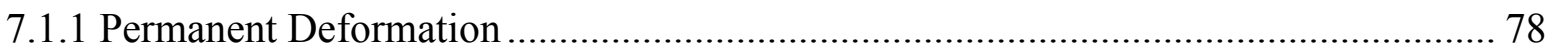

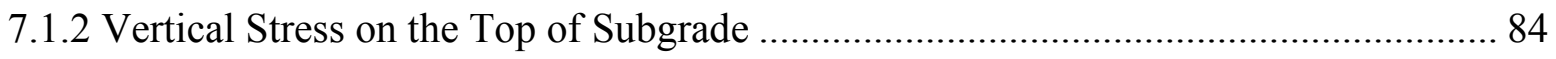

7.1.3 Horizontal Strain at the Bottom of HMA Layer ........................................................ 90

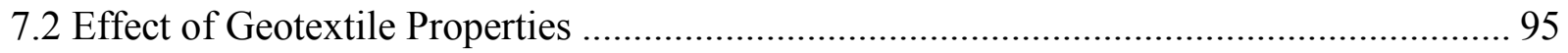

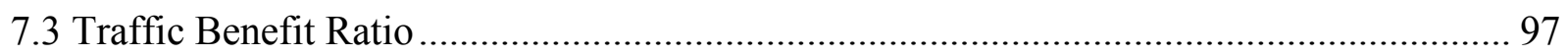

Chapter 8 - Conclusions and Recommendations …………………........................................ 99

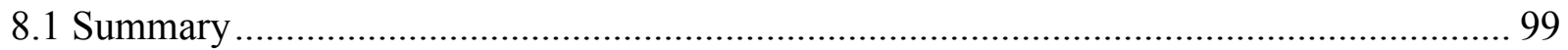

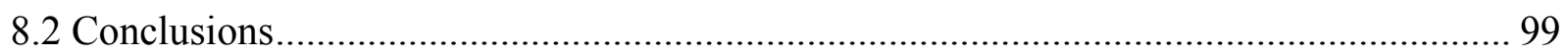

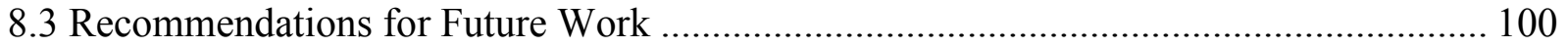




\section{List of Figures}

Figure 2-1 Schematic of mixing and separation (Zhang, 2007) ............................................. 5

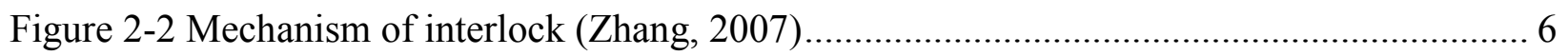

Figure 2-3 Tension membrane effect (Zhang, 2007) f...................................................... 7

Figure 2-4 Illustration of a) elastic-plastic, b) thermo-visco, c) anisotropic and d) ratcheting

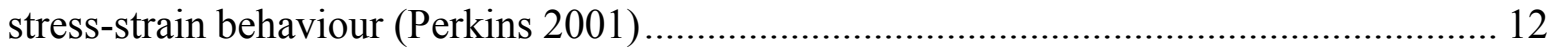

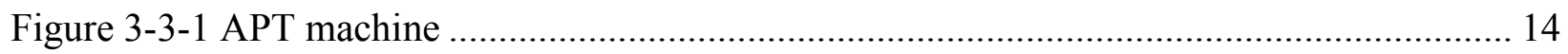

Figure 3-3-2 Truncated wander of APT machine at Kansas State University .......................... 14

Figure 4-1 Monitoring transverse profile using the Chicago Dial Indicator ............................ 29

Figure 6-1 Sensitivity analysis for optimum mesh size .................................................. 59

Figure 6-2 Effect of number of elements on predicted maximum rut depth after 10,000 wheel passes

Figure 6-3 Effect of number of elements on predicted maximum pressure on top of subgrade after 10,000 wheel passes 60

Figure 6-4 Effect of number of elements on computation time required for 10,000 wheel passes

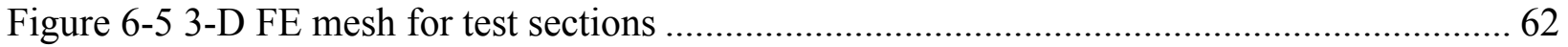

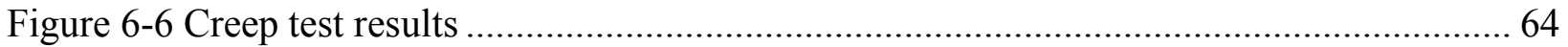

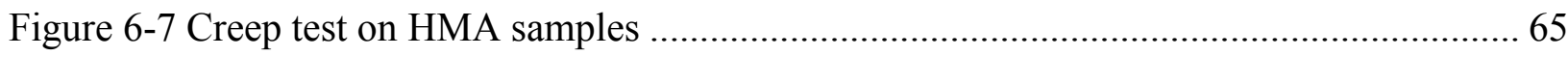

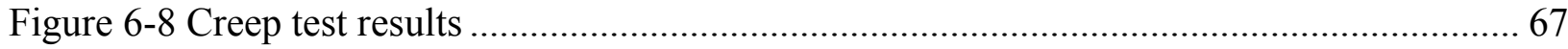

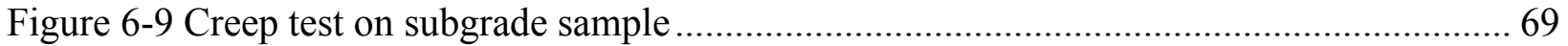

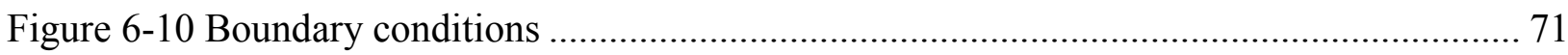

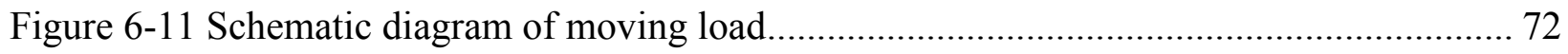

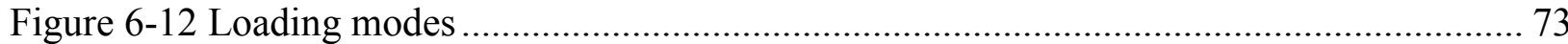

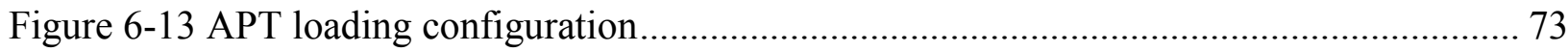

Figure 7-1 Permanent surface deformation versus load cycle applied first experiment............. 79

Figure 7-2 Permanent surface deformation versus load cycle applied second experiment .......... 79

Figure 7-3 Permanent surface deformation versus load cycle applied Section A ..................... 80

Figure 7-4 Permanent surface deformation versus load cycle applied Section B...................... 80

Figure 7-5 Permanent surface deformation versus load cycle applied Section C..................... 81 
Figure 7-6 Permanent surface deformation versus load cycle applied Section D .................... 81

Figure 7-7 Permanent surface deformation versus load cycle applied Section D ..................... 82

Figure 7-8 Permanent surface deformation versus load cycle applied Section F ...................... 82

Figure 7-9 Permanent surface deformation versus load cycle applied Section G .................... 83

Figure 7-10 Permanent surface deformation versus load cycle applied Section $\mathrm{H}$.................... 83

Figure 7-11 Predicted vertical stress on subgrade-Section A-D ........................................... 85

Figure 7-12 Predicted vertical stress on subgrade-Section E-H .......................................... 85

Figure 7-13 Vertical pressure on top of subgrade- Section A ................................................ 86

Figure 7-14 Vertical pressure on top of subgrade- Section B............................................ 86

Figure 7-15 Vertical pressure on top of subgrade- Section C............................................. 87

Figure 7-16 Vertical pressure on top of subgrade- Section D ............................................... 87

Figure 7-17 Vertical pressure on top of subgrade- Section E ................................................ 88

Figure 7-18 Vertical pressure on top of subgrade- Section F ........................................... 88

Figure 7-19 Vertical pressure on top of subgrade- Section G ............................................ 89

Figure 7-20 Vertical pressure on top of subgrade- Section H ............................................. 89

Figure 7-21 Predicted horizontal strain at the bottom of AC layer- Sections A-D................... 90

Figure 7-22 Predicted horizontal strain at the bottom of AC layer- Sections E-H................... 91

Figure 7-23 Horizontal strain at the bottom of AC layer- Section A...................................... 91

Figure 7-24 Horizontal strain at the bottom of AC layer- Section B..................................... 92

Figure 7-25 Horizontal strain at the bottom of AC layer- Section C.................................... 92

Figure 7-26 Horizontal strain at the bottom of AC layer- Section D..................................... 93

Figure 7-27 Horizontal strain at the bottom of AC layer- Section E ...................................... 93

Figure 7-28 Horizontal strain at the bottom of AC layer- Section F ..................................... 94

Figure 7-29 Horizontal strain at the bottom of AC layer- Section G..................................... 94

Figure 7-30 Horizontal strain at the bottom of AC layer- Section H...................................... 95 


\section{List of Tables}

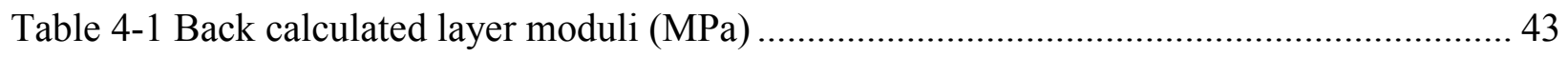

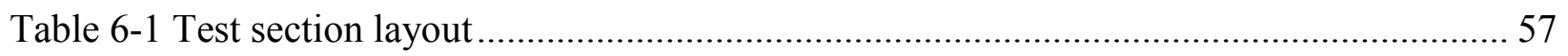

Table 6-2 Effect of number of elements on predicted responses ............................................5 58

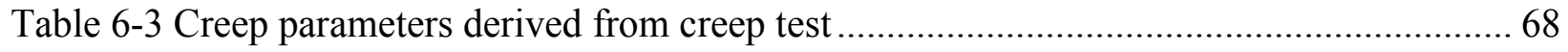

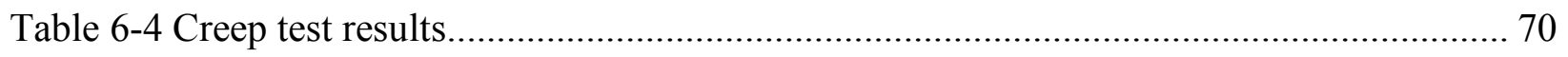

Table 7-1 Effects of geosynthetic modulus on pavement responses ..................................... 96

Table 7-2 Effects of geosynthetic interface friction on pavement responses ............................ 96

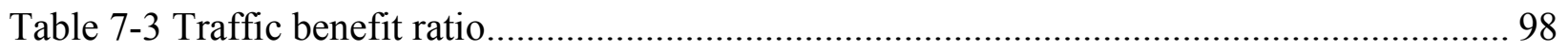




\section{Chapter 1 - Introduction}

\subsection{Background}

The American Society for Testing and Materials (ASTM) (ASTM, 1986) defines geosynthetics as "a planar product manufactured from polymeric materials used with soil, rock, earth, or other geotechnical engineering related material as an integral part of a man-made project, structure, or system." Geosynthetics are usually classified into seven categories: geotextiles, geogrids, geonets, geomembranes, geosynthetic clay liners, geofoam, and geocomposites. Out of those categories, geotextiles and geogrids are most common for pavement applications; geotextiles have been used in pavement systems over the past 30 years. The claim has been made that use of geosynthetics/geotextile at the subgrade-base course interface of a paved road beneficially increases the number of load repetitions until failure or decreases pavement layer thickness because of the separation, lateral restraint, and/or tensioned membrane effect of geosynthetics (Ericks \& Drescher, 2001; Maxwell et al., 2005). These benefits are thought to be provided by the separation, lateral restraint, and/or a tensioned membrane effect of the geosynthetics (Ericks \& Drescher, 2001; Maxwell et al., 2005; Tingle \& Jersey, 2005). Intermixing at the base course/subgrade interface causes a reduction of the effective base thickness and elastic/resilient modulus. Geosynthetics as separator layers prevent this intermixing. Vertical stresses transferred through the geosynthetic-reinforced base onto subgrade can be lower than that on the unreinforced pavement due to load spreading over a wider area. Geosynthetics can also absorb shear stresses, consequently decreasing subgrade stress. Tensioned membrane effect of geosynthetics occurs in highly deformed pavements. In unpaved roads with large rutting, tension in geosynthetics typically causes a vertical resultant counter force which helps the subgrade support higher load (Zhang, 2007).

\subsection{Problem Definition}

Various small-scale or laboratory studies have previously been conducted to evaluate geotextile-reinforced pavement performance. Attempts were made to develop design methods for 
geotextile-reinforced pavements with limited success. As mentioned earlier, the geotextile and geo-grid reinforcements of geosynthetics have been developed over the last three decades for applications in pavements as reinforcement. These reinforcements, when placed within the base course, can enhance load distribution capacity by confining soil/aggregate particles. This may result in reduced base course thickness and prolonged pavement service life. For example, the Federal Aviation Administration (1994) funded studies by the U.S. Army Corps of Engineers to evaluate the benefits of geotextiles and geogrids for reinforcement of flexible pavements intended to serve light aircraft. The results of these studies have been published in research reports DOT/FAA/RD-90/28, Geogrid Reinforced Base Courses for Flexible Pavements for Light Aircraft: Literature Review and Test Section Design and DOT/FAA/RD-92/25, Geogrid Reinforced Base Courses for Flexible Pavements for Light Aircraft: Test Section Construction, Behavior Under Traffic, Laboratory Tests, and Design Criteria. Flexible pavements with and without geogrids were trafficked to failure under a $469 \mathrm{kPa}$ (68 psi) tire pressure. These studies show some geogrids are capable of increasing pavement life under traffic; while others have little or no effect on pavement life. The physical properties a geogrid must possess in order to enhance flexible pavement performance were defined in the study. A relationship between unreinforced thickness and equivalent reinforced thickness was developed and is shown in Figure 1.1. However, such an established procedure for the geotextile reinforcement for highway pavements, though needed, is currently missing. Therefore, a larger-scale study is needed under real-world load condition.

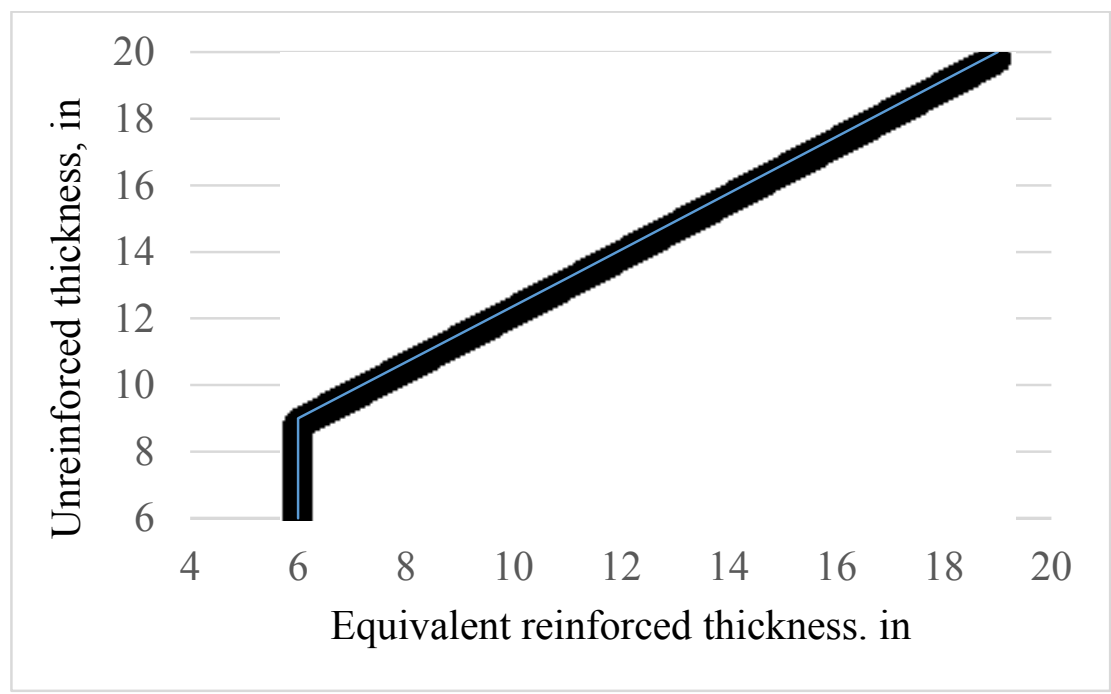




\section{Figure 1-1 Design Criteria for Unreinforced Thickness (AC surface plus Base) vs. Equivalent Reinforced Thickness (FAA, 1994)}

\subsection{Objective}

The primary objective of this study was to evaluate the performance of pavements with geotextilereinforced bases under controlled loading and environmental conditions. Another objective was to develop a numerical model to establish optimum properties of geotextiles for highway pavement applications. To achieve these objectives, eight pavement test sections were constructed at the Civil Infrastructure System Laboratory (CISL) of Kansas State University. Six sections had different types of geotextile and crushed stone base with variable thickness, and two unreinforced sections were designated as control. All sections were paved with variable thicknesses of hot-mix asphalt (HMA) concrete, and sections were loaded under wheel loading up to 500,000 repetitions of $80-\mathrm{kN}$ (18-kip) single axle load or $12.5 \mathrm{~mm}(1 / 2 \mathrm{in})$ rut depth, whichever came first. Finite element models (FEMs) were developed and verified using results of full-scale accelerated pavement tests (APT) previously conducted. The calibrated model can be used to study pavements with geotextile-reinforced base.

\subsection{Synopsis of Research Plan}

Full-scale APTs were conducted on eight lanes of pavement test sections. Six of these eight sections had granular bases reinforced with various types of woven geotextiles. Each section was fully instrumented with pressure cells, strain gages, thermocouples, and time domain reflectometers. Mechanistic responses of each section were monitored and analyzed.

A three-dimensional (3-D) finite element (FE) model was constructed using the commercial FE software ABAQUS. The developed model was calibrated with the APT results from the geotextile-reinforced sections.

\subsection{Dissertation Outline}

This dissertation contains eight chapters. Chapter 1 provides the introduction. Chapter 2 outlines state-of-the-art knowledge regarding the use of geosynthetics in the pavement system, recent studies on advanced pavement design, and numerical modeling of pavement materials. Chapter 3 presents details of full-scale tests conducted at Kansas State University on pavements 
with geotextile-reinforced bases. Chapter 3 also includes details of the test sections and material characterization, construction process, and instrumentation. Chapter 4 discusses results of the fullscale tests. In this chapter, details of data collection from the sensors and surface deflections from the falling weight deflectometer (FWD) tests are summarized and analyzed. Chapter 5 discusses steps in the process to develop FE model. Chapter 6 explains the numerical model developed for the APT test sections. Results of FE modeling are discussed in Chapter 7 and a summary of results and recommendations from this study are presented in Chapter 8 . 


\section{Chapter 2 - Literature Review}

\subsection{Mechanism of Geosynthetic Reinforcement in Pavements}

Geogrid and geotextiles are commonly used as reinforcements in pavement systems. Nonwoven geotextile is beneficial to separation, filtration, and drainage; however, woven geotextiles and geogrids provide reinforcement benefits, including separation, lateral confinement, and tension membrane effect (Zhang, 2007).

\subsubsection{Separation}

One of the most important benefits of geotextile in pavements is separation. The overlying granular base tends to lose desired properties when fines from the subgrade migrate into this layer due to repeated traffic load. This results in reduced base layer modulus and effective thickness, potentially leading to structural failure of the pavement system. A geosynthetic layer between the subgrade and base creates a separation that prevents mixing. Figure 2-1 demonstrates this separation effect.

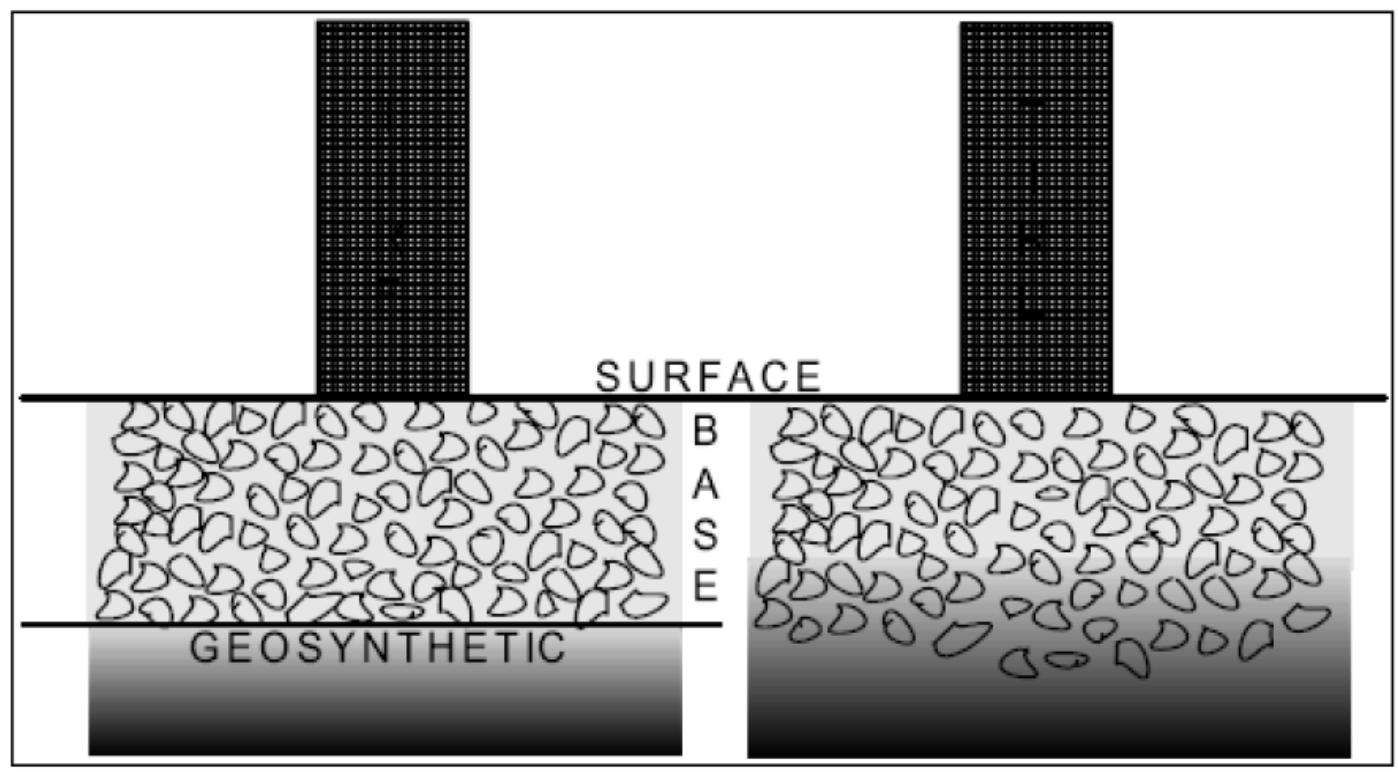

Figure 2-1 Schematic of mixing and separation (Zhang, 2007) 


\subsubsection{Lateral Confinement}

A spreading effect occurs when pressure from the wheel load creates shear stresses. Vertical strain resulting from the spreading effect can eventually cause rutting, or channelized depression in the wheel paths of highway pavement. One solution to limit this vertical strain would be through geosynthetics limitation of lateral movement with frictional force between the geosynthetic and base course based on compaction of the base material into the geosynthetics (Zhang, 2007). A partial penetration works through the apertures; this interlocking effect occurs specifically with the geogrid (Figure 2-2) thereby increasing the modulus of the base layer because of the confinement effect. This effect occurs when the geosynthetics and aggregates interlock and reduce lateral movement.

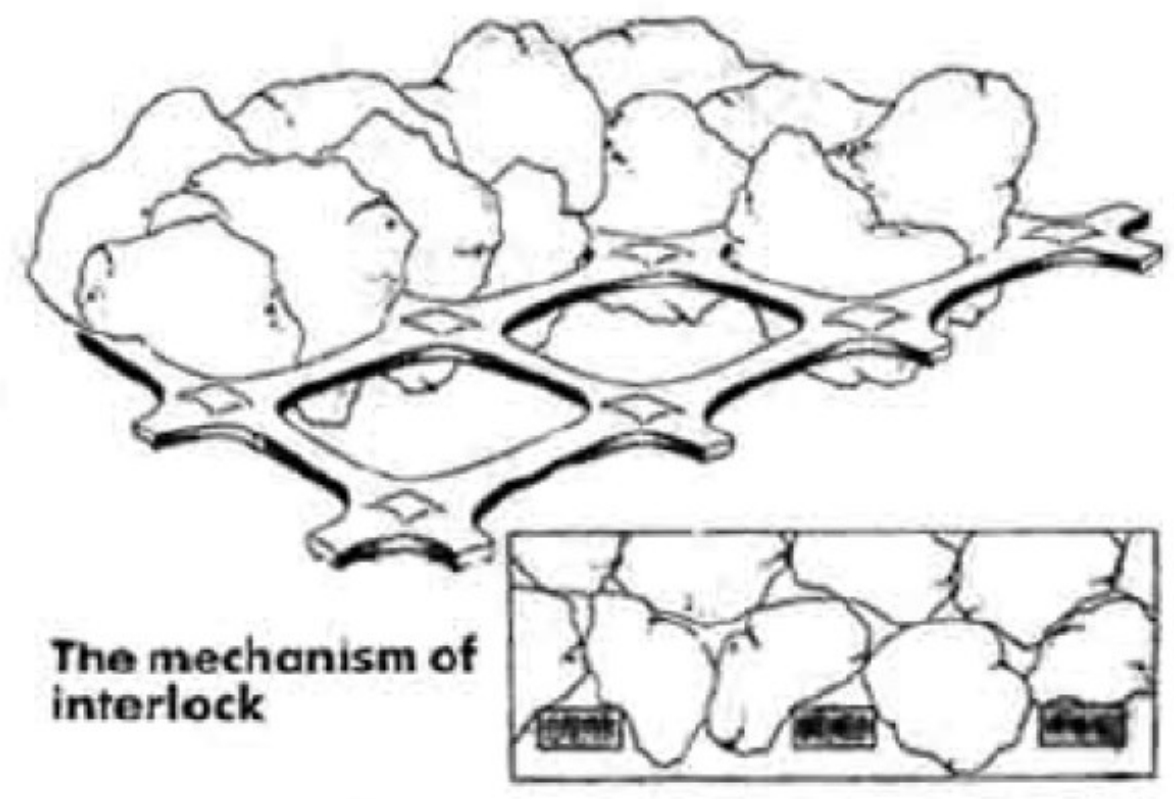

Figure 2-2 Mechanism of interlock (Zhang, 2007)

\subsubsection{Tension Membrane Effect}

The other mechanism of interaction between geosynthetics and granular materials is the tension membrane effect. This effect develops through a concave shape in the geosynthetic layer formed by vertical deformity at the bottom of the base layer. Specifically, the subgrade experiences a reduction in vertical stress due to geosynthetic tensile force. This effect is contingent upon a large deformation in the geosynthetics after mobilization of tensile resistance, as illustrated in Figure 2-3. 


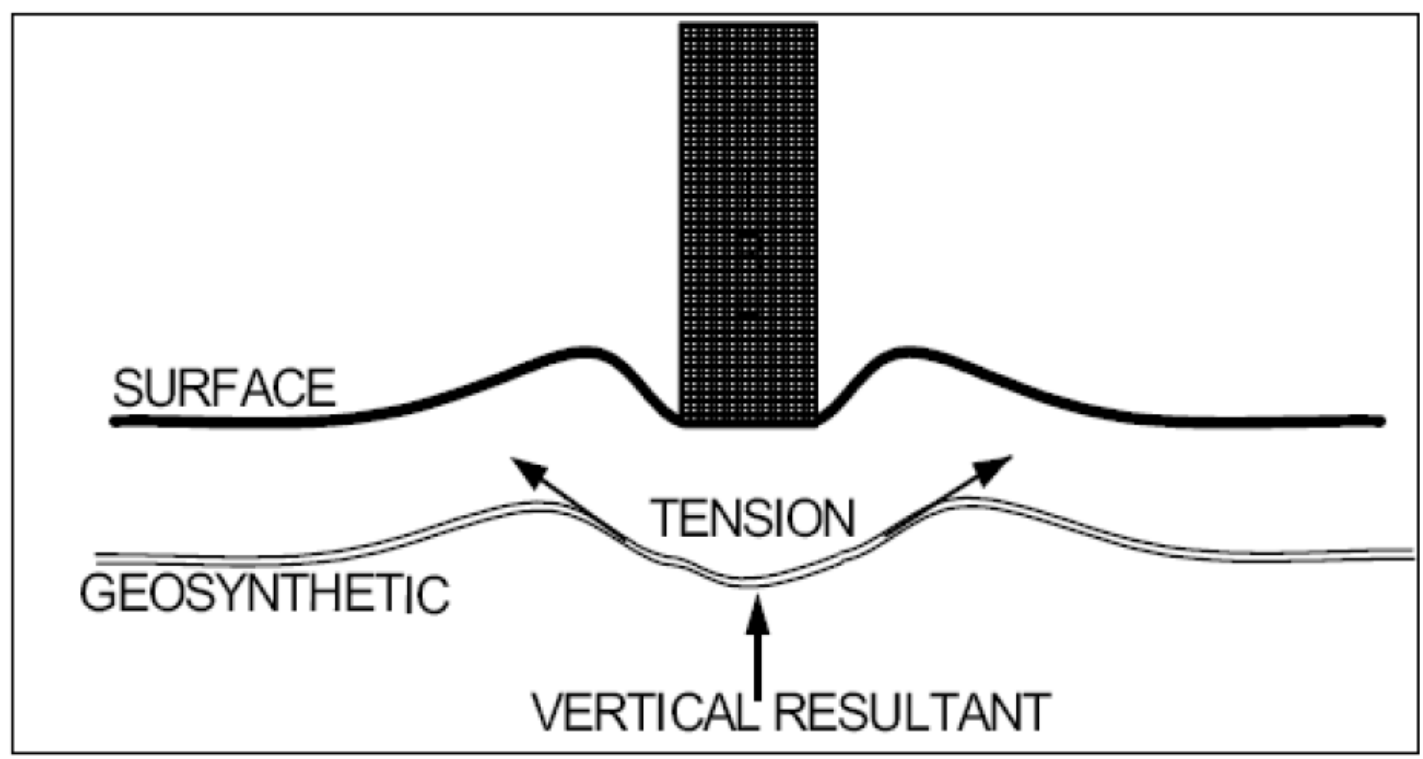

Figure 2-3 Tension membrane effect (Zhang, 2007)

\subsection{Previous Studies on Geosynthetic-Reinforced Pavement}

A literature review reveals numerous studies performed to determine the effect of geotextiles on the pavement system (Webster \& Alford, 1978; Webster, 1992; Gregory \& Bang, 1994; Kelly et al., 1995; Bayomy et al., 1996; Al-Qadi \& Bhutta, 1999; Ericks \& Drescher, 2001; Brandon et al., 2005; Maxwell et al., 2005; Tingle \& Jersey, 2005). Small-scale laboratory tests, field investigations, and numerical modeling techniques were used to examine the impact of geotextiles on pavement performance.

Bayomy et al. (1996) used 320-mm cylindrical molds to test the effect of geotextiles on bearing capacity and resistance to permanent deformation of the base layer. They found that geotextiles improve bearing capacity and resistance of the soil-aggregate system to permanent deformation in dry and saturated conditions, but effectiveness was more significant in the saturated condition. Repeated plate load tests were conducted by Kelly et al. (1995) to examine the effects of various geosynthetics on pavement stiffness. They found that woven geotextiles provide more stiffness than unwoven geotextiles. Gregory and Bang (1994) studied the effect of geotextiles on soil material strength. Results of California Bearing Ratio (CBR) tests showed that geotextiles improve pavement stiffness especially when CBR of subgrade was lower than 11. However, 
laboratory tests may not be as accurate of a performance indicator as full-scale tests because laboratory tests are done on small sections- section size and loading condition are not accurate (Brandon et al., 2005).

However, because of cost, logistics, and risk involved, few full-scale tests were conducted on geotextile-reinforced pavement systems. Webster and Alford (1978) conducted full-scale tests on unpaved roads reinforced by nonwoven geotextiles and geomembranes. Their first section consisted of $380 \mathrm{~mm}$ of well-graded crushed limestone as the base course and a subgrade with CBR of 1 . This section was reinforced by a nonwoven geotextile at the base/subgrade interface. Their second test section was constructed from a $150-\mathrm{mm}$ crushed limestone layer on a subgrade of 3.3 CBR reinforced with a geomembrane. Rutting results indicated that geosynthetic reinforcement reduced required base thickness. This study also proved that effects of geosynthetics were more significant when a low strength subgrade was used. Webster (1992) conducted tests on six aggregate-surfaced road sections. Test sections included control, one geogrid reinforced, and three geotextile reinforced. All sections had 100-mm base course thickness and poorly-graded sand subgrade with a CBR of 10. Geotextile-reinforced sections did not perform better than the control section. Therefore, the conclusion was made that lateral movement of aggregates at the aggregategeotextile interface limits the reinforcement effect of geotextiles.

A secondary road pavement in Bedford County, Virginia was instrumented in 1994 to measure pavement response to vehicular loading (Al-Qadi \& Bhutta, 1999). Nine 15-m long sections were instrumented with strain gauges, pressure cells, piezoelectric sensors, thermocouples, and moisture sensors. Three sections were reinforced with geotextiles, three were stabilized with geogrids, and three control sections were not reinforced. Pavement responses were monitored for more than three years. Geotextile-reinforced sections showed less vertical stress at the top of the subgrade and lower rate of rutting.

A pooled-fund study, TPF-5(010), conducted by the Corps of Engineers and the University of Maine utilized geogrid-reinforced and unreinforced (control) base layers in test sections over a marginal subgrade (Henry, 2009). In this study, a target modulus value of $35 \mathrm{MPa}$ or CBR value of approximately 3 was used for the subgrade layer. Specific objectives of this project were: (1) To determine whether geogrids increase structural capacity of pavements typically constructed by state departments of transportation (DOTs) when they are used to reinforce the base layer for a given subgrade modulus; (2) To measure in-situ stress and strain response of pavement sections 
as a function of traffic loading for use in current or future pavement design processes. Unfortunately, instrumentation in this study was applied only to geogrids.

Perkins (1999a; 1999b) found that geosynthetic reinforcement of test sections with $75 \mathrm{~mm}$ of asphalt overlying 200 to $375 \mathrm{~mm}$ thick bases provided significant benefits when the subgrade had a CBR of 1.5, but no improvement was noted when the subgrade had a CBR of 20.

Perkins and Ismeik (1997), Vischer (2003) and Perkins and Cortez (2005) noted that part of the problem in finding definite effects of geotextiles on pavement performance results from the fact that research in this area has been spotty and of limited scope.

\subsection{Numerical Modeling of Pavements}

Numerical analysis helps researcher predict performance of pavements via simulation. Finite element method (FEM), discrete element method (DEM), and finite difference method (FDM) are three types of numerical analysis commonly used by civil engineers. In FEM and DEM, the structure is divided into numerous cell/grid points. DEM is primarily used to analyze granular and discontinuous materials. Intense computational process of DEM limits method application for analysis of massive structures such as pavement. FDM is applicable in computational science and engineering analysis, such as thermal engineering and fluid mechanics. FEM is capable of modeling various material behaviors and complicated geometry and loading conditions, consequently making FEM a common technique for analyzing pavement structure.

Early FE models commonly were comprised of two-dimensional (2-D) geometry with linear or nonlinear material properties. Duncan et al. (1968) were among the first researchers to use FE to model pavement. In 1980, ILLI PAVE software was developed by Raad \& Figueroa. Lytton and Tseng (1990) developed FEM called the FLEXPASS. FLEXPASS is a 2-D FEM capable of modeling multiple tire and multiple axle assemblies. This model can predict distresses such as rutting and fatigue cracking and consider seasonal variations of material properties.

In many FE modeling, the pavement system is simplified into plane strain or axisymmetric 2-D structure. Structures that are considerably great length in one direction compared to other 2Ds can be considered plane strain. In these structures, normal strain and shear strain associated with length are close to zero. Due to relatively higher pavement length compared to width and 
thickness, many researchers have considered pavement structure as plane strain (Wu, 2001; White et al., 2002; Kim et al., 2005). A 2-D axisymmetric model has been used in many studies to reduce computational time (Helwany et al., 1998; Homych and Abd, 2004; Howard and Warren, 2009; Nazzal 2010; Wu et al., 2011). The newly released Mechanistic-Empirical Pavement Design Guide (MEPDG) also uses a 2-D axisymmetric model to analyze pavement structure. However, although 2-D models can decrease analysis time, this models cannot simulate real-world wheel load. Therefore, current pavement structures have been modeled in three-dimension (3-D) for accurate representation of loading and geometry (Cho et al., 1996; White, 1998; Huang et al., 2001; Erkens et al., 2002; Desai, 2002; Wu et al., 2011).

\subsubsection{Numerical Modeling of Geosynthetic-Reinforced Pavements}

As mentioned, previous studies have revealed several difficulties and uncertainties regarding modeling of geosynthetic-reinforced pavements (Perkins, 2011). These uncertainties are related to simulation of the reinforcement mechanism of geosynthetic layers. Long-term performance is defined as pavement responses such as permanent surface deformation, stress, and strain after application of a large number of load cycles. Application of the reinforcement benefit is that a reinforced section can tolerate a higher number of load cycles than an unreinforced section before failure occurs. In addition, long-term reinforcement benefits are significantly more apparent when compared with short-term application (Perkins, 2011). In order to predict long-term performance of the section, some simplification must be done. Specifically, any model that fails to consider plastic material behavior and accumulation of plastic strain suggests an inability to predict long-term pavement performance. Therefore, an applicable model should be constructed of materials that allow for plastic deformation under simulated load cycles. Without such features, the asphalt layer rebounds upwards after load removal due to artificial stresses. Such a model has been attempted in several studies.

Reinforcement benefits are clearly apparent in several numerical modeling studies. The 1972 AASHTO design method was modified by Barksdale et al. (1989) to determine design thickness of pavement sections with geosynthetic reinforcement. The study showed that reinforcement reduced lateral pressure at the bottom of the HMA layer by 4 to $16 \%$ and vertical pressure on top of the subgrade by 6 to 18\%. A similar study by Burd and Houlsby (1986) used a 
large-strain FE model; this was beneficial because of the model's accuracy in predicting deformation. The model excluded interface elements between the geosynthetic and base layers; however, model predictions were completely supported by laboratory test results. Results of the model and lab tests showed a clear reduction of rutting due to reinforcement. A further study by Brown and Chan in 1989 verified pressure reduction on the upper part of the subgrade and base layer as another significant benefit of reinforcement. In that study, results showed that geogrid resilience should be at least $1500 \mathrm{lbs} / \mathrm{inch}$. Additional benefits were found by Kwon et al. (2005) through their application of FE methodology. Their study involved a non-linear mechanistic model which verified a reduction in critical pavement responses (stresses and strains) through analysis of isotropic and cross-anisotropic characterization. The models predicted increased stiffness of subgrade layers and granular base due to geosynthetic reinforcement. This application of the FE model continues to be beneficial through the use of ABAQUS software.

\subsubsection{Soil/Aggregate-Geosynthetic Rnterface Model}

Several studies were conducted on soil/aggregate-geosynthetic interface (Perkins and Cuelho1999; Perkins 2001 Eiksund et al. 2002; Leng and Gabr 2003). A Coulomb interface model available in ABAQUS software was used in studies by Perkins and Cuelho (1999) and Perkins (2001). In those studies, soil/aggregate-geosynthetic interface behavior was modeled by the friction coefficient and elastic slip. A friction coefficient equal to one and elastic slip of $1 \mathrm{~mm}$ was measured for the geogrid-soil interface through laboratory pull-out test. Perkins (2001) conducted sensitivity analysis on pavement responses. Results showed that elastic slip parameter plays an important role in reinforcement. A similar study on the effect of geosynthetic-reinforced pavement was done by Leng and Gabr (2003). In that study, geogrid-reinforced unpaved roads were modeled by ABAQUS program. The cyclic road test was conducted on test sections to compare results with the FE model. Interface contact behavior of the reinforced layer was modeled by a shear resistance model. Results showed that unpaved road performance can be improved by enhancing soil/aggregate-geosynthetic contact properties and elastic modulus of the geosynthetic layer. A similar study was done by Eiksund et al. (2002) in which they used a cross-anisotropic model with Coulomb interface to investigate effects of geogrid-reinforced layer. This study confirmed results of the previous study by Leng and Gabr and showed that improvement from the geogrid reinforcement is higher when more contact exists between the geosynthetic and soil/aggregate. 


\subsubsection{Material Modeling of Geosynthetics}

Geosynthetic materials exhibit complicated elastic-plastic behavior. The stress-strain curve for these materials is nonlinear under the application of loading and unloading (Figure 2-4a). Geosynthetic materials are thermo-viscous, and stress-strain behavior of viscous material changes when the temperature and/or loading rate changes (Figure 2-4b). Geosynthetics experience increased typically stiffness at lower temperatures and faster loading rates (Perkins, 2001).
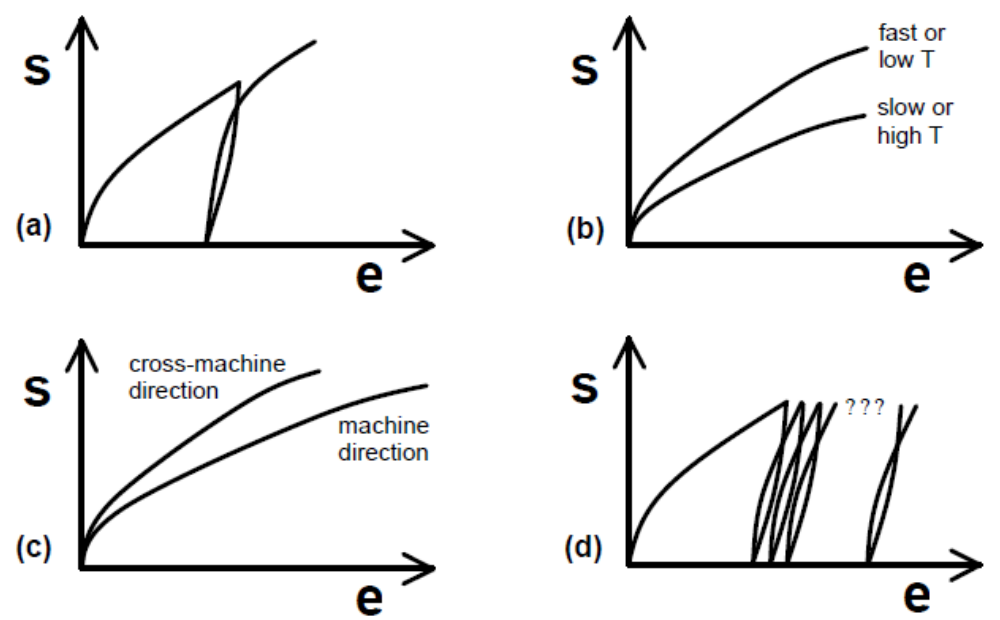

Figure 2-4 Illustration of a) elastic-plastic, b) thermo-visco, c) anisotropic and d) ratcheting stress-strain behaviour (Perkins 2001)

Some geosynthetics are anisotropic materials with stiffness varying in different directions (Figure 2-4c). In addition, plastic strain in geosynthetics accumulates after each load cycle. Therefore, these materials demonstrate hardening behavior due to kinematic hardening and creep/stress relaxation (Figure 2-4d). A previous study by Perkins (2001) showed that geogrid demonstrated all characteristics mentioned earlier. However, research by Ashmawy and Bourdeau (1996) indicated that woven-geotextile exhibits linear elastic behavior. That study also proved that permanent strain accumulation in woven geotextiles is not significant after cyclic loading when compared to nonwoven geotextile. 


\section{Chapter 3 - Accelerated Pavement Testing of Geotextile-Reinforced Paved Roads}

\subsection{Civil Infrastructure Systems Laboratory}

The Civil Infrastructure Systems Laboratory (CISL) at Kansas State University is capable of testing large-scale asphalt and concrete pavement sections under full-scale truck traffic loading. CISL houses an accelerated pavement testing (APT) machine and three pits for test section construction, as shown in Figure 3.1. Two of the pits are $6.1 \mathrm{~m}$ long, $5.5 \mathrm{~m}$ wide, and $1.8 \mathrm{~m}$ deep. The third pit is $6.1 \mathrm{~m}$ long, $4.9 \mathrm{~m}$ wide, and $1.8 \mathrm{~m}$ deep. Travel distance of the APT machine is approximately $6.6 \mathrm{~m}$, and the machine applies single or dual axle load with air-bag suspension. The wheel assembly is belt-driven by a 20 -HP electric motor, while the load is controlled by hydraulic pressure (Lewis, 2008).

The loading mechanism at CISL APT can be controlled via hydraulic pressure, tire pressure, and test speed. In this test, an 80-kN (18-kip) single axle load with air-bag suspension was applied on dual tires. The tire pressure was $620 \mathrm{kPa}(90 \mathrm{psi})$ and testing speed was $11.3 \mathrm{~km} / \mathrm{h}$ (7 mph). The APT machine is able to wander laterally during passes, thereby simulating realistic trafficking on highways. A $\pm 150 \mathrm{~mm}$ ( \pm 6 in.) wander was applied in a truncated normal distribution with 676 repetitions for one wander cycle, as shown in Figure 3-2. 


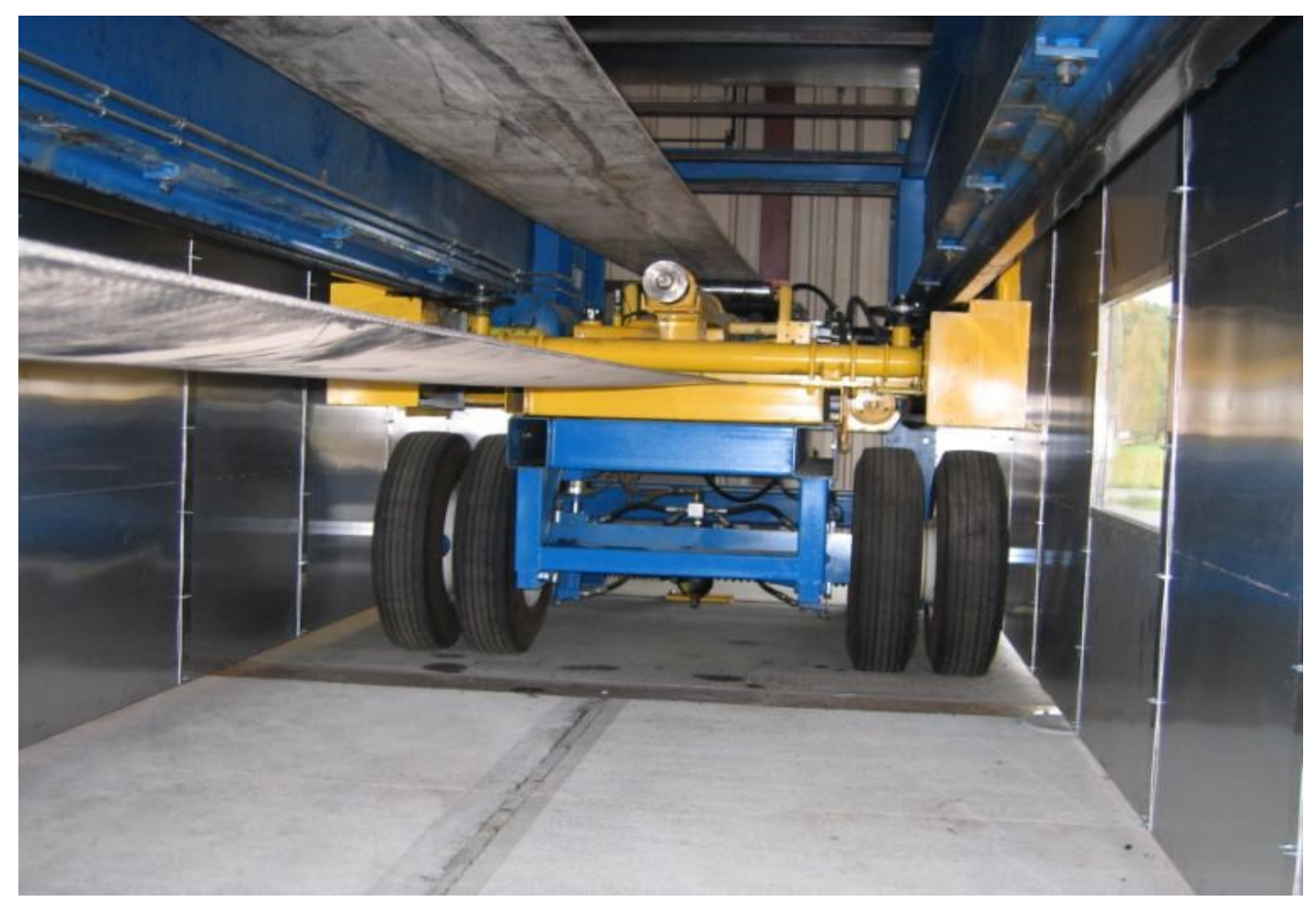

Figure 3-33-1 APT machine

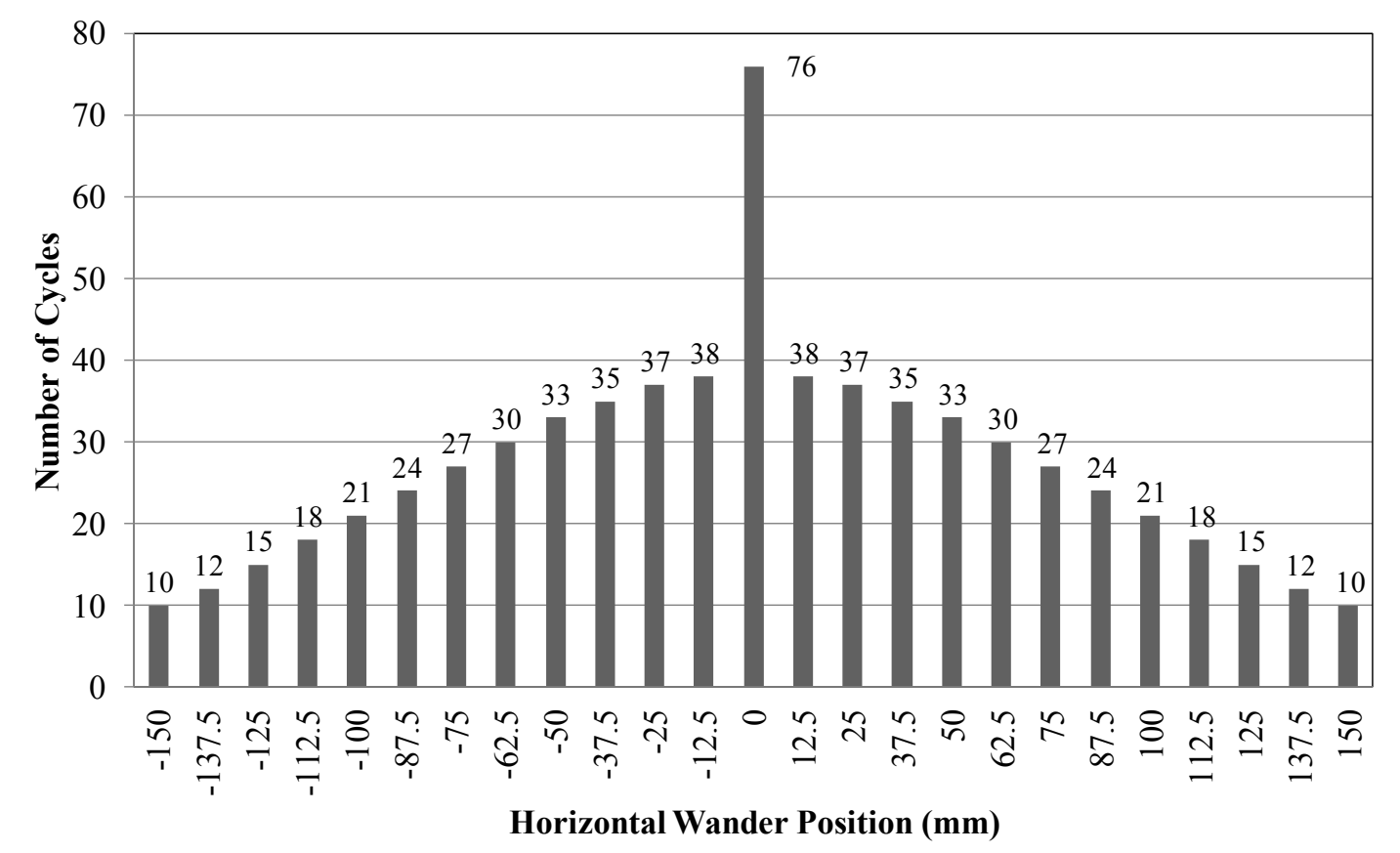

Figure 3-3-2 Truncated wander of APT machine at Kansas State University 


\subsection{Material Properties}

\subsubsection{Subgrade}

An AASHTO A-7-6 clay was used to construct the subgrade layer. Standard Proctor compaction and California bearing ratio (CBR) tests were carried out on the subgrade soil samples. Figure 3-3 shows results of those tests. Maximum dry density of the subgrade soil was $1.61 \mathrm{~g} / \mathrm{cm}^{3}$ at an optimum moisture content of $21 \%$. However, $24 \%$ moisture content was used to produce a target CBR of 2.6 (corresponding to a subgrade resilient modulus of $32.4 \mathrm{MPa}$ ). Subgrade soil was placed and compacted in five separate lifts. Dynamic Cone Penetrometer (DCP) testing was done on each lift to evaluate CBR values. CBR profiles of the test sections, as plotted in Figure 3-4, show that as-constructed CBR values of the test sections are close. In addition to the DCP test, Vane shear, nuclear gauge, and Light Falling Weight Deflectometer (LFWD) tests were conducted to ensure uniformity of the subgrade.

\subsubsection{Base Course}

A well-graded crushed limestone, known as AB-3 in Kansas, was used as the base layer material for all test sections. Laboratory compaction results and CBR values of the base material are plotted in Figure 3-5. This AB-3 had a mean particle size of $4.4 \mathrm{~mm}$, coefficient of curvature of 1.55, and coefficient of uniformity of 21. Optimum moisture content of the base material was $10.2 \%$ and the maximum dry density was $2.13 \mathrm{~g} / \mathrm{cm}^{3}$. Base courses were compacted to $95 \%$ of the maximum dry density. DCP and Light Falling Weight Deflectometer (LFWD) tests were done to assess layer CBR and stiffness values, respectively. Base layer modulus calculated from the LFWD test and average CBR and stiffness of the base courses are shown in Table 2-2. CBR values are close, but the control section exhibited the highest stiffness. Among the geotextile reinforced sections, Section B had the highest stiffness. 


\section{Compaction curve}

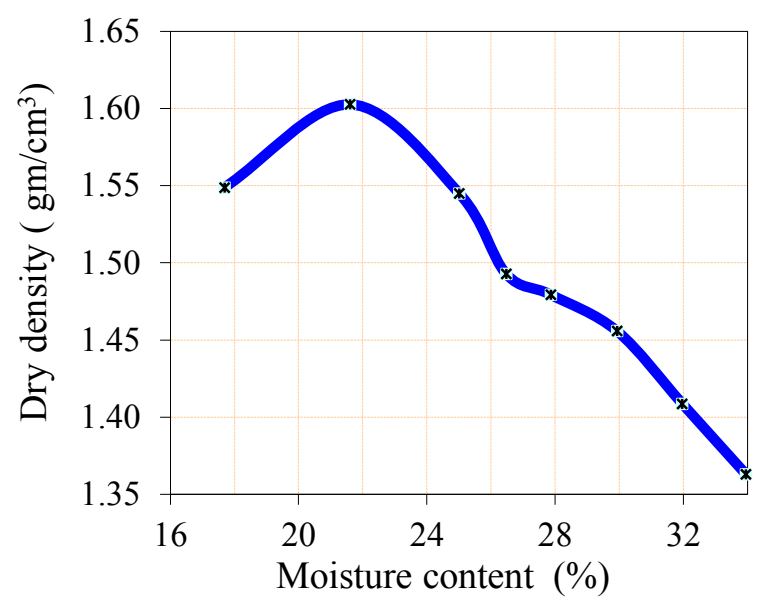

CBR value

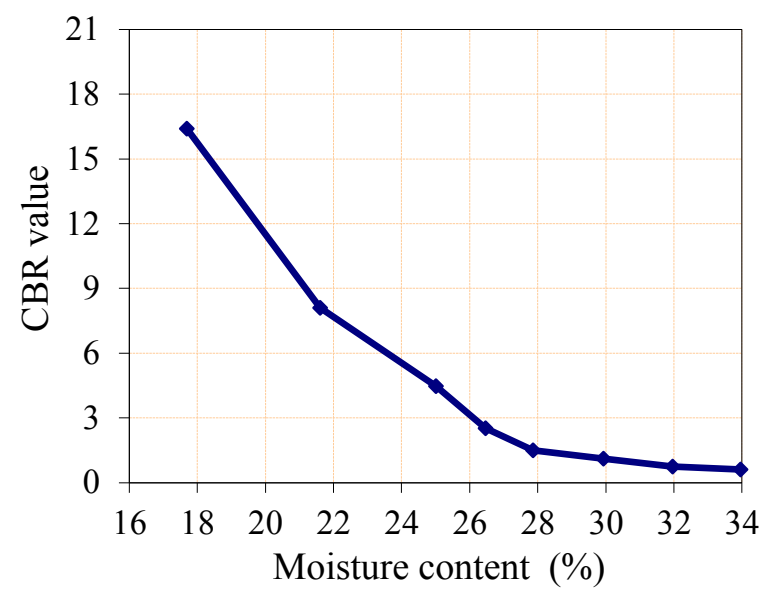

Figure 3-3 Laboratory compaction and CBR curves of subgrade

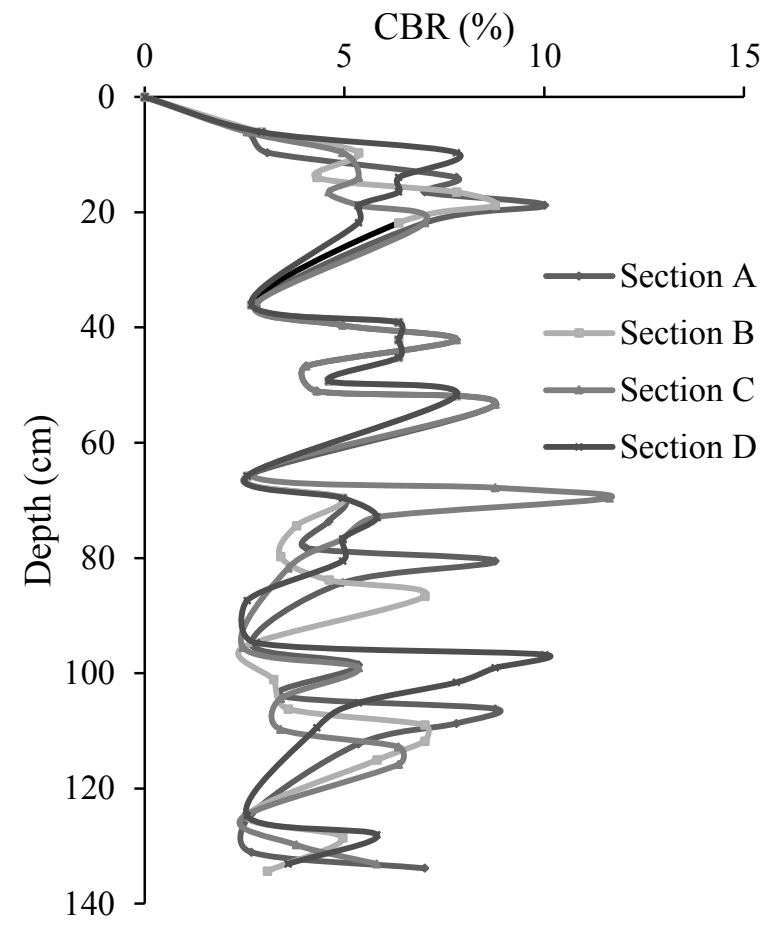

First Test

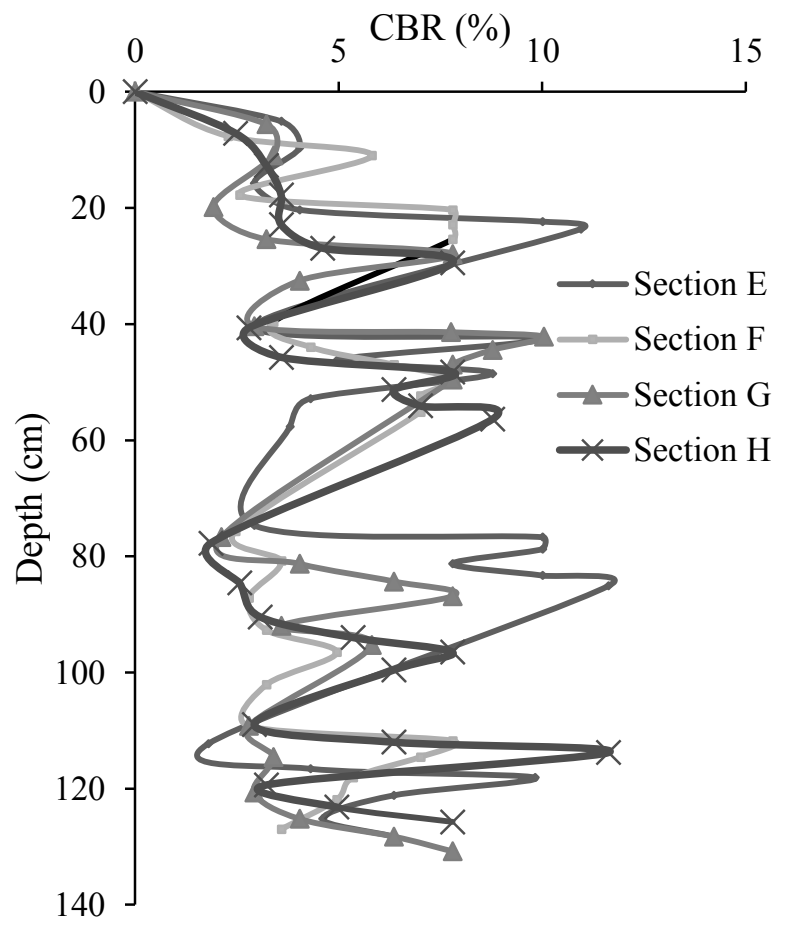

Second Test

Figure 3-4 As-constructed CBR profile of subgrade 


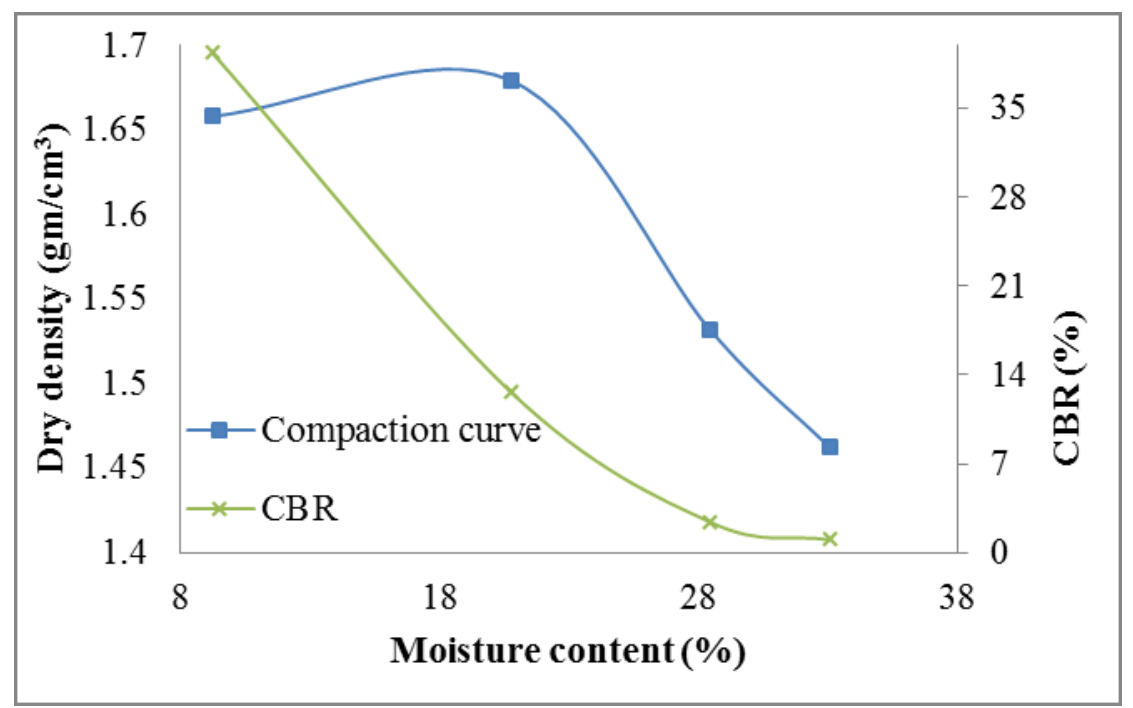

Figure 3-5 Laboratory compaction and CBR curves for base course

Table 3-1 Average stiffness and CBR value of base layer

\begin{tabular}{|c|c|c|}
\hline Section & $\begin{array}{c}\text { Average Modulus } \\
\text { from LFWD } \\
\text { (MPa) }\end{array}$ & $\begin{array}{c}\text { Average } \\
\text { CBR (\%) }\end{array}$ \\
\hline Section A & 64 & 23 \\
\hline Section B & 73 & 25 \\
\hline Section C & 65 & 23 \\
\hline Section D & 67 & 24 \\
\hline Section E & 56 & 23 \\
\hline Section F & 62 & 22 \\
\hline Section G & 56 & 23 \\
\hline Section H & 59 & 21 \\
\hline
\end{tabular}




\subsubsection{Hot-Mix Asphalt (HMA)}

All sections were paved with a $12.5-\mathrm{mm}(1 / 2$ in.) Nominal Maximum Aggregate Size Superpave mixture with fine gradation. This HMA mixture, known as SR-12.5A in the Kansas Department of Transportation (KDOT), contained 25\% recycled asphalt pavement (RAP) materials. A PG 58-28 binder was used in the HMA.

\subsubsection{Geotextile}

Three types of woven geotextiles, composed of high-tenacity polypropylene yarns woven into a network so the yarns retain their relative position, were used. The strength values of the geotextiles based on ASTM D4595 standard are shown in Table 3-2. As shown in the table, G1 is the weakest geotextile and G3 is the strongest.

Table 3-2 Properties of geotextiles used in this study

\begin{tabular}{|l|c|c|c|}
\hline \multicolumn{1}{|c|}{ Strength (kN/m) } & G1 & G2 & G3 \\
\hline 2\% Wide Width Tensile Strength (MD) & 7 & 9 & 7 \\
\hline 2\% Wide Width Tensile Strength (XD) & 9 & 15 & 26 \\
\hline 5\% Wide Width Tensile Strength (MD) & 18 & 26 & 21 \\
\hline 5\% Wide Width Tensile Strength (XD) & 20 & 33 & 64 \\
\hline Ultimate Wide Width Strength (MD) & 39 & 66 & 70 \\
\hline Ultimate Wide Width Strength (XD) & 39 & 53 & 70 \\
\hline
\end{tabular}

Note: MD: Machine Direction; XD: Cross Direction

\subsection{Test Sections}

In this study, two pits were divided into two lanes each, totaling four lanes. In the first test, each lane had a length of $6.1 \mathrm{~m}(20 \mathrm{ft})$, width of $2.45 \mathrm{~m}(8 \mathrm{ft})$, and depth of $1.83 \mathrm{~m}(6 \mathrm{ft})$. In the second test, test section width was increased to simulate expected geotextile behavior (full-width mobilization) in the field, so each section had a length of $3.05 \mathrm{~m}(10 \mathrm{ft})$ in the direction of the moving axle and a width of $4.9 \mathrm{~m}(16 \mathrm{ft})$ in the direction perpendicular to traffic. The second configuration was done to accommodate full-width of the geotextiles. Figure 3-6 shows cross sections of the test sections. Sections A and E were unreinforced sections with a deep (305 mm) 
crushed stone base. Other test sections had crushed stone bases with varying thicknesses, reinforced with different types of woven geotextiles. HMA, base course aggregate, and subgrade materials for all sections were identical, but layer thicknesses varied.
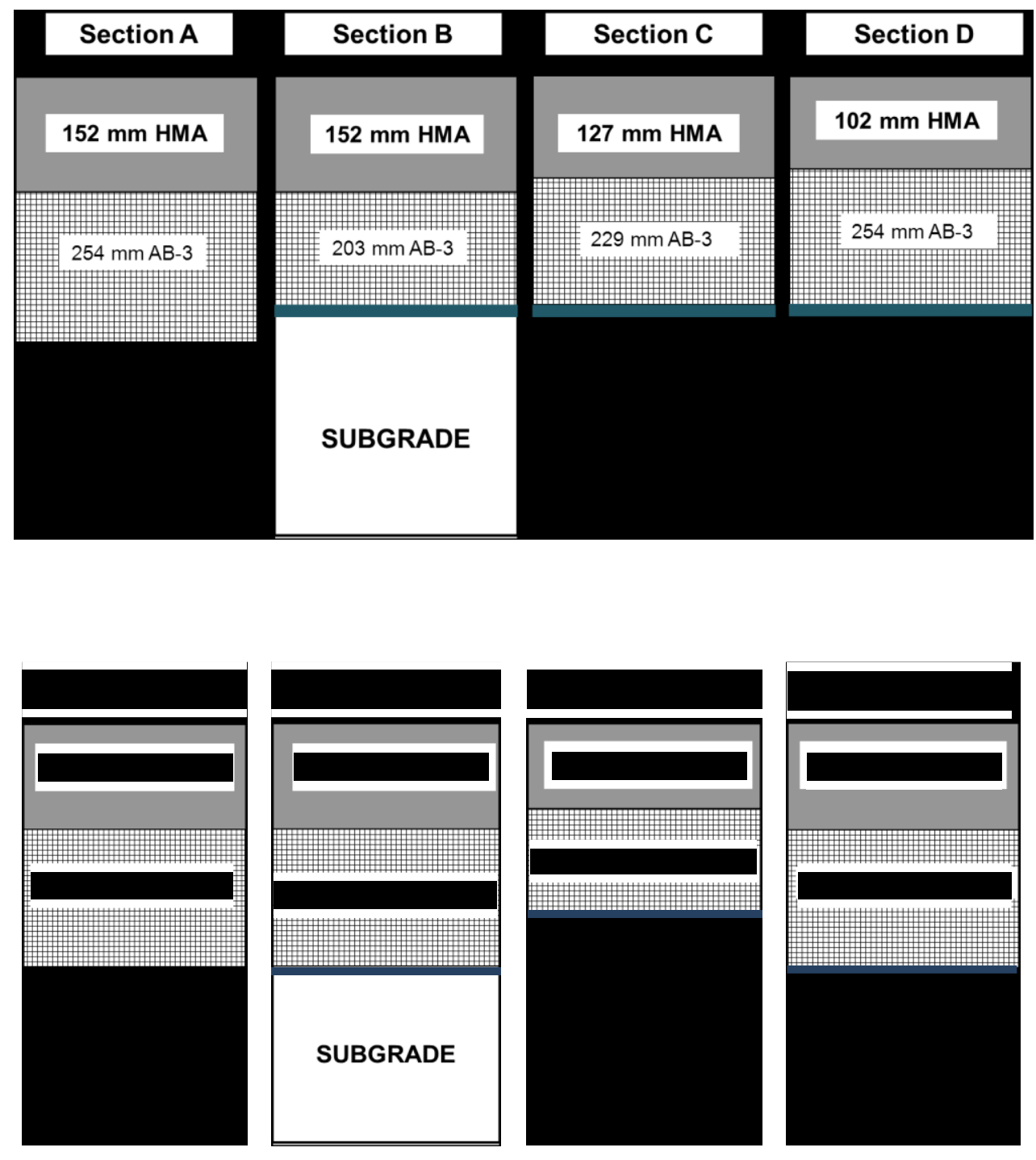

Figure 3-6 Cross sections of test sections

\subsection{Instrumentation Selection and Installation}

\subsubsection{Sensor Selection}

Permanent deformation and fatigue are two major failure criteria for flexible pavements. To measure the effect of geotextile inclusion on subgrade stresses, earth pressure cells were placed 
on top of the subgrade below geotextiles. Strain gages were attached to the geotextiles to measure the amount of strain for each type of geotextile and for each HMA and base thickness. To evaluate the effect of geotextile on the fatigue resistance of HMA pavements, strain gages were placed at the bottom of the HMA layer. In addition to the sensors for measuring structural responses, thermocouples and time domain reflectometers (TDR) sensors were placed in each section to monitor the temperature and moisture change during the test. All sensors were placed in the wheel path with the exception of TDRs.

Two pressure cells were installed on the east and west sides of each test section $0.5 \mathrm{~m}(1.5$ $\mathrm{ft}$ ) from the edges of the test lanes. Geotextile strain gages are extremely delicate, so six strain gages were used in each section (except control) in this study to provide enough redundancy. Six H-bar strain gages were placed at the bottom of the HMA layer: Three of the gages were installed in the transverse and three were installed in the longitudinal direction. Figure 3-7 shows the instrumentation layout of this study.
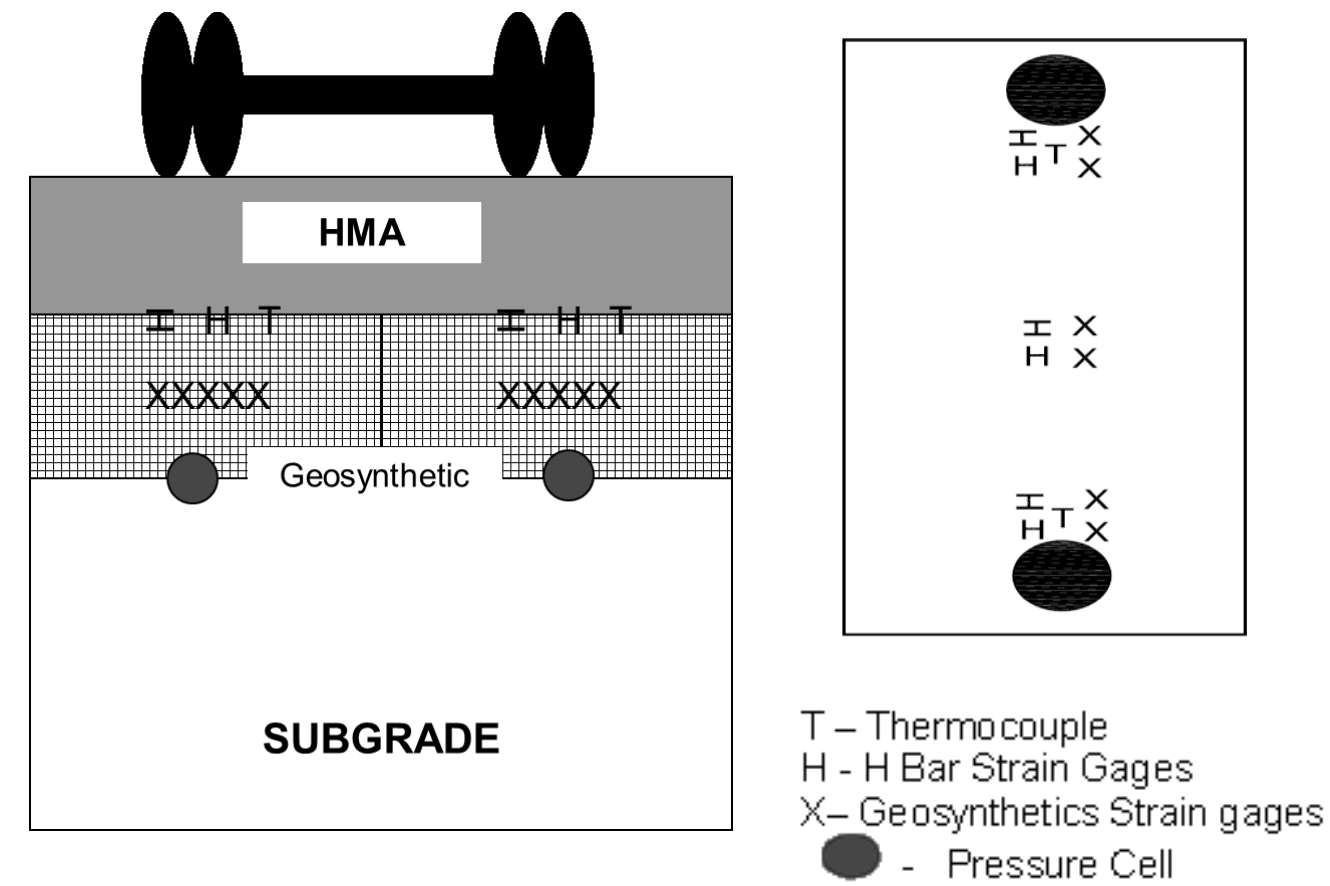

Figure 3-7 Instrumentation layout 


\subsubsection{Sensor Preparation}

\subsubsection{Pressure Cells}

Appropriate pressure sensors are required to measure pressure changes in the soil without significant disturbance. Diaphragm cells and hydraulic pressure cells are two common types of earth pressure cell. A diaphragm cell is constructed from a stiff circular membrane supported by a stiff edge ring and electrical resistance strain gage transducer. Strain due to membrane deflection under soil pressure is measured by the strain transducer and related to the magnitude of external soil pressure. Hydraulic pressure cells measure hydraulic pressure of de-aired hydraulic oil between two circular steel plates. Fluid pressure is converted into an electrical signal by a semiconductor-type or vibrating wire transducer. A vibrating wire transducer measures long-term static pressure and a semiconductor-type transducer measures dynamic pressures from traffic loads (Perkins \& Ismeik, 1997; Perkins, 1999a).

Since hydraulic pressure cells have been successfully used in previous experiments (Webster, 1978; Warren \& Howard, 2007; Tang, 2007), Geokon 3500 pressure cells with 0-400 $\mathrm{kPa}$ pressure range were used in this study. These pressure cells can work within a temperature range of $-20^{\circ} \mathrm{C}$ to $+80^{\circ} \mathrm{C}\left(-5^{\circ}\right.$ to $\left.180^{\circ} \mathrm{F}\right)$. The manufacturer calibrated each cell and attached a 7.6$\mathrm{m}(25 \mathrm{ft})$ wire to the cells. The pressure cells were installed after compaction of the last lift of the subgrade material. The subgrade was excavated to place cells. Fine soils were used to fill voids under the pressure cells, and then the pressure cells were positioned and re-leveled. Finally, fine soil was used to surround the pressure cells in order to avoid stress concentration. Installation of pressure cells is shown in Figure 3-8.

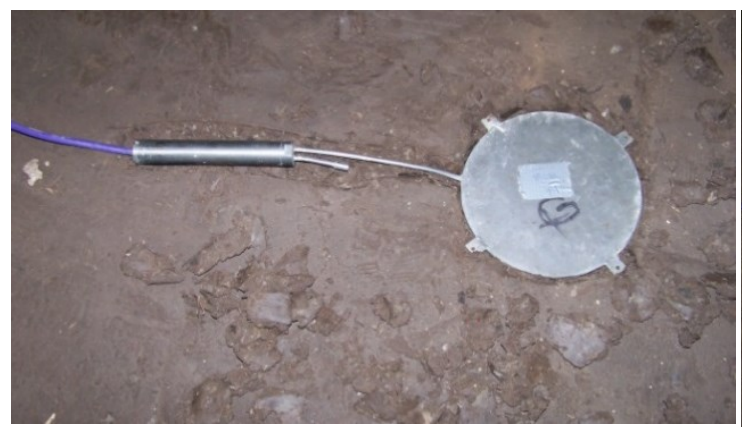

a)

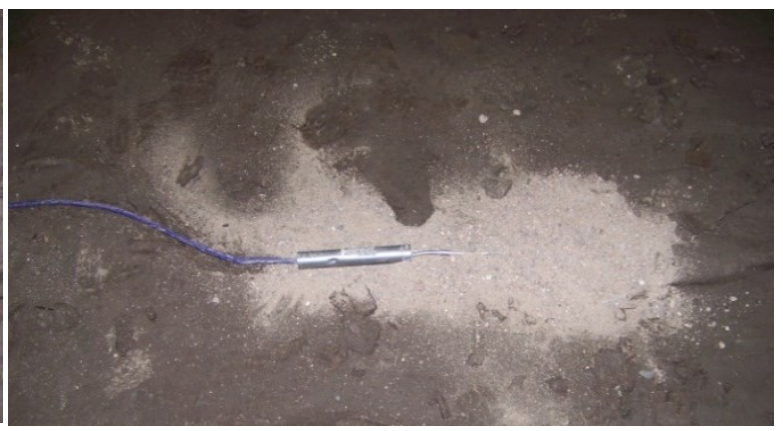

b)

Figure 3-8 Installation of pressure cell: (a) pressure cell was placed at top of subgrade; (b) excavation was backfilled by fine soils 


\subsubsection{H-bar Strain Gages}

Three types of strain gages are used to measure strain in the HMA: foil strain gages, strain coils, and H-bar gages. Foil strain gages are placed in carrier block or on extracted pavement cores (Perkins, 1999a). Among various types of strain gages, H-bar gages are more accurate and have been successfully used in previous experiments (Gray, 1939; Webster, 1992). In this study, PML60-2L strain gages from Tokyo Sokki Kenkyujo Co. were used. Each strain gage was connected to two aluminum rods, as shown in Figure 3-9. Strain gages include lead wires; however, original wires cannot tolerate high temperature of the asphalt mixture during construction. Therefore, 22 AWG, 2 conductor wires with braided shields were soldered to the H-bars. The solder was covered by a heat shrinking sheath and gage resistance was examined to ensure it was close to $120 \mathrm{ohms}$. The calibration factor provided by the manufacturer was used as the gage factor.

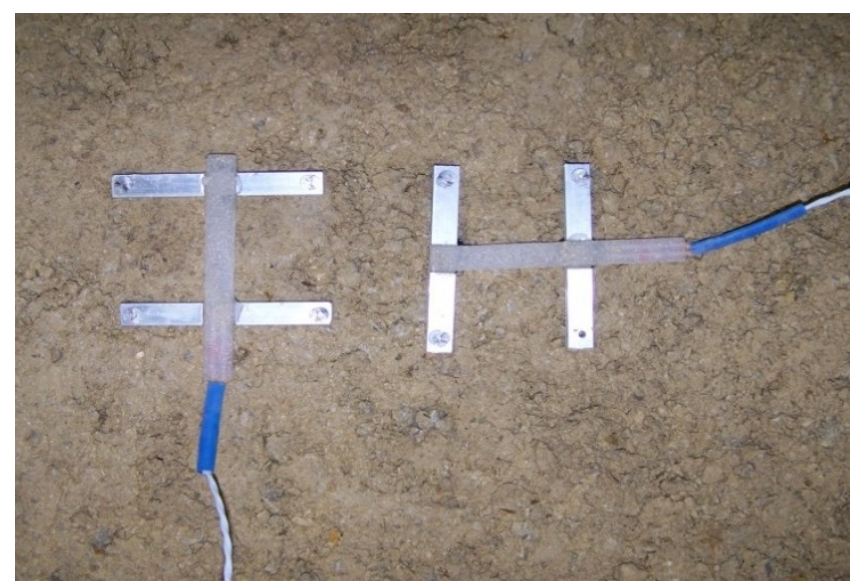

Figure 3-9 H-bar strain gages

\subsubsection{Geotextile Strain Gages}

Selection of strain gage type and installation method was challenging. As mentioned, geosynthetic strain gages are extremely delicate. After extensive literature review and personal communication with the experts (Warren \& Howard, 2007; Tang, 2007), N2A-06-20CBW-120 strain gages from Vishay Micro-Measurements were selected. At $50 \mathrm{~mm}$ (2 in), this gage was the longest available gage. Two bonding adhesive types (M-Bond 200 and M-Bond AE-10) suggested by the strain gage manufacturer were tested on samples of geotextiles. However, these adhesives stiffened the geotextile and increased the chance of geotextile and strain gage rupture. Next, 
silicone rubber adhesive 3145 RTV, successfully used by Warren and Howard (2007), was applied. This adhesive was used to bond and waterproof the strain gages which were installed using the following steps (Figure 3-10):

- $\quad$ A thin layer of 3145 RTV Silicone rubber adhesive was applied to the geotextile.

- $\quad$ A gage was placed at the desired location using tweezers.

- $\quad$ A Teflon strip was placed over the gage and adhesive and a dead weight was placed over the area for approximately 10 minutes.

- $\quad$ The weight and Teflon were removed, and the adhesive was allowed to cure for 24 hours.

- $\quad$ The gage was wired to the terminal blocks.

- $\quad$ The complete assembly was covered in silicone adhesive to waterproof the gage.

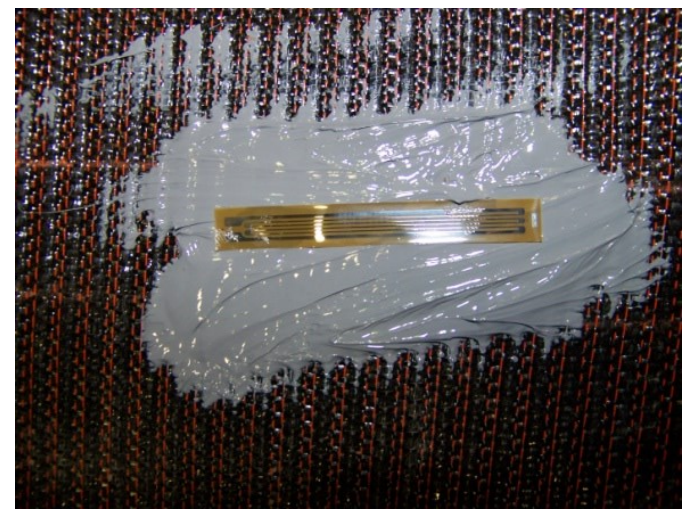

a)

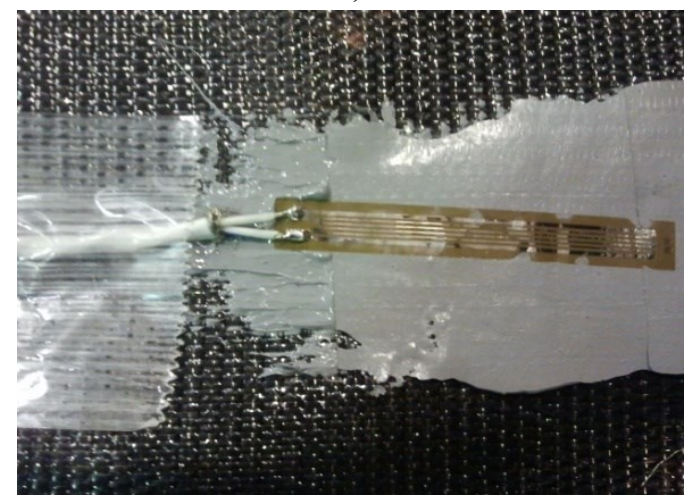

c)

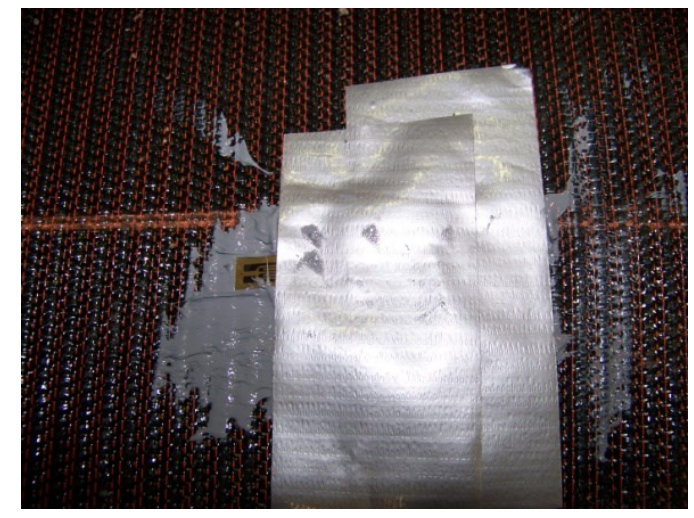

b)

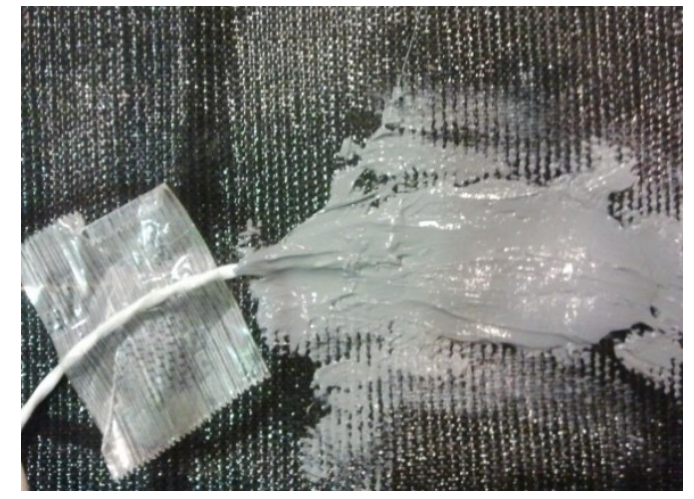

d)

Figure 3-10 Installation of geotextile strain gage: (a) strain gage placed onto silicone rubber; (b) Teflon strip placed over the gage (c) smallest available tip used to solder wires to terminals (d) strain gage and terminals covered in silicone adhesive 


\subsection{Data Acquisition Hardware}

A compact DAQ (cDAQ) system from National Instruments was used for data collection. The cDAQ system allows multiple interchangeable modules to be used with an electronic chassis, with a simple USB interface and a personal computer (PC). For this setup, three types of terminal block modules were used with the cDAQ-9178 chassis. A thermocouple module (NI 9211, 4 channel, $+/-80 \mathrm{mV}, 24$ bit differential analog input), two quarter-bridge input modules (NI 9235, $120 \mathrm{ohm}, 8$ channel, 24 bit, $2.5 \mathrm{ex}$ ), and an analog input module (NI 9205, 32 channel, +/- $10 \mathrm{~V}$, 16 bit) were installed in the chassis for data collection during the experiments. The quarter-bridge modules completed the Wheatstone bridge circuit for strain gages, as shown in Figure 3-11, and applied necessary excitation voltage. The strain gage factor was applied via software (described in the following section). The strain gage module was selected so that resistance of R4 in Figure 311 had the same nominal resistance as the strain gage, thereby balancing the bridge.

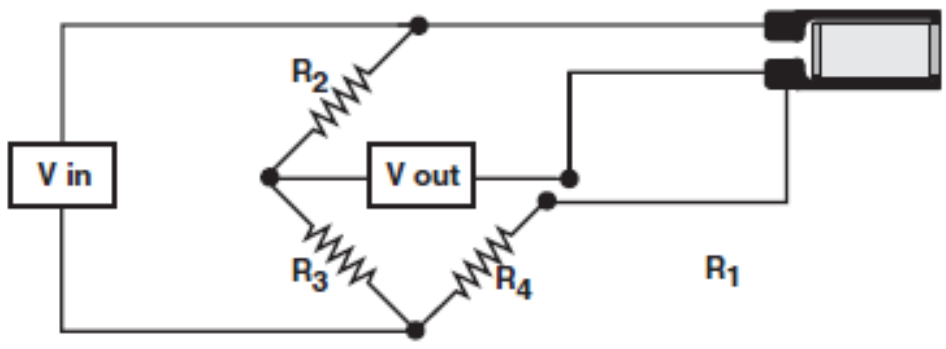

Figure 3-11 Completed quarter-bridge Wheatstone bridge circuit for strain gage (Vishay, 2010)

All instrument wires were initially hardwired into the terminal blocks. Approximately one hour was required to connect all wires during transportation of the CISL APT load assembly from pit to pit. To minimize downtime between pit changes, military connectors were used to connect the cDAQ to the sensors; one military connector connected one test section to the $\mathrm{cDAQ}$. A single military connector was hardwired into multiple terminal block modules (strain gage and pressure cell modules) to be plugged into a military connector on the end of the wire bundle from the sensors for a given pit. However, thermocouples remained hardwired into the thermal terminal block. The use of military connectors reduced the amount of time spent connecting to the cDAQ to five minutes. 


\subsubsection{Data Acquisition Software}

The cDAQ system interfaced with a PC equipped with LabVIEW 2009 through a simple USB 2.0 connection. A schematic of the entire system, from module to software, is shown in Figure 3-12. A custom virtual instrument (VI) was constructed in LabVIEW to collect necessary data for the study. The VI created a *.csv file (or appends onto the existing file) with specified column headers and then acquired data from the cDAQ system at a rate of 100 readings per second, using the built-in DAQ Assistant VI. The pulse for each sensor was displayed in a chart (in pairs to show sensors that lie under the moving wheel on the same chart in order to simplify observation). Data for each sensor was output to a specific column in the created *.csv file (or appended to it). This file was continuously saved and after the VI stopped, the file could be opened and viewed. Figure 3-13 shows this acquisition and display process. Within the DAQ Assistant VI settings, input from the strain gages was read as strain gage input and the correct strain gauge factor was applied.

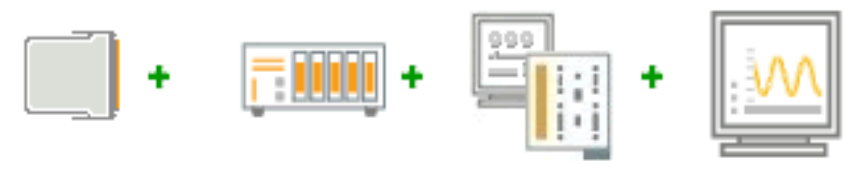

NI 9235 Chassis PC/Controller Software

Figure 3-12 Schematic of DAQ (NI 9235 module shown) 


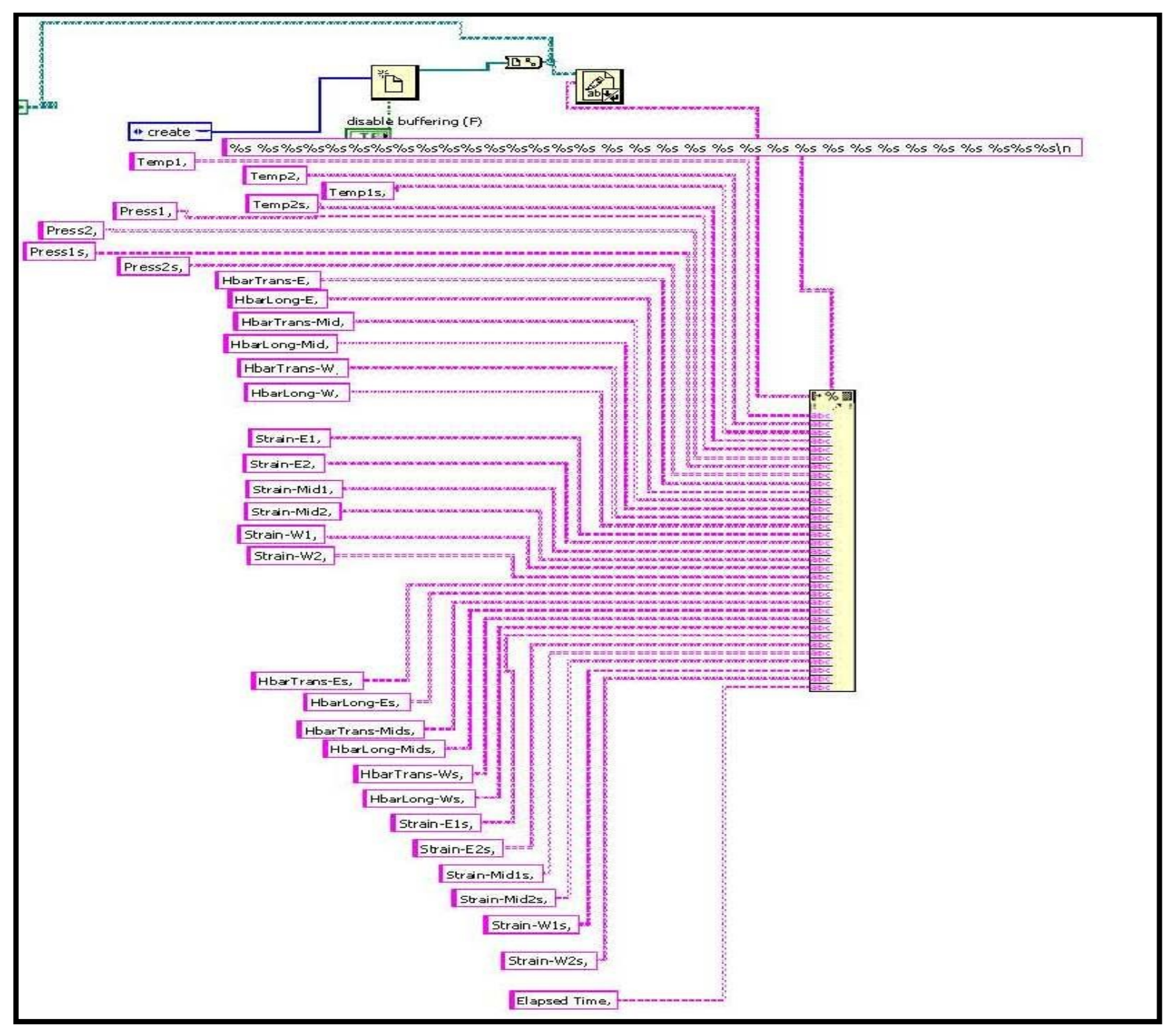

FIGURE 3-13(a) First frame of VI 


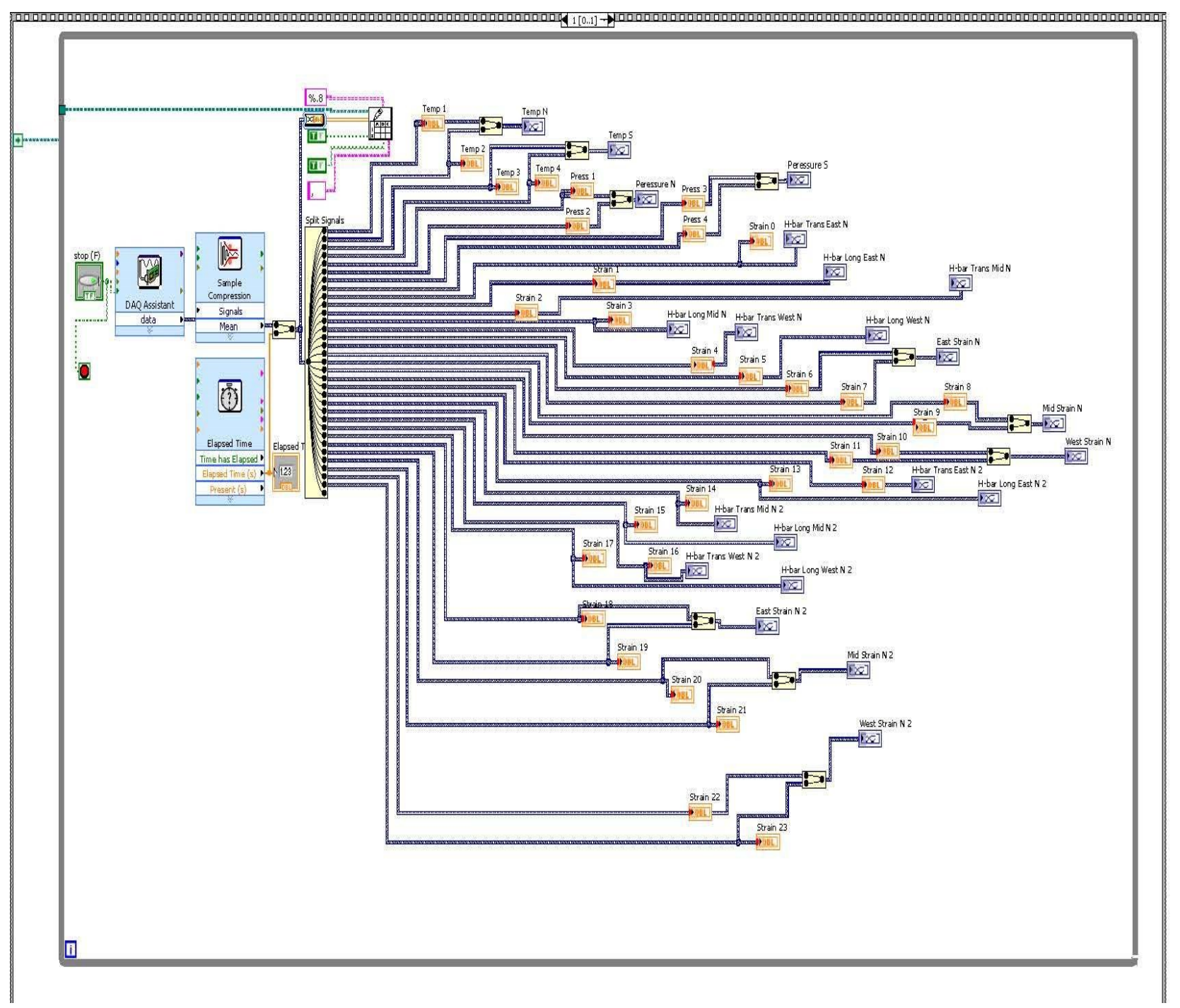

Figure 3-13 (b) Second frame of custom VI

Data was collected at a rate of 100 data points per second for one wander through the VI and exported to a *.csv file. Data was then sorted and analyzed. For one wander of 676 passes, approximately 4,800 lines of data were collected. 


\section{Chapter 4 - Full-Scale Accelerated Pavement Testing Results}

\subsection{Permanent Surface Deformation}

In this study, transverse profiles were taken at three places on each lane every $12.5-\mathrm{mm}$ intervals using a Chicago Dial Indicator digital gage, shown in Figure 4-1. The gage produced a digital output and sent the data to a computer in spreadsheet format. Three fixed reference points every $1.5 \mathrm{~m}$ ( $4.55 \mathrm{ft}$.) of lane length were placed on the HMA outside the lanes and measurements were taken with reference to these monuments (Lewis, 2008). Average rut depth was taken over the middle $127 \mathrm{~mm}$ ( 5 in.) of wheel path with readings every $13 \mathrm{~mm}$ (1/2 in.). Figures 4-1 through 4-6 show transverse profiles for the test sections.

In the first test, loading was discontinued when average rut depth of the control section reached $12.5 \mathrm{~mm}(0.5 \mathrm{in}$.). A total of 250,000 repetitions of the moving wheel load were applied to all sections in the first test. Average rut depth against the number of wheel passes is plotted in Figure 4-1. In the first test, Section A (unreinforced section) had the lowest average rut depth to nearly 250,000 repetitions. At that point, performance of Section $C$ became equivalent to Section A although Section $C$ had a base that was $75 \mathrm{~mm}$ (3 in.) thinner and HMA thickness was $25 \mathrm{~mm}$ (1 in.) thinner than the control section. Sections D and B showed higher rutting and Section D had more geotextile strength in the cross direction. However, HMA thickness in Section D was significantly less than other sections in the first test. Because of excessive deformation in Sections $\mathrm{B}$ and $\mathrm{D}$, these sections were excavated and examined. Visual observation after excavation showed that geotextile in Section B was unable to carry tensile stress during loading because it ruptured at some point during loading. 


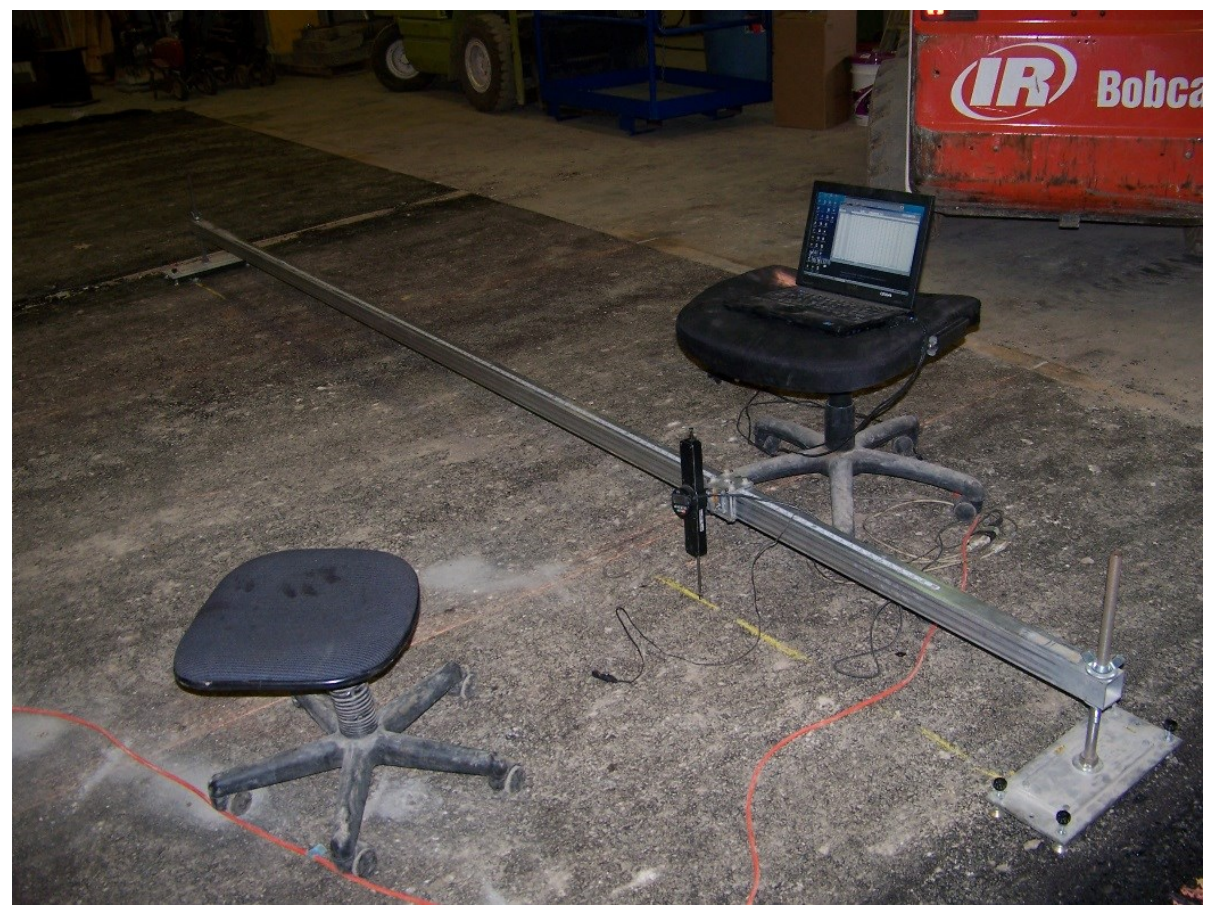

Figure 4-1 Monitoring transverse profile using the Chicago Dial Indicator

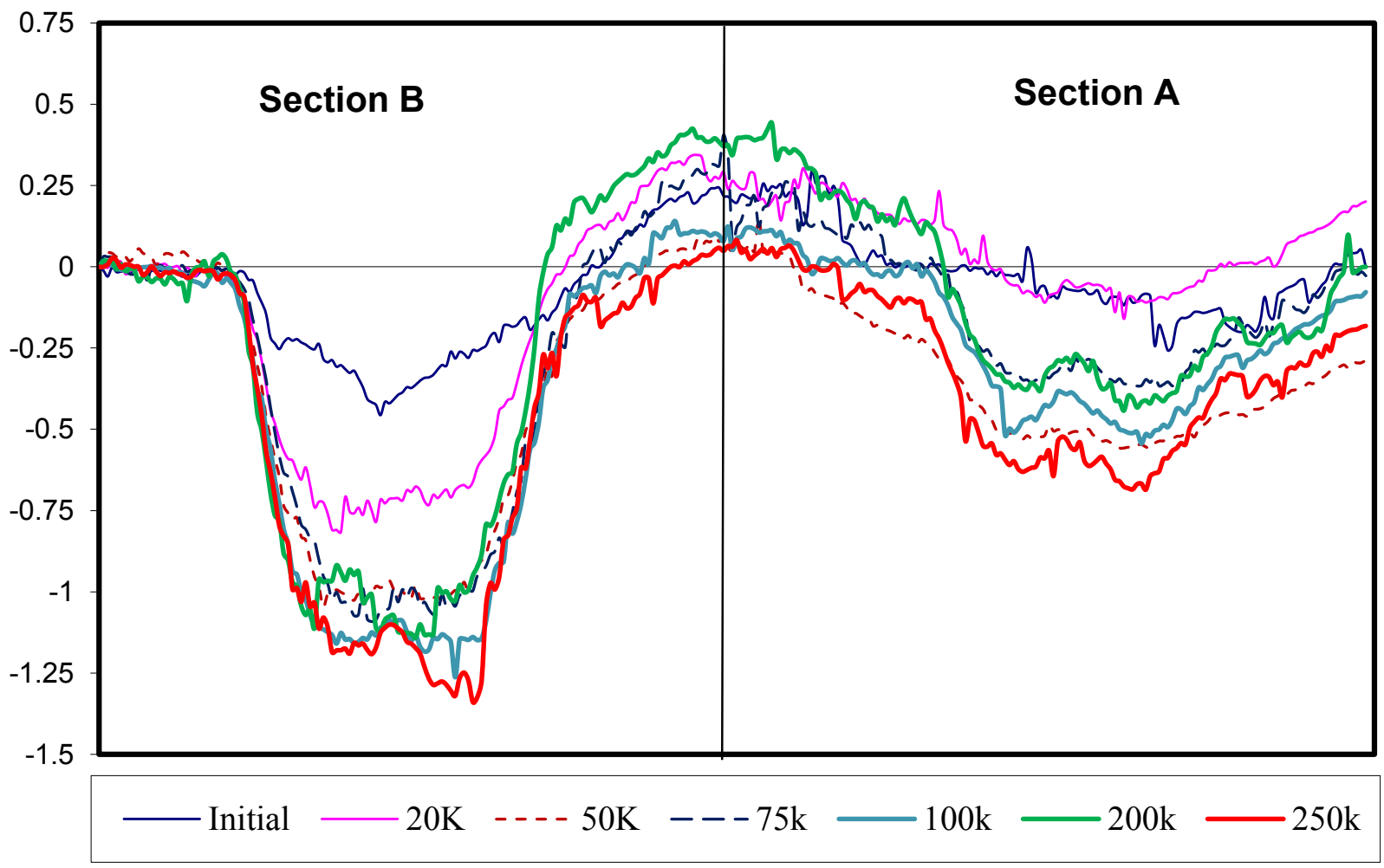

Figure 4-2 Transverse profiles of test sections A and B 


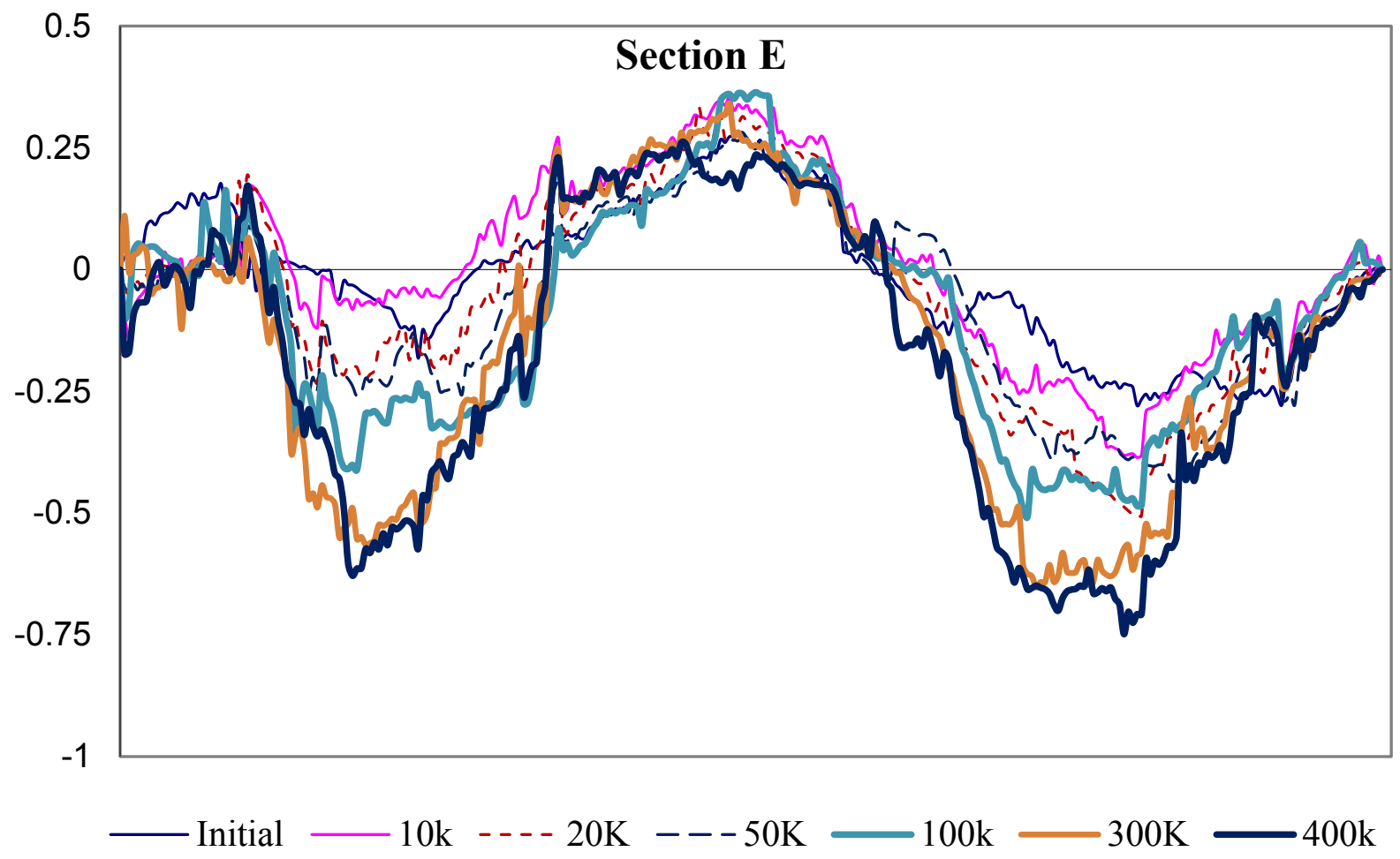

Figure 4-3 Transverse profiles of test section $\mathbf{E}$ 


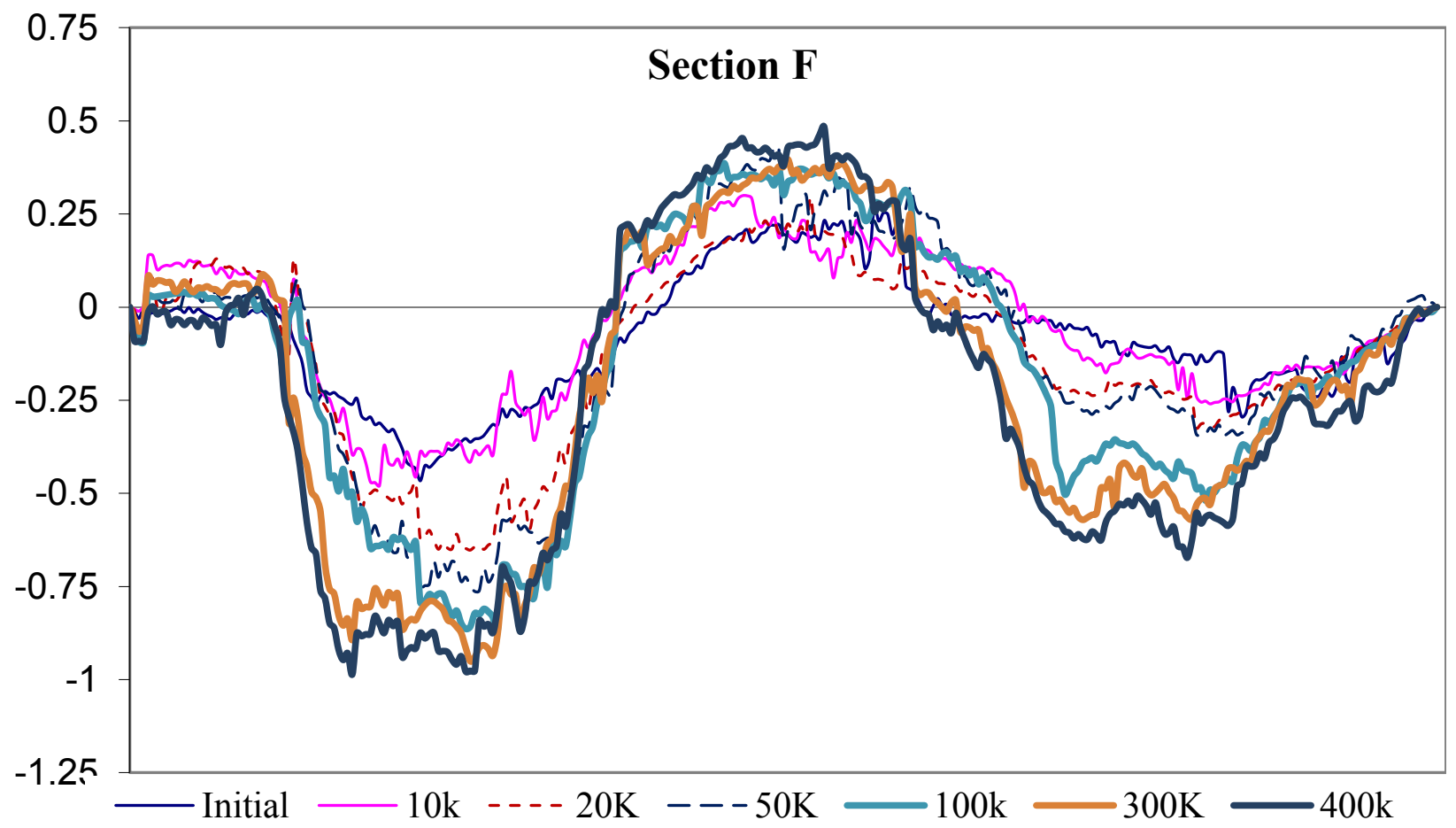

Figure 4-4 Transverse profiles of test section $F$ 


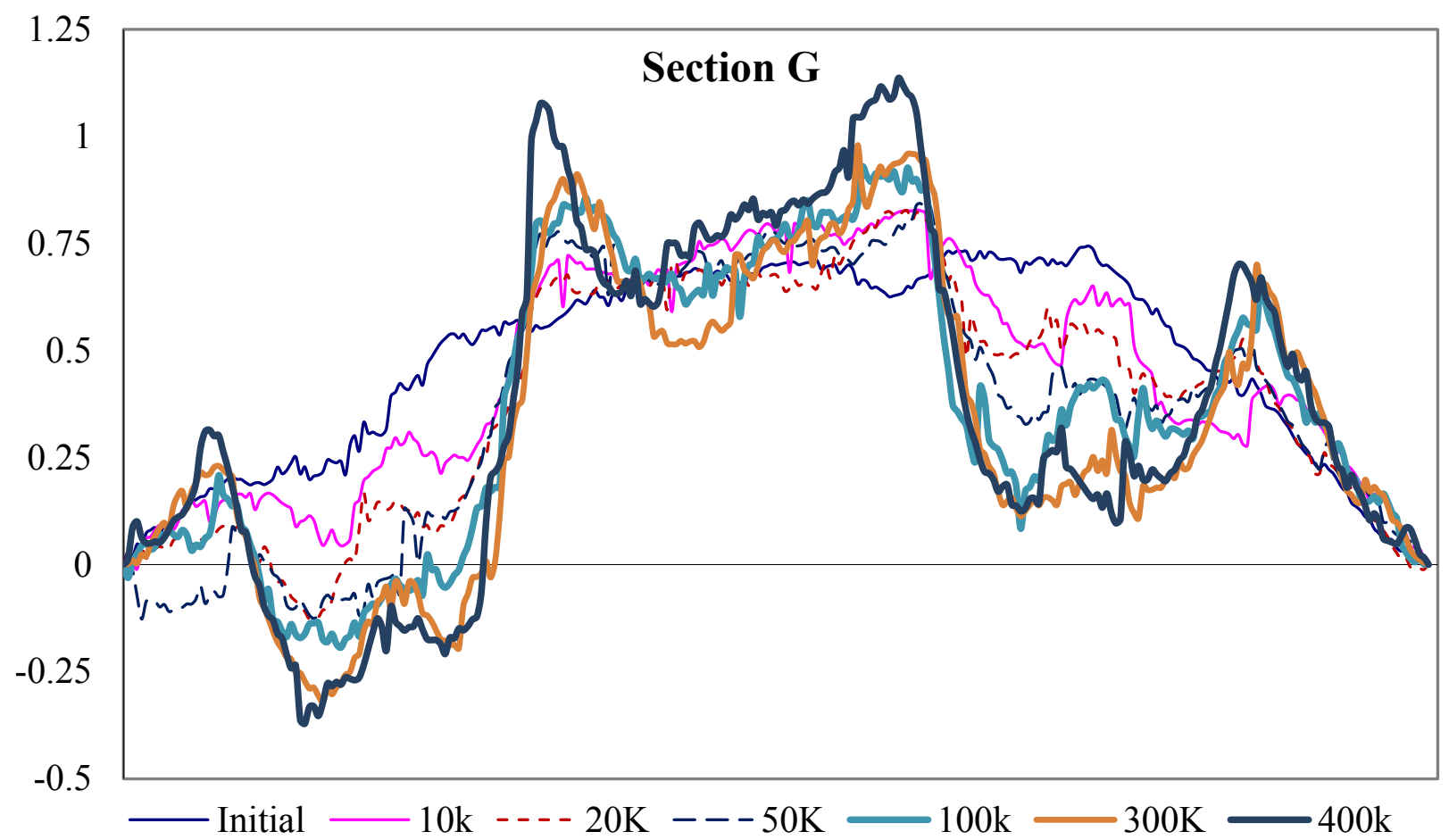

Figure 4-5 Transverse profiles of test section G

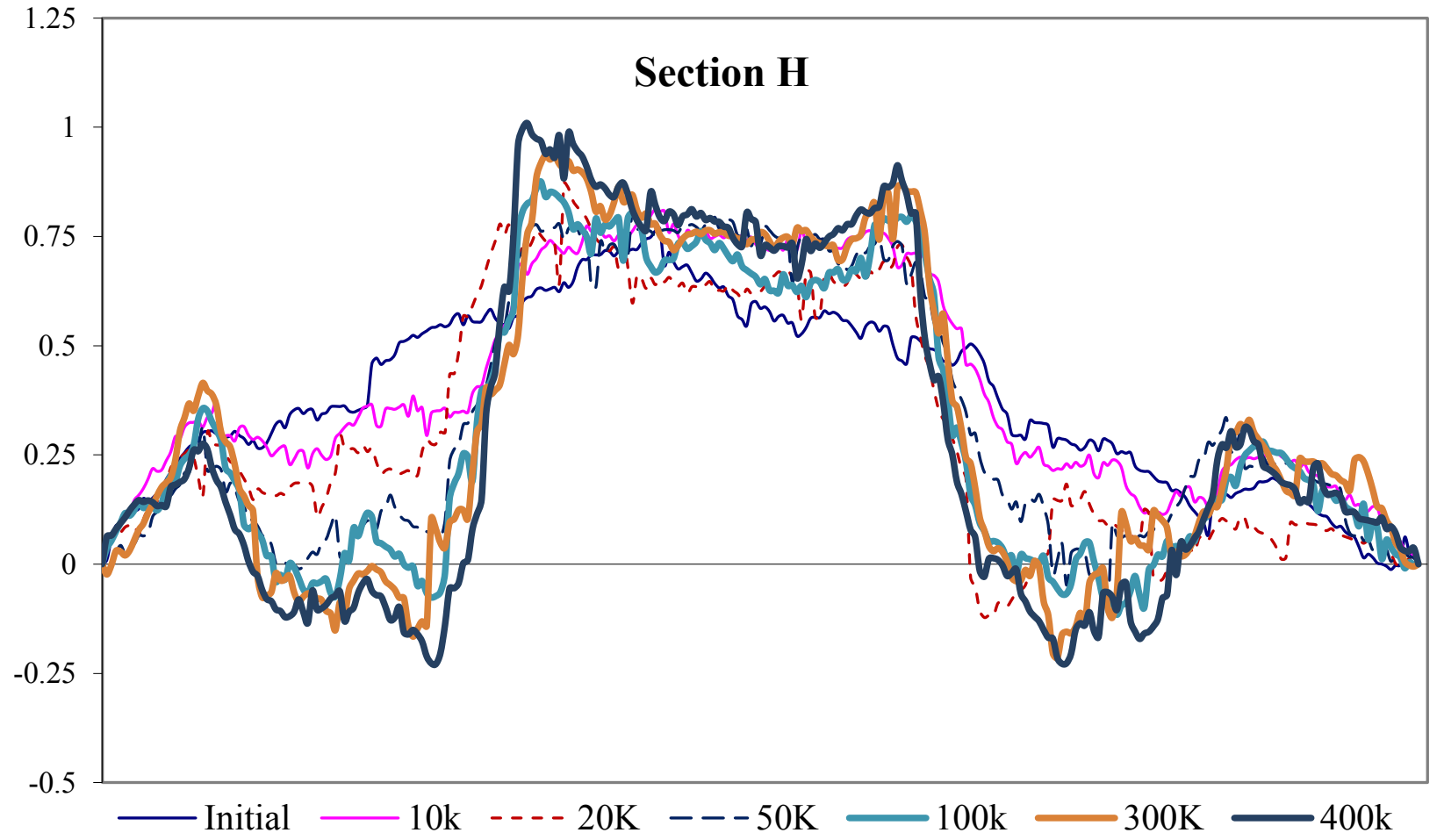

Figure 4-6 Transverse profiles of test section $H$ 
Average rut depths during the second test were lower on the reinforced sections due to the increase in total pavement thickness above the subgrade on those sections. Section H showed the lowest deformation. Control sections in the first (Section A) and second (Section E) tests had similar thicknesses. After 250,000 repetitions, rut depths on these sections were close. Widening the test section improved the effectiveness of geotextile G3. Section G experienced significantly less rutting than Section D with similar geotextile and layer thickness.

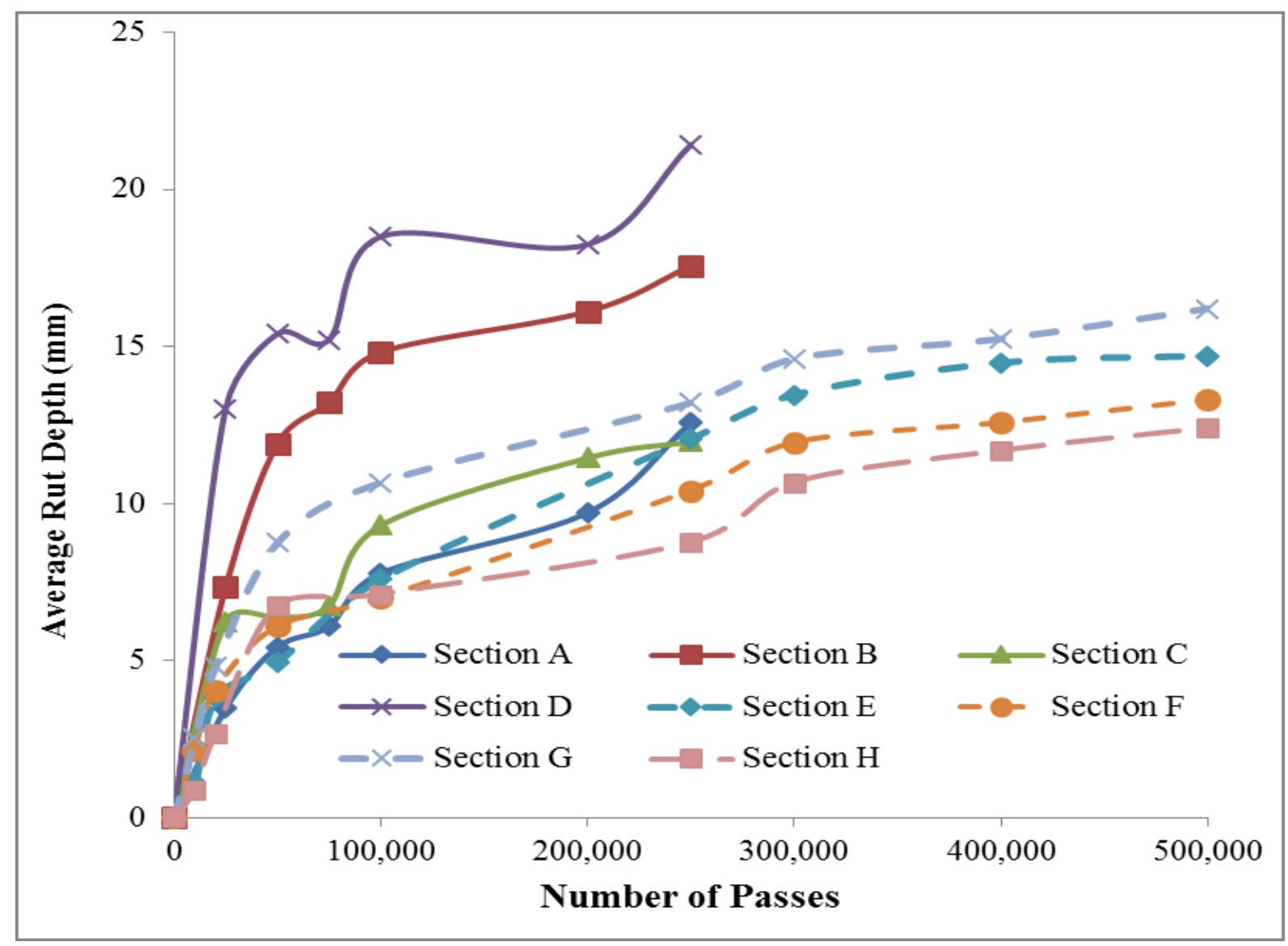

Figure 4-7 Average rut depth 


\subsection{Subgrade Pressure}

Two pressure cells were placed on top of the subgrade and below the geotextile. Pressure readings were recorded for one full wander cycle (676 wheel passes) at selected intervals, and 50 peak pressures were averaged and plotted, as shown in Figure 4-8.

In the first test, stress on the subgrade in all sections was lower than the $105 \mathrm{kPa}(15.2 \mathrm{psi})$ unconfined compressive strength of subgrade. Pressures on the subgrade initially tended to fluctuate possibly due to consolidation of the HMA and base layers. After approximately 100,000 repetitions, ordered results demonstrated a clear trend among the sections. Initially, the control section had the lowest pressure. Section B with identical HMA thickness as Section A (control) but with a $100 \mathrm{~mm}$ (4 in.) thinner base also had a pressure similar to Section A. However, even though the control section had base thickness of $300 \mathrm{~mm}$ (12 in.) compared to $229 \mathrm{~mm}$ (9 in.) of Section C, pressure on the subgrade for those sections was almost equal after 200,000 repetitions. This shows that the geotextile in that section distributed the wheel load over a wider area, resulting in lower pressure. Pressures on Sections C and D decreased after 50,000 repetitions possibly because of the tensioned membrane effect of the geotextiles. After rutting, the tensioned geotextile provided an upward resistance which decreased pressure on the subgrade.

During the second test measured vertical stresses at the interface between the subgrade and the base fluctuated for the first 100,000 wheel passes. However, vertical stresses on all sections were significantly less than the $620 \mathrm{kPa}(90 \mathrm{psi}$ ) tire pressure applied on the test sections. After 300,000 wheel passes, pressure in the unreinforced section (Section E) was higher than the reinforced sections with identical layer thicknesses (Sections F and H). Section G with $102 \mathrm{~mm}$ (4 in.) HMA thickness experienced the highest stress at the top of the subgrade. 

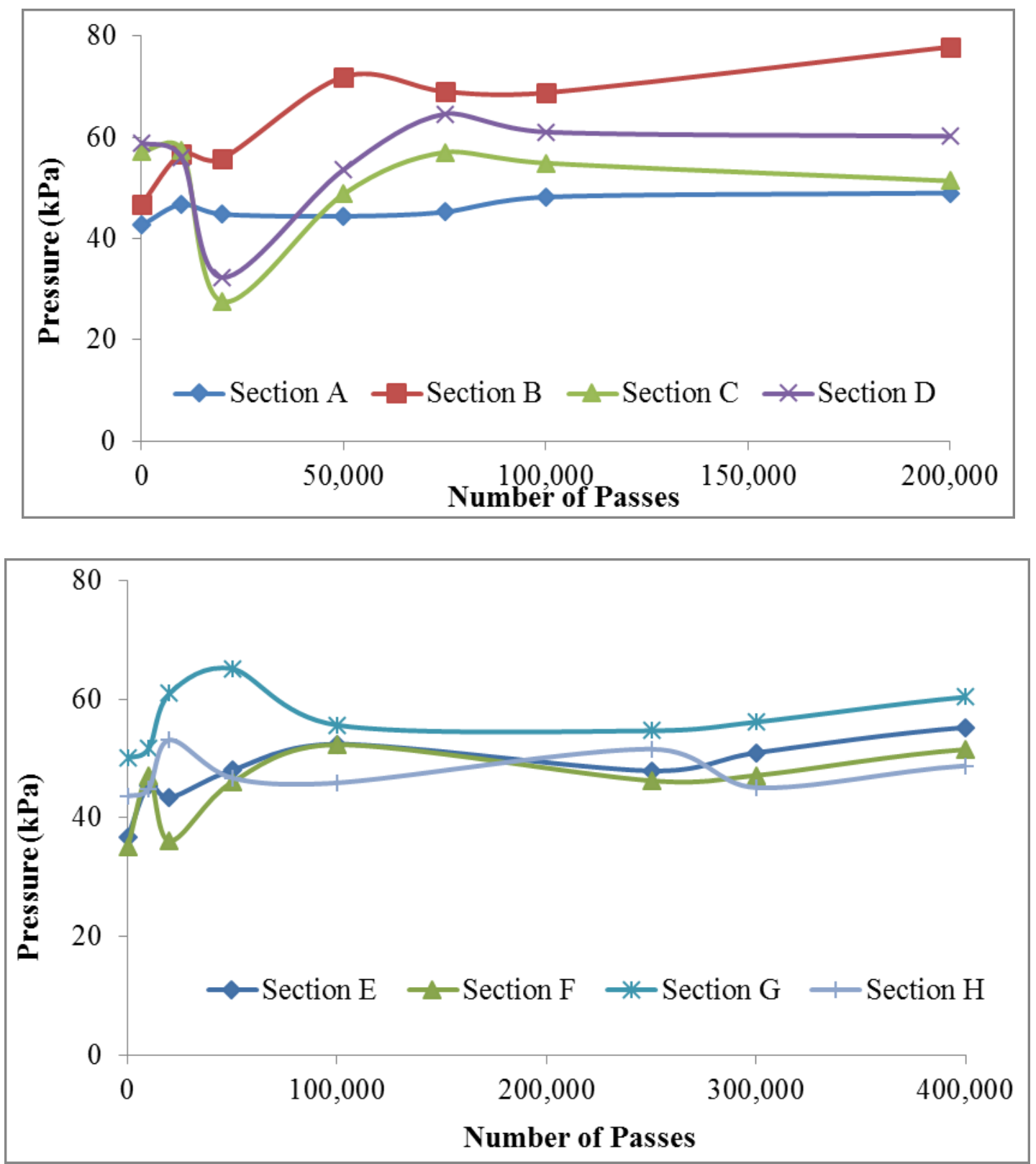

(b) $2^{\text {nd }}$ Test

Figure 4-8 Vertical stresses on the top of subgrade

\subsection{Strains on the Geosynthetics}

Six strain gages were attached to the top of the geotextile in each reinforced section. In the first test, all gages were placed in the longitudinal direction. In the second test, three of six strain 
gages were placed in the transverse direction. Average strain values for the active strain gages are shown in Figure 4-9. Tensile strain in the geotextiles fluctuated for the first 100,000 passes, after which strains did not change substantially. This trend shows that some deformation or densification is required to mobilize the geotextile. This is true in the machine direction (MD) of the geotextiles because the crimp (over - under - over - under) is removed from the weave. This may not always be evident since cross direction (XD) yarns lay flat and will go into tension very quickly compared to the MD yarns in these geotextiles. After some repetitions of the wheel load, tensile strains on the geotextiles decreased possibly due to further compaction of the materials. This may also be because the geotextiles were placed in tension and, from this point forward, they carried load rather than reorienting yarns in the weave in the machine direction.

In the first test, Section $\mathrm{C}$ absorbed a majority of tensile stress at the bottom of the base layer after 100,000 repetitions, as shown in Figure 4-9. Higher strain in Section C indicates that geotextile in this section was more effective, thus conforming to the rutting results showing that Section $\mathrm{C}$ demonstrated the best rutting performance compared to all geotextile-reinforced sections in the first test. Transverse strains in Sections $\mathrm{H}$ and $\mathrm{F}$ were close, but geotextile in Section $\mathrm{H}$ absorbed more longitudinal strain than that in Section F.

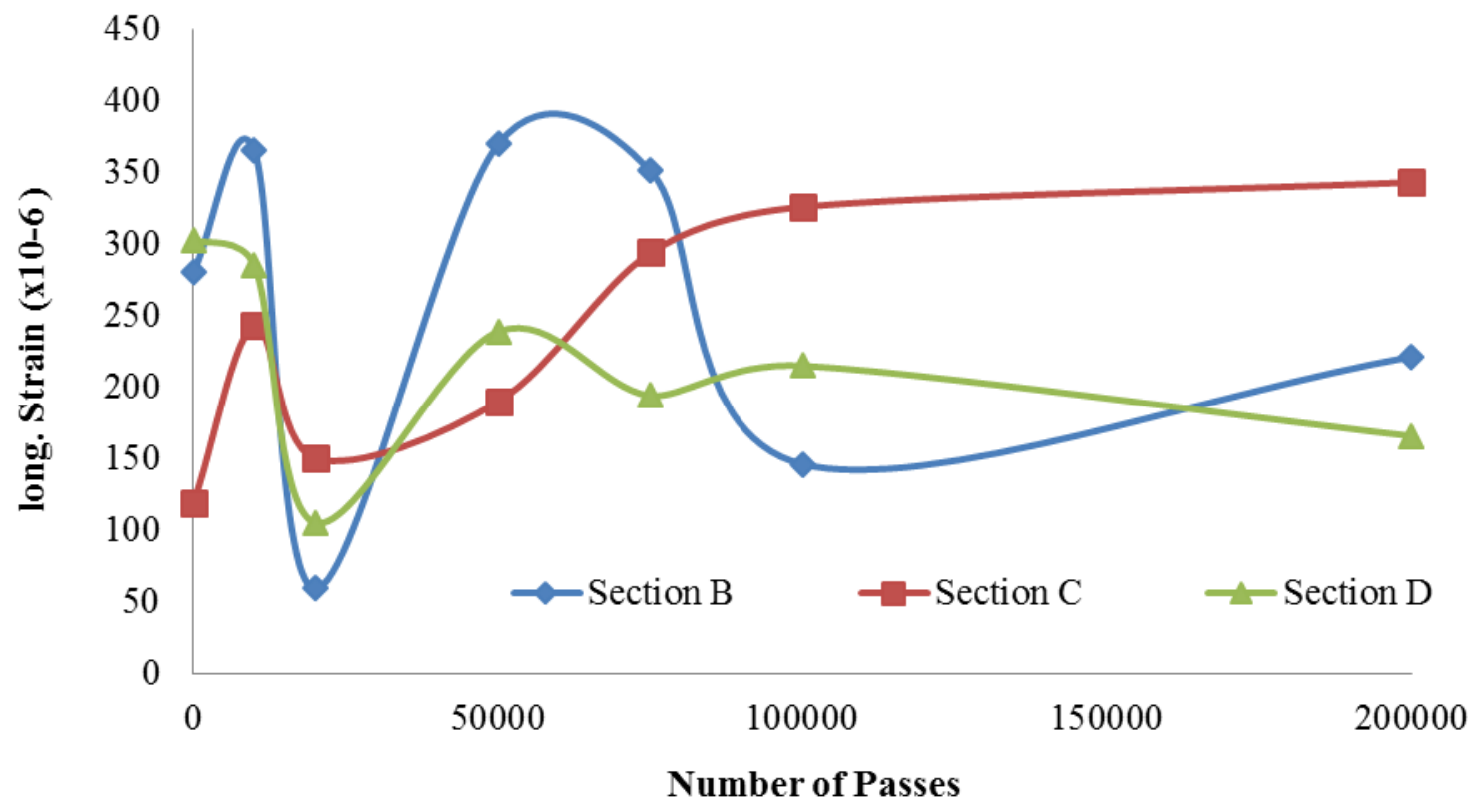

(a) Ist Test 

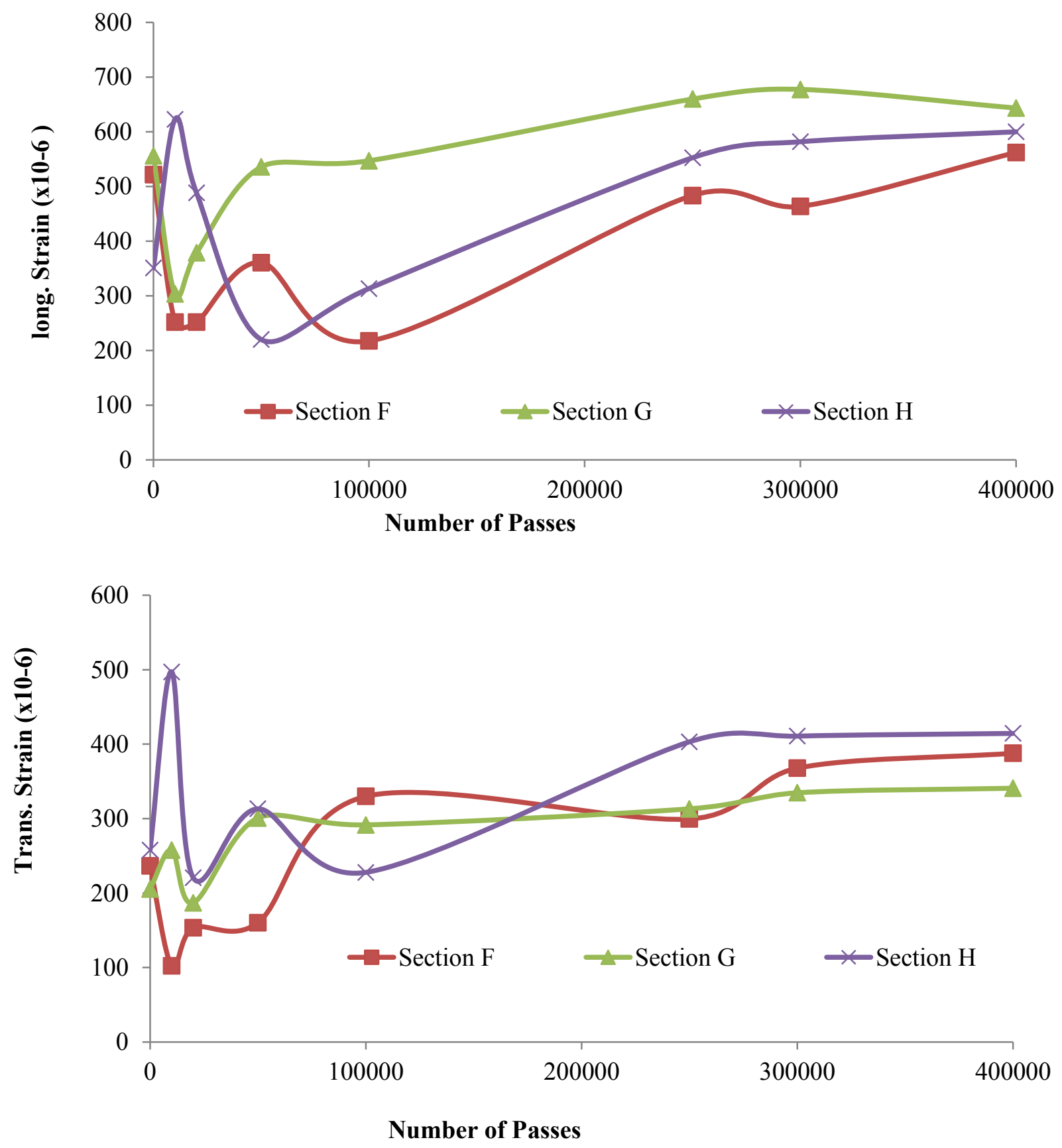

(b) 2nd Test

Figure 4-9 Strains in geotextiles 


\subsection{Strain at the Bottom of HMA Layer}

Six H-bar strain gages were placed at various places of each section to measure longitudinal and transverse strains at the bottom of HMA. Results are shown in Figures 4-10 through 4-13. Again, these strain responses widely fluctuated up to approximately 100,000 repetitions and then showed a clear trend. In both tests, longitudinal strains were higher than the transverse strains and longitudinal strains at the bottom of HMA were lower in the unreinforced sections (Sections A and E). Strain at the bottom of the HMA layer is usually related to the fatigue performance of the pavement, and higher strain repetitions caused the section to be more fatigue-prone. Consequently, the geotextiles did not improve the fatigue life of the sections during this testing.

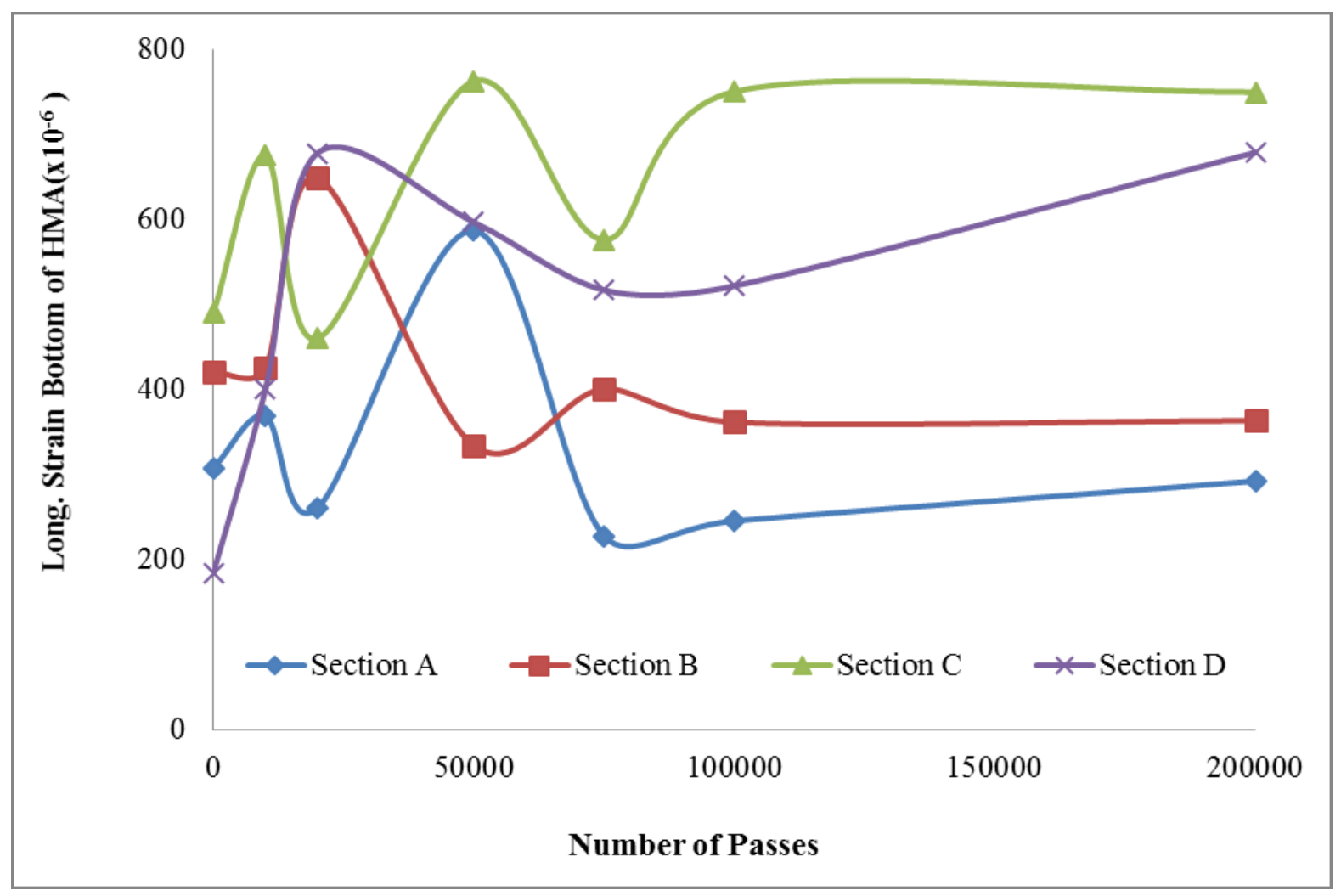

Figure 4-10 Longitudinal strains at the bottom of the HMA layer during the first test 


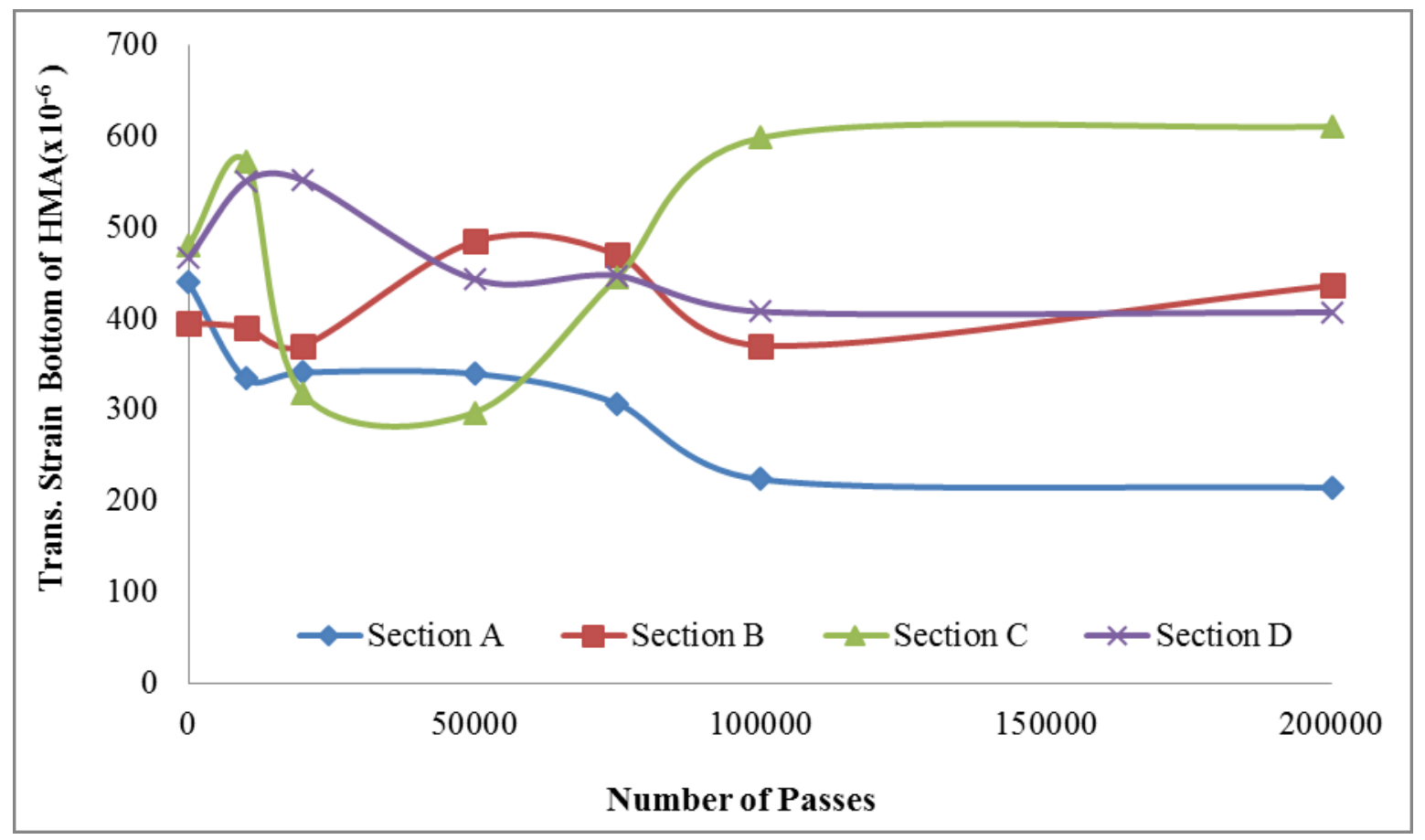

Figure 4-11 Transverse strains at the bottom of the HMA layer during the first test

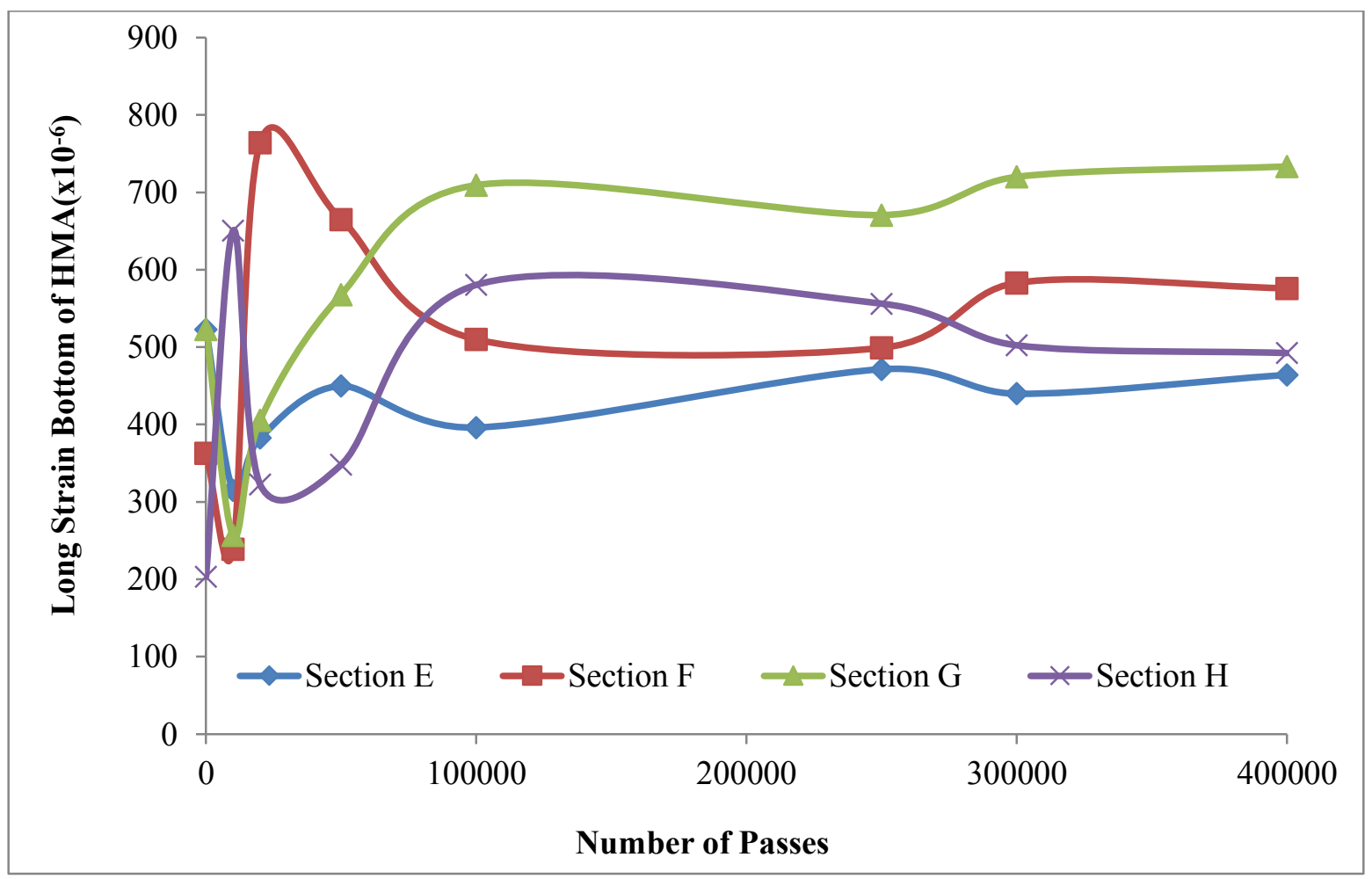

Figure 4-12 Longitudinal strains at the bottom of the HMA layer during the second test 


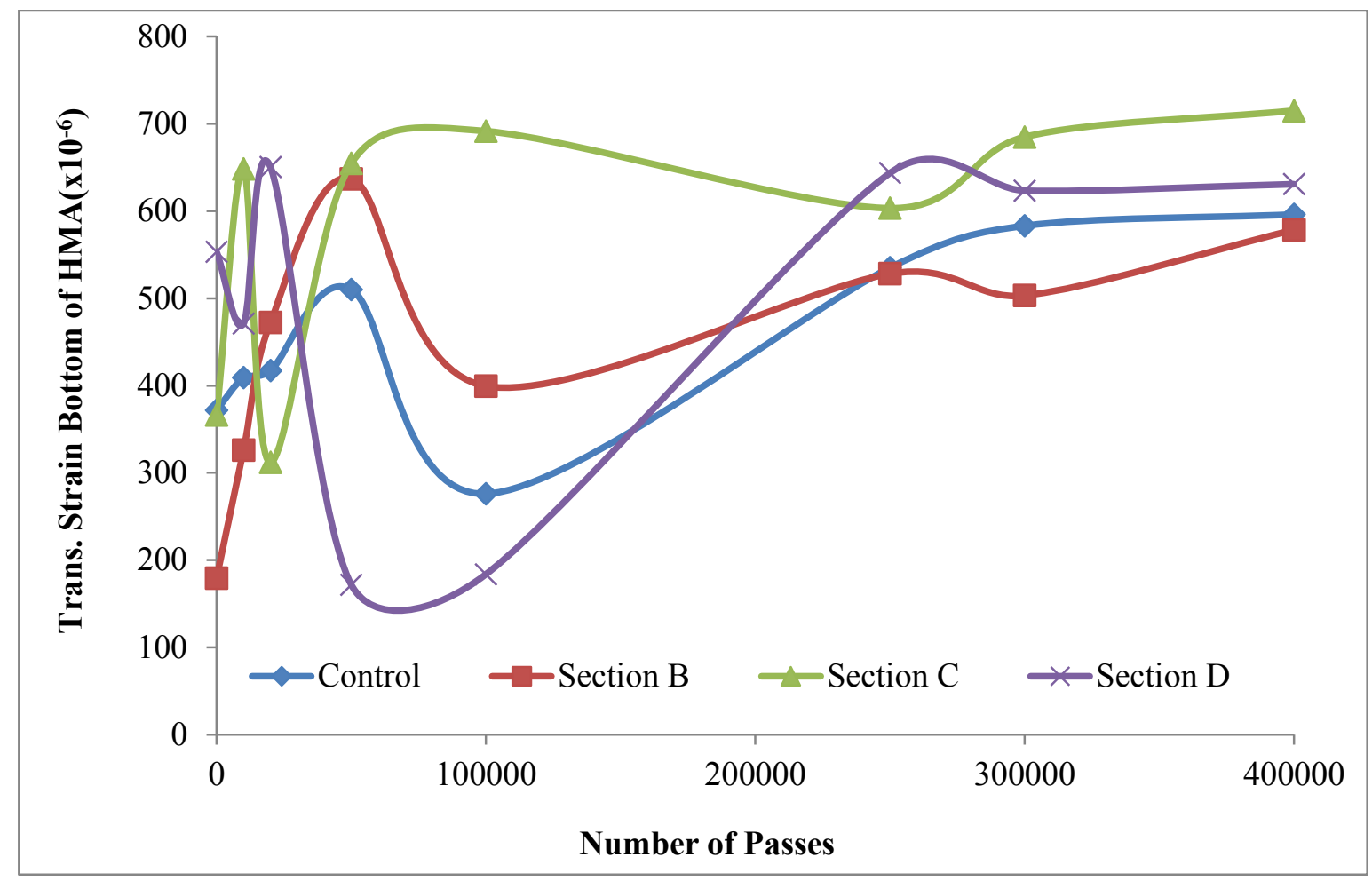

Figure 4-13 Transverse strains at the bottom of the HMA layer during the second test

\subsection{Back-Calculated Layer Moduli}

The Falling Weight Deflectometer (FWD) is one of the most common nondestructive testing devices for pavement evaluation and rehabilitation design. The FWD test applies an impulse load to the pavement surface and measures the response. Surface vertical deformation caused by the impulse load is measured through a couple of transducers. The use of an FWD enables determination of a deflection basin caused by a controlled load (Figure 4-14). 


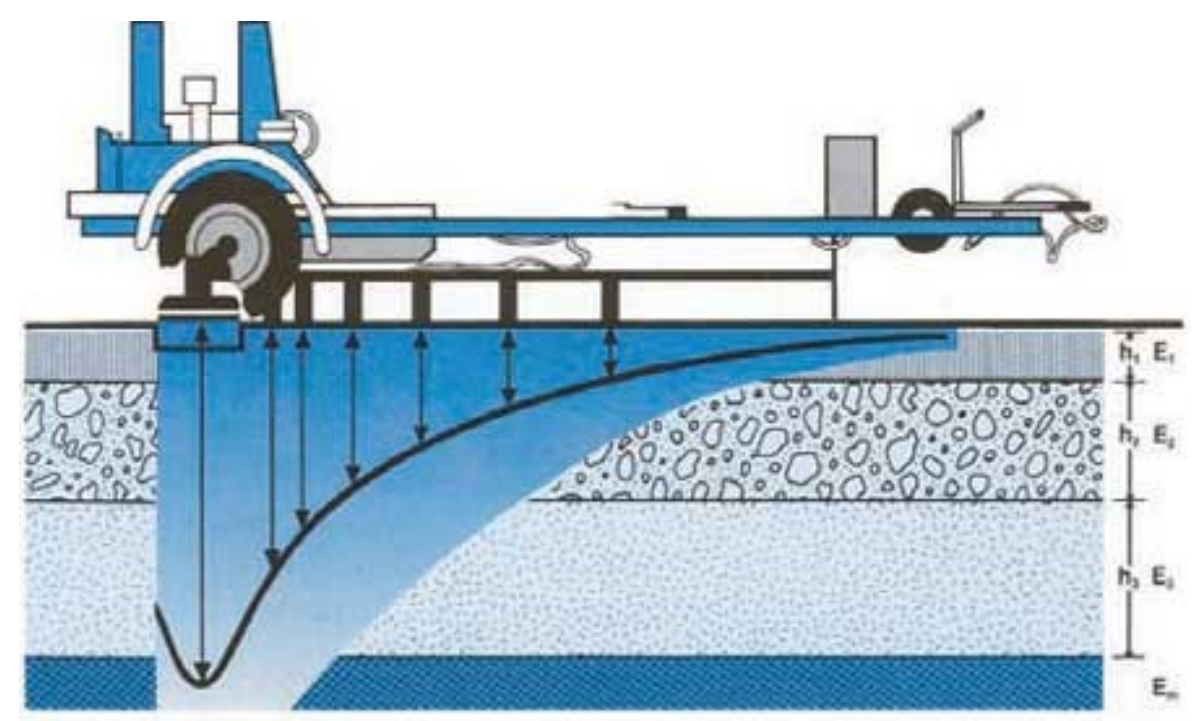

Figure 4-14 FWD and typical deflection basin

Before loading and at selected load repetitions during the APT tests at CISL, surface deflection was measured using a Dynatest falling weight deflectometer (FWD) with a 305-mmradius split load plate and transducer sensors, as shown in Figure 4-15. Seven sensors were placed at offset locations of $0,305,610,914,1219$, and $1829 \mathrm{~mm}(0,12,24,36,48,60$ and $72 \mathrm{in}$.) from the center of the load plate. The target load was $40 \mathrm{kN}$ (9 kip).

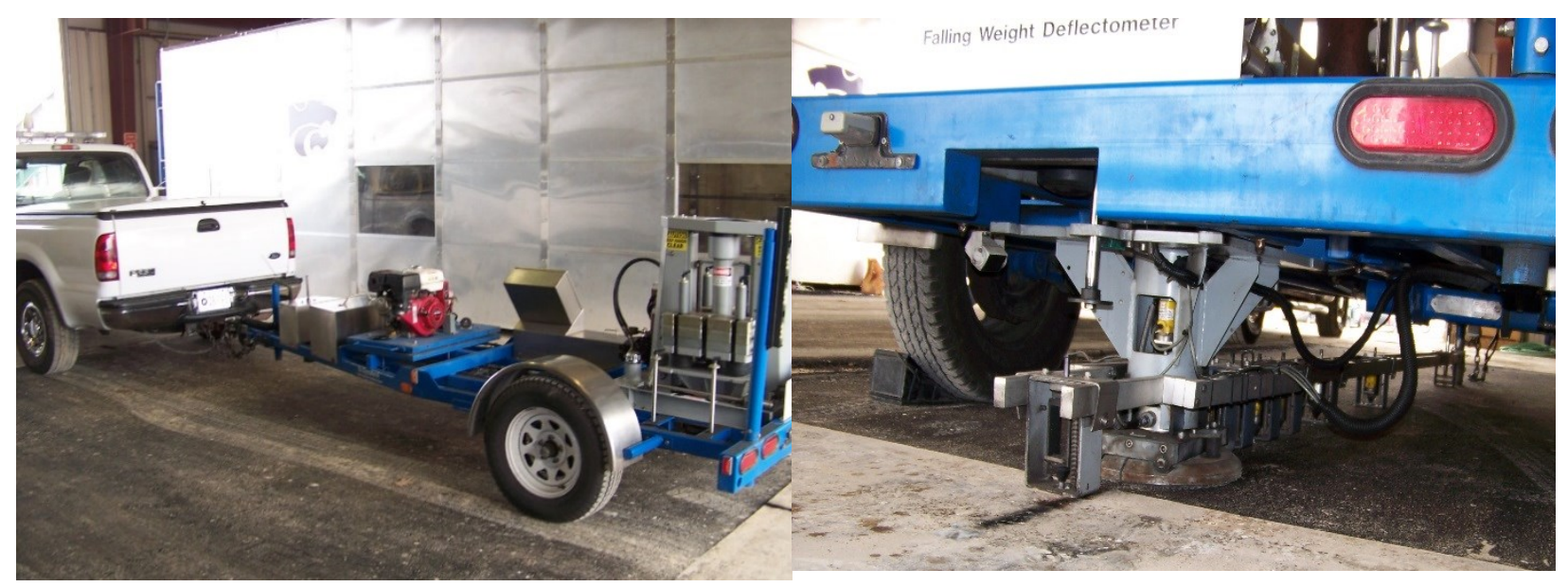

(a) Test Position (b) Load plate and sensor positions

Figure 4-15 Falling weight deflectometer (FWD) 
Six tests were conducted on each test section in two directions at three trafficking intervals: 0, 250,000 and 500,000 passes. EVERCALC software program from the Washington State DOT was used to backcalculate the layer moduli. EVERCALC computed theoretical deflections using a layered elastic solution and modified Augmented Gauss-Newton algorithm for optimization. Basis assumptions used in EVERCALC software are (Sivaneswaran et al. 2001):

- Infinite length of layers in the horizontal direction

- Uniform thickness

- Existence of semi-infinite bottom layer

- Homogeneous, isotropic, linear elastic materials

Up to 10 sensors and five layers can be modeled in EVERCALC. The software initially estimates layer moduli and calculates surface deflections at the sensor locations for given layer thicknesses and Poisson's ratios based on the layer theory. Calculated deflections are compared to the measured deformations and then estimated layer moduli are gradually adjusted to increase the accuracy of predicted deflections. This trend continues until the error between the predicted and measured deflections falls within allowable tolerance or the number of iterations reaches a preset limit.

Average backcalculated layer moduli for the test sections from the FWD tests in two directions are shown in Table 4-1. To increase accuracy of the results, deflections from only the first four sensors were used. As shown in Table 4-1, a substantial increase occurred in the backcalculated aggregate base layer moduli after 250,000 repetitions. This increase in moduli can be attributed to the densification of the pavement sections and mobilization of the reinforcement. An increase in other layer moduli in some test sections was also observed. 
Table 4-1 Back calculated layer moduli (MPa)

\begin{tabular}{||l|c|c|c|c|c|c|c|c|c||}
\hline & \multicolumn{3}{|c|}{ 0K } & \multicolumn{3}{c|}{ 250K } & \multicolumn{3}{c||}{ 500K } \\
\cline { 2 - 10 } & HMA & Base & Subgrade & HMA & Base & Subgrade & HMA & Base & Subgrade \\
\hline Section A & 300 & 20 & 5.2 & 300 & 21 & 6.2 & - & - & - \\
\hline Section B & 300 & 20 & 5.1 & 300 & 23 & 5.5 & - & - & - \\
\hline Section C & 321 & 20 & 5 & 325 & 23 & 6.2 & - & - & - \\
\hline Section D & 363 & 20 & 5 & 334 & 22.4 & 6.3 & - & - & - \\
\hline Section E & 300 & 33.7 & 6.3 & 366 & 37 & 5 & 300 & 35 & 6.4 \\
\hline Section F & 300 & 22 & 5.9 & 425 & 47 & 5 & 300 & 26.6 & 7.7 \\
\hline Section G & 425 & 60 & 7.7 & 425 & 73 & 6 & 425 & 29 & 6.5 \\
\hline Section H & 300 & 55 & 8.9 & 425 & 75 & 6.1 & 300 & 20 & 6.6 \\
\hline
\end{tabular}

\subsection{Predicted Fatigue Life}

Fatigue cracking is prevalent in HMA pavements because repeated traffic loads cause tensile stress repetitions in the bound layers. Under these repeated strains, fatigue cracks initiate at locations where the largest tensile strains and stresses develop. These critical locations depend on factors such as pavement structural configuration, layer stiffness, and load configuration (area of load distribution, magnitude of stresses at the tire-pavement interface, etc.). After crack initiation at the critical locations, cracks propagate throughout the layer under continued load repetitions. Water infiltrates through these cracks, consequently weakening subsurface unbound layers and negatively affecting pavement performance. Many pavement structural models assume cracks initiate at the bottom of the asphalt concrete surface layer and propagate upward.

In the majority of fatigue life models for HMA, the number of load applications to fatigue crack appearance $\left(\mathrm{N}_{\mathrm{f}}\right)$ is related to the tensile strain at the bottom of the asphalt layer $\left(\varepsilon_{\mathrm{t}}\right)$ and elastic modulus of the HMA layer $\left(E_{1}\right)$. The Asphalt Institute expressed the following formula as failure criterion for fatigue cracking (Huang, 2008): 


$$
N_{f}=f_{1}\left(\varepsilon_{t}\right)^{-f_{2}}\left(E_{1}\right)^{-f_{3}}
$$

$f_{1}, f_{2}$ and $f_{3}$ are constants determined from the fatigue tests. Table 4-2 shows $f_{1}, f_{2}$, and $f_{3}$ values suggested by the Asphalt Institute and Shell models.

TABLE 4-2 Parameters in fatigue cracking models (Huang, 2008)

\begin{tabular}{|c|c|c||}
\hline PARAMETERS & $\begin{array}{c}\text { ASPHALT } \\
\text { INSTITUTE }\end{array}$ & SHELL \\
\hline $\mathrm{f}_{1}$ & 0.0796 & 0.0685 \\
\hline $\mathrm{f}_{2}$ & 3.291 & 5.671 \\
\hline $\mathrm{f}_{3}$ & 0.854 & 2.363 \\
\hline
\end{tabular}

As mentioned, six H-bar strain gages were placed at various locations in each test section to measure longitudinal and transverse strains at the bottom of the HMA layer. Results are shown in Tables 4-3 and 4-4. These strains were used for fatigue life computation. Layer moduli used in fatigue life computation were backcalculated from the deflection data obtained during FWD testing. Table 4-5 shows the predicted remaining fatigue lives of the test sections for 676, 250,000, and 400,000 wheel load repetitions. After 676 repetitions, strain at the bottom of the HMA layer in Section D was less than other sections, so predicted fatigue life for this section is higher than other sections. When consolidation of the HMA and base layers was completed and strains were recorded, no significant improvement in fatigue life of the test sections constructed with a geotextile was apparent. In both experiments, remaining fatigue life for the unreinforced section (Section A or E) was higher than that for the reinforced sections after 250,000 and 400,000 repetitions. Also, geotextile in Section H carried more transverse and longitudinal strains than the geotextile in Section F after mobilization; therefore, this section performed better.

HMA fatigue life did not increase with the use of a geotextile reinforcing layer below the base layer. Therefore, geotextile-reinforced bases did not improve fatigue resistance of these 
sections. A reinforced HMA layer is expected to lower strain at the bottom of the HMA layer, thereby increasing fatigue life.

TABLE 4-3 Longitudinal strains at the bottom of the HMA layer

\begin{tabular}{|c|c|c|c|c|c|c|}
\hline \multirow{2}{*}{ Reps. } & \multicolumn{3}{|c|}{ Section A } & \multicolumn{3}{|c|}{ Section B } \\
\hline & $\begin{array}{c}\text { No. of } \\
\text { Readings }\end{array}$ & $\begin{array}{c}\text { Ave. Strain } \\
\qquad\left(1^{-6}\right)\end{array}$ & $\begin{array}{l}\text { Std. } \\
\text { Dev. }\end{array}$ & $\begin{array}{c}\text { No. of } \\
\text { Readings }\end{array}$ & $\begin{array}{c}\text { Ave. Strain } \\
\left(10^{-6}\right)\end{array}$ & $\begin{array}{l}\text { Std. } \\
\text { Dev. }\end{array}$ \\
\hline 676 & 2 & 308 & -- & 3 & 422 & 92 \\
\hline 10,000 & 2 & 369 & & 3 & 426 & 32 \\
\hline 20,000 & 2 & 261 & & 3 & 649 & 202 \\
\hline 50,000 & 2 & 587 & & 2 & 335 & 124 \\
\hline 75,000 & 2 & 228 & & 2 & 401 & 290 \\
\hline 100,000 & 2 & 246 & & 2 & 362 & 315 \\
\hline \multirow[t]{2}{*}{250,000} & 2 & 293 & & 2 & 364 & 357 \\
\hline & \multicolumn{3}{|c|}{ Section C } & \multicolumn{3}{|c|}{ Section D } \\
\hline 676 & 3 & 490 & 210 & 2 & 185 & \\
\hline 10,000 & 3 & 675 & 154 & 2 & 400 & \\
\hline 20,000 & 3 & 460 & 113 & 2 & 678 & \\
\hline 50,000 & 3 & 763 & 43 & 2 & 597 & \\
\hline 75,000 & 3 & 576 & 127 & 2 & 517 & \\
\hline 100,000 & 3 & 750 & 178 & 2 & 522 & \\
\hline \multirow[t]{2}{*}{250,000} & 3 & 750 & 107 & 2 & 679 & \\
\hline & \multicolumn{3}{|c|}{ Section E } & \multicolumn{3}{|c|}{ Section F } \\
\hline 676 & 2 & 436 & -- & 2 & 276 & \\
\hline 10,000 & 2 & 228 & & 2 & 152 & \\
\hline 20,000 & 2 & 296 & & 2 & 677 & \\
\hline 50,000 & 2 & 363 & & 2 & 578 & \\
\hline 100,000 & 2 & 309 & & 2 & 423 & \\
\hline 250,000 & 2 & 484 & & 2 & 582 & \\
\hline 300,000 & 2 & 553 & & 2 & 596 & \\
\hline 400,000 & 2 & 577 & & 2 & 619 & \\
\hline
\end{tabular}




\begin{tabular}{|c|c|c|c|c|c|c|}
\hline \multirow{2}{*}{ Reps. } & $\begin{array}{c}\text { No. of } \\
\text { Readings }\end{array}$ & $\begin{array}{c}\text { Ave. Strain } \\
\left(\mathbf{1 0}^{-6}\right)\end{array}$ & $\begin{array}{c}\text { Std. } \\
\text { Dev. }\end{array}$ & $\begin{array}{c}\text { No. of } \\
\text { readings }\end{array}$ & $\begin{array}{c}\text { Ave. } \\
\text { Strain } \\
\left(\mathbf{1 0}^{-6}\right)\end{array}$ & $\begin{array}{c}\text { Std. } \\
\text { Dev. }\end{array}$ \\
\cline { 2 - 8 } & \multicolumn{3}{|c|}{ Section G } & \multicolumn{3}{|c|}{ Section H } \\
\hline $\mathbf{6 7 6}$ & 2 & 636 & & 2 & 116 & \\
\hline $\mathbf{1 0 , 0 0 0}$ & 2 & 370 & & 2 & 563 & \\
\hline $\mathbf{2 0 , 0 0 0}$ & 2 & 518 & & 2 & 261 & \\
\hline $\mathbf{5 0 , 0 0 0}$ & 2 & 681 & & 1 & 569 & \\
\hline $\mathbf{1 0 0 , 0 0 0}$ & 2 & 622 & & 1 & 613 & \\
\hline $\mathbf{2 5 0 , 0 0 0}$ & 2 & 664 & & 1 & 585 & \\
\hline $\mathbf{3 0 0 , 0 0 0}$ & 2 & 725 & & & 2 & \\
\hline $\mathbf{4 0 0 , 0 0 0}$ & 2 & 746 & & & & \\
\hline
\end{tabular}


TABLE 4-4 Transverse strains at the bottom of the HMA layer

\begin{tabular}{|c|c|c|c|c|c|c|}
\hline \multirow[b]{2}{*}{ Reps. } & \multicolumn{3}{|c|}{ Section A } & \multicolumn{3}{|c|}{ Section B } \\
\hline & $\begin{array}{c}\text { No. of } \\
\text { Readings }\end{array}$ & $\begin{array}{c}\text { Ave. } \\
\text { Strain } \\
\left(1^{-6}\right)\end{array}$ & $\begin{array}{l}\text { Std. } \\
\text { Dev }\end{array}$ & $\begin{array}{c}\text { No. of } \\
\text { Readings }\end{array}$ & $\begin{array}{l}\text { Ave. } \\
\text { Strain } \\
\left(1^{-6}\right)\end{array}$ & Std. Dev \\
\hline 676 & 2 & 439 & - & 3 & 395 & 209 \\
\hline 10,000 & 2 & 334 & & 3 & 390 & 255 \\
\hline 20,000 & 2 & 341 & & 3 & 370 & 30 \\
\hline 50,000 & 2 & 339 & & 3 & 484 & 62 \\
\hline 75,000 & 2 & 307 & & 3 & 470 & 170 \\
\hline 100,000 & 2 & 224 & & 3 & 370 & 226 \\
\hline 250,000 & 2 & 215 & & 3 & 436 & 145 \\
\hline Rep. & \multicolumn{3}{|c|}{ Section C } & \multicolumn{3}{|c|}{ Section D } \\
\hline 676 & 3 & 480 & 287 & 3 & 466 & 65 \\
\hline 10,000 & 3 & 572 & 465 & 3 & 550 & 68 \\
\hline 20,000 & 2 & 317 & - & 2 & 551 & - \\
\hline 50,000 & 2 & 297 & & 2 & 443 & \\
\hline 75,000 & 1 & 445 & - & 2 & 447 & \\
\hline 100,000 & 2 & 598 & - & 2 & 408 & \\
\hline 250,000 & 2 & 610 & & 2 & 407 & \\
\hline Rep. & \multicolumn{3}{|c|}{ Section $\mathbf{E}$} & \multicolumn{3}{|c|}{ Section F } \\
\hline 676 & 2 & 366 & - & 2 & 179 & - \\
\hline 10,000 & 2 & 409 & & 2 & 326 & \\
\hline 20,000 & 2 & 417 & & 2 & 472 & \\
\hline 50,000 & 2 & 510 & & 2 & 637 & \\
\hline 100,000 & 1 & 276 & - & 2 & 399 & \\
\hline 250,000 & 2 & 528 & - & 2 & 527 & \\
\hline 300,000 & 2 & 583 & & 2 & 503 & \\
\hline 400,000 & 2 & 596 & & 2 & 578 & \\
\hline
\end{tabular}




\begin{tabular}{|c|c|c|c|c|c|c|}
\hline \multirow[t]{2}{*}{ Rep. } & $\begin{array}{c}\text { No. of } \\
\text { Readings }\end{array}$ & $\begin{array}{c}\text { Ave. } \\
\text { Strain } \\
\left(10^{-6}\right)\end{array}$ & $\begin{array}{l}\text { Std. } \\
\text { Dev }\end{array}$ & $\begin{array}{c}\text { No. of } \\
\text { Readings }\end{array}$ & $\begin{array}{c}\text { Ave. } \\
\text { Strain } \\
\left(10^{-6}\right)\end{array}$ & Std. Dev \\
\hline & \multicolumn{3}{|c|}{ Section $\mathbf{G}$} & \multicolumn{3}{|c|}{ Section $\mathbf{H}$} \\
\hline 676 & 2 & - & 304 & 2 & 553 & - \\
\hline 10,000 & 2 & & 196 & 2 & 471 & \\
\hline 20,000 & 2 & & 168 & 1 & 650 & - \\
\hline 50,000 & 2 & & 113 & 1 & 171 & \\
\hline 100,000 & 2 & & 185 & 1 & 183 & \\
\hline 250,000 & 2 & & 109 & 1 & 643 & \\
\hline 300,000 & 2 & & 116 & 1 & 623 & \\
\hline 400,000 & 2 & & 180 & 1 & 631 & \\
\hline
\end{tabular}


TABLE 4-5 Predicted Fatigue Life

\begin{tabular}{|c|c|c|c|c|}
\hline Section & E1(ksi) & $\begin{array}{c}\text { Tensile Strain } \\
\left(10^{-6}\right)\end{array}$ & Asphalt Institute & Shell Model \\
\hline \multicolumn{5}{|c|}{ Remaining fatigue life after 676 load repetitions } \\
\hline Section A & 300 & 308 & 602,048 & 640,740 \\
\hline Section B & 300 & 422 & 213,574 & 107,425 \\
\hline Section C & 307.3 & 490 & 127,967 & 43,499 \\
\hline Section D & 300 & 185 & $3,222,474$ & $11,537,778$ \\
\hline Section E & 300 & 436 & 191,823 & 89,274 \\
\hline Section F & 300 & 270 & 928,610 & $1,352,039$ \\
\hline Section $\mathbf{G}$ & 308 & 636 & 54,139 & 9,859 \\
\hline Section $\mathbf{H}$ & 300 & 316 & 553,326 & 554,023 \\
\hline \multicolumn{5}{|c|}{ Remaining fatigue life after 250,000 load repetitions } \\
\hline Section A & 300 & 293 & 709,562 & 850,446 \\
\hline Section B & 300 & 364 & 347,430 & 248,455 \\
\hline Section $\mathbf{C}$ & 313.3 & 750 & 31,012 & 3,718 \\
\hline Section D & 314 & 679 & 42,939 & 6,500 \\
\hline Section $\mathbf{E}$ & 366 & 484 & 114,782 & 30,862 \\
\hline Section F & 325 & 582 & 69,247 & 14,363 \\
\hline Section $\mathbf{G}$ & 325 & 664 & 44,876 & 6,801 \\
\hline Section $\mathbf{H}$ & 325 & 569 & 74,592 & 16,326 \\
\hline \multicolumn{5}{|c|}{ Remaining fatigue life after 400,000 load repetitions } \\
\hline Section E & 300 & 577 & 76,282 & 18,223 \\
\hline Section F & 310 & 619 & 58,862 & 11,322 \\
\hline Section $G$ & 325 & 746 & 30,590 & 3,514 \\
\hline Section H & 305 & 585 & 71,880 & 16,209 \\
\hline
\end{tabular}




\section{Chapter 5 - Finite Element Modeling}

\subsection{Introduction}

As mentioned in the research objective, FEM was used in this study to understand geotextile behavior in pavement and to develop a design method for pavements with geotextilereinforced base. A 3-D FE model was constructed using the commercial FE software ABAQUS. The developed model was calibrated with results from the full-scale tests on the pavement sections with geotextile-reinforced bases.

\subsection{General Features of FEM}

ABAQUS was used to model the following important features:

1. Boundary conditions such as sides and bottom boundary conditions of the pits for the test sections at CISL;

2. Non-linear material properties;

3. Wheel path wander; and

4. Loading condition.

ABAQUS, or CAE, is a program that creates an easy interface for viewing computer simulations. These simulations are specific to ABAQUS and are based on a geometric model analysis. This analysis has three stages: (1) a consideration of applicable geometry; (2) a consideration of material properties; and (3) and the generated mesh. The first stage of analysis occurs with ABAQUS creating an input file of the relevant geometry. The second stage takes the input file and performs the initial analysis by sending data through simulation. The data is then recorded and the output file generated. The third stage involves this output file being modified for specific visualization. This stage is where the analysis has been finalized for viewing.

Each of these stages can be further examined through a specific implementation of modules. The modules are commonly known as: part module, property module, assembly module, steps module, interaction module, load module, mesh module, job module, sketch module and visualization module. 


\subsubsection{Part Module}

The part module is the base element of ABAQUS. The part module creates each of the parts that the assembly module later uses to assemble. The part is created using the tools section of the software. The part is not specific to the ABAQUS tools and may also be exported from certain CAD software packages.

\subsubsection{Elements}

A 20-node quadratic brick element with reduced integration (C3D20), shown in Figure 51, was used to model HMA, base, and subgrade. Quadratic elements use quadratic interpolation instead of linear interpolation for linear elements, thereby providing smoother solutions (ABAQUS 2011). These solid elements can be used for linear and nonlinear analysis involving contact and plasticity. The reduced integration uses a lower-order integration to form the element stiffness. This reduction reduces computational running time (ABAQUS 2011).

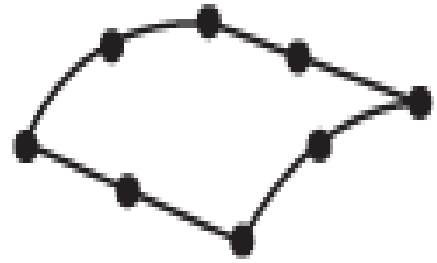

(a) Membrane element

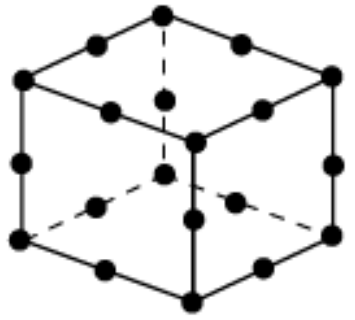

1. (b) Continuum elements (quadratic element)

\section{FIGURE 5-1 Membrane and quadratic brick elements in ABAQUS}

The FE type chosen for the geosynthetic is a critical feature. Geosynthetics have essentially zero bending resistance. Therefore, a membrane element (Figure 5.1(a)) is the most appropriate element for modeling the geosynthetic because these elements are formulated to have no in-plane bending resistance.

\subsubsection{Material Module}

The properties of the material are defined by the material module. With ABAQUS the materials are defined by choosing specific material behavior and defining them. 


\subsubsection{Assembly Module}

The parts from the part module are combined in the assembly module. Each of the parts created has a specific place in the system that the assembly module combines. When placed appropriately, the parts constitute the assembly. The assembly-specific combination is formed with a one-way negotiation on how each part aligns selected vertices, edges, or faces; this is also done through rotation or translation of the part. Therefore there is only one combination of parts from the part module and the assembly module is where the load module occurs. An assembly must be created even if the model consists of only a single part (ABAQUS 2011).

\subsubsection{Load Module}

The load module defines and manages the load through boundary conditions. The predefined conditions of ABAQUS occur through a step-specific analysis. The analysis is implemented with specific conditions of load and boundary. Each of these can be changed or predefined with the context bar. Complicated time or frequency conditions can be adjusted through the Amplitude toolset; these are often applied to prescribed conditions. Boundary conditions are used to define the loading condition of the sets of loads that compose a load case. A load case can be created in static perturbation and steady-state dynamic, direct steps (ABAQUS 2011).

\subsubsection{Mesh Module}

The parts and assemblies created within AQABUS are generated into meshes within the Mesh module. The mesh module has various levels of automation to ensure the mesh meets the needs of the analysis. The level of modification allows for how the assembly and even the part may be modified. The specified parameters can also be used to verify an existing or completed mesh (ABAQUS 2011).

\subsubsection{Job Module}

The final analysis of all tasks that define a model occurs through the job module. Here the job is created and then submitted for analysis or monitoring. The analysis file input may be modified or edited for submission for complete analysis (ABAQUS 2011). 


\subsection{Pavement Layer Material Models}

In this study two material models were considered for the HMA layer: elastic and creep model. Initially, the HMA layer was modeled based only on its elastic modulus. The elastic model, however, could not show permanent strain in this layer after unloading; the layer rebounded after removal of the load and the vertical plastic strain in this layer was zero. Therefore, the elastic model is not an appropriate model for HMA and other pavement layers.

Plastic deformation of aggregate base and subgrade layer has a defining role in determining pavement performance. A majority of rutting in HMA pavements happens due to permanent deformation of the base and/or subgrade layer(s). Therefore, an accurate model should consider plastic behavior of the underlying layers. There are 13 plasticity models in ABAQUS: plastic, cap plasticity, cast iron plasticity, clay plasticity, concrete damage plasticity, concrete smeared cracking, crushable foam, Drucker Prager (DP), Mohr Coulomb plasticity, porous metal plasticity, creep, swelling, and viscous. However, a majority of these models are not applicable to aggregate and soil. Based on the literature, DP and Mohr Coulomb plasticity are the most common models that have been used for the base course and subgrade layer.

\subsubsection{Creep Model}

Creep is defined as the time-dependent tendency of solid material to deform under constant stress. This phenomenon occurs when a material is subjected to long-term stress that is less than the yield strength. High temperature may increase creep rate. In addition to temperature, loading time and material properties also affect creep rate; longer loading time results in higher deformation.

In general, creep occurs in three stages: primary, secondary, and tertiary. In the first stage, creep rate starts at a very high rate and reduces over time due to strain hardening. In the second stage, creep rate is nearly uniform. This stage usually takes longer than the primary and tertiary stages; therefore, many creep models only consider the secondary stage. Necking phenomena is dominant in the last stage, leading to exponential increase of strain rate until the material breaks or ruptures. These stages are shown in Figure 5-2. 


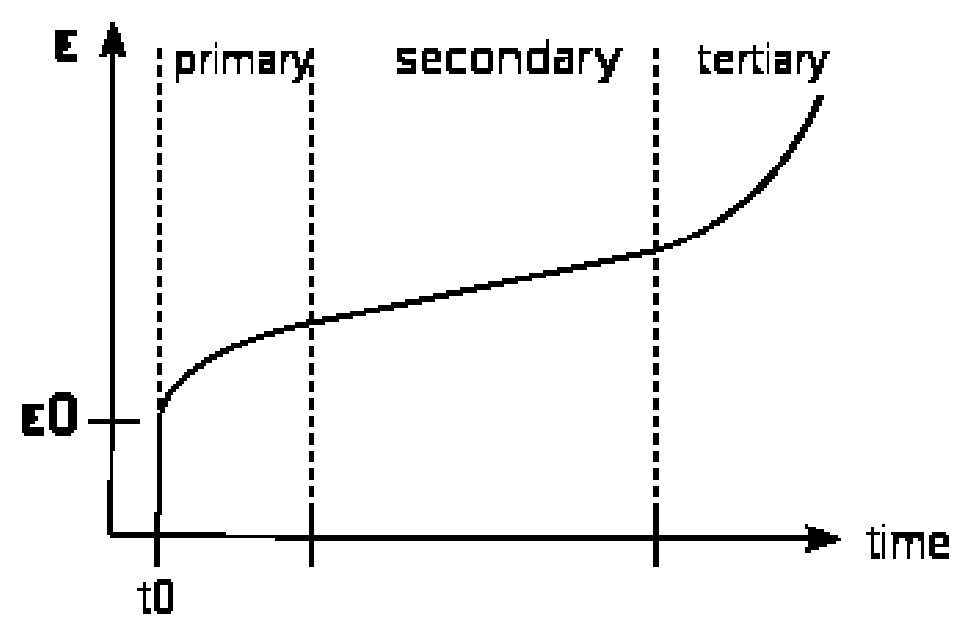

Figure 5-2 Stages in creep (ABAQUS, 2011)

In ABAQUS, a power-law model is used to model creep performance of the materials. Two versions of this power-law creep model are available: time hardening and strain hardening. The strain hardening model is recommended for use when stress varies throughout the analysis. Time hardening can be considered when constant stress is applied. However, for constant load and temperature, time-hardening and strain-hardening models are identical.

In the time hardening version of the power-law model, uniaxial equivalent creep strain rate $\left(\dot{\bar{\varepsilon}}^{c r}\right)$ depends on the uniaxial equivalent deviator stress $(\bar{\sigma})$ and total time $(\mathrm{t})$. This model is shown in Equation 5.1.

$\dot{\bar{\varepsilon}}^{c r}=A \bar{\sigma}^{n} t^{m}$

Where $\mathrm{A}, n$, and $\mathrm{m}$ are constant parameters defined by the user as functions of temperature and material.

In the strain hardening version, uniaxial equivalent creep strain rate depends on Mises equivalent stress or Hill's anisotropic equivalent deviatoric stress $(\tilde{q})$. Mises equivalent stress is used by ABAQUS for isotropic creep behavior. Hill's anisotropic equivalent deviatoric stress is considered when anisotropic creep behavior is defined. The strain hardening form of the powerlaw is shown in Equation 5.2. 
$\dot{\bar{\varepsilon}}^{c r}=\left(A \tilde{q}^{n}\left[(m+1) \bar{\varepsilon}^{c r}\right]^{m}\right)^{(m+1)^{-1}}$

Where $\dot{\bar{\varepsilon}}^{c r}$ and $\tilde{q}$ are defined above and $\bar{\varepsilon}^{c r}$ is the equivalent creep strain.

In the power-law equation, $\mathrm{A}$ and $\mathrm{n}$ must be positive and $-1<m \leq 0$.

\subsubsection{Drucker-Prager Model}

DP models are used to model frictional materials such as granular-like soil, rock, and asphalt concrete. DP model can also be used to model materials in which compressive yield strength is greater than the tensile yield strength. They allow materials to harden or soften isotropically and allow volume change with inelastic behavior (ABAQUS, 2011). Yield criteria for DP models are based on the shape of the yield surface in the meridional plane. The yield surface can have a linear form, hyperbolic form, or general exponent form. These surfaces are illustrated in Figure 5-3(a), 5-3(b), and 5-3(c).

The linear model (Figure 5-3(a)) provides a linear yield surface in the deviatoric plane to match various yield values in triaxial tension and compression: associated inelastic flow in the deviatoric plane and separate dilation and friction angles. The original DP model is available within this model, but this model cannot provide a close match with the Mohr-Coulomb (MC) behavior.

The hyperbolic and general exponent models (Figure 5-3(b) and 5-3(c)) use a von Misses (circular) section in the deviatoric stress plane and, in the meridional plane, a hyperbolic flow potential is used, generally meaning non-associated flow. Required yield criteria is activated in ABAQUS/CAE by setting the shear criterion equal to the linear, hyperbolic, or exponent form in 
order to define linear, hyperbolic, or exponent yield criterion, respectively. (ABAQUS, 20011).

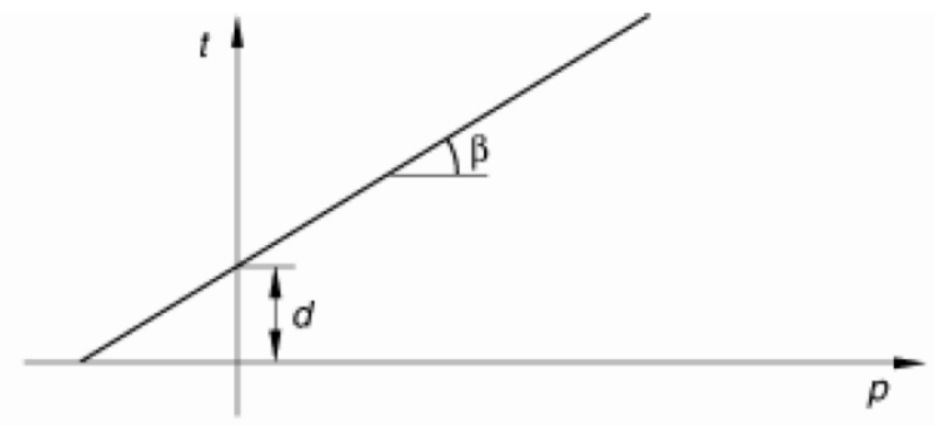

a) Linear Drucker-Prager: $F=t-p \tan \beta-d=0$

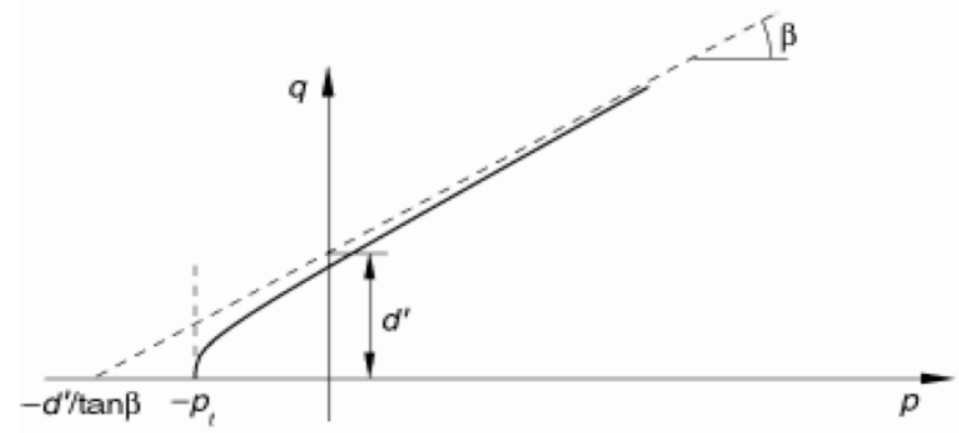

b) Hyperbolic: $F=\sqrt{\left(d^{\prime} \mid 0-p, 0 \tan \beta\right)^{2}+q^{2}}-p \tan \beta-d^{\prime \prime}=\mathrm{C}$

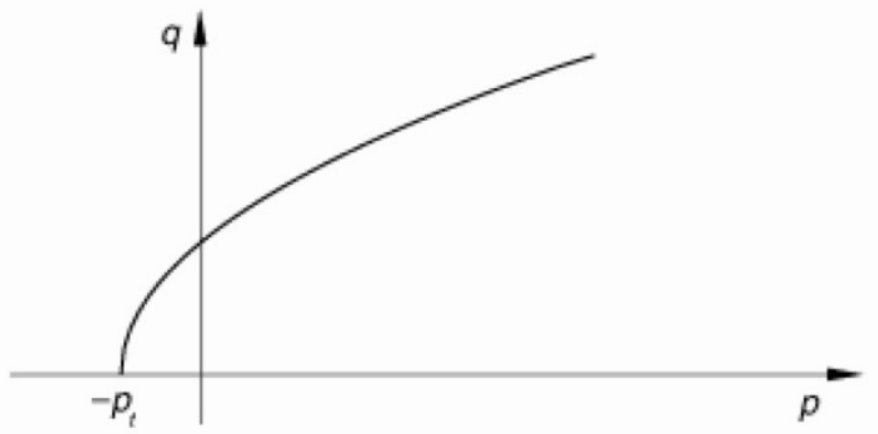

c) Exponent form: $F=a q^{b}-p-p_{t}=0$

Figure 5-3 Yield surfaces in the meridional plane (ABAQUS, 20011) 


\section{Chapter 6 - Finite Element Modeling of APT Sections}

\subsection{Geometry}

Two APT test pits in this study were $6 \mathrm{~m}(20 \mathrm{ft})$ long by $4.9 \mathrm{~m}(16 \mathrm{ft})$ wide and $1.8 \mathrm{~m}(6$ $\mathrm{ft})$ deep. Each pit was divided into two test sections. In the first experiment, each test section was

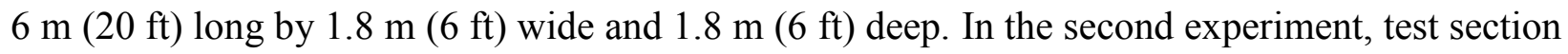
width increased to $4.9 \mathrm{~m}(16 \mathrm{ft})$ and length decreased to $3 \mathrm{~m}(9.8 \mathrm{ft})$. Only half the test lane was modeled because of test section geometry and dual wheel symmetry. Based on a sensitivity analysis, maximum mesh size of 51 (2 in.), 102 (4 in.), 102 (4 in.), and 102 (4 in.) mm was considered for HMA, base, geotextile, and subgrade, respectively. Table 6-1 shows test section thicknesses.

Table 6-1 Test section layout

\begin{tabular}{|l|l|l|l|l|l|l||}
\hline & $\begin{array}{l}\text { Sections A } \\
\text { \& E }\end{array}$ & Section B & Section C & $\begin{array}{l}\text { Sections D } \\
\& \mathrm{H}\end{array}$ & Section F & Section G \\
\hline Geosynthetics & None & G1 & G2 & G3 & G2 & G3 \\
\hline Base & $305 \mathrm{~mm}$ & $203 \mathrm{~mm}$ & $229 \mathrm{~mm}$ & $254 \mathrm{~mm}$ & $305 \mathrm{~mm}$ & $305 \mathrm{~mm}$ \\
\hline $\begin{array}{l}\text { Hot-Mix } \\
\text { Asphalt }\end{array}$ & $152 \mathrm{~mm}$ & $152 \mathrm{~mm}$ & $127 \mathrm{~mm}$ & $102 \mathrm{~mm}$ & $152 \mathrm{~mm}$ & $152 \mathrm{~mm}$ \\
\hline
\end{tabular}




\subsection{Mesh Size}

Mesh size may affect stress gradient and deflection pattern. In general, finer mesh size increases analysis accuracy but requires additional computational resources. Four factors control mesh size: structure geometry, loading condition, locations in which responses must be predicted, and desired accuracy. One strategy to reduce computational time includes the use of fine mesh size in the area of stress concentration and coarse mesh size far away from the load.

To determine optimum mesh size that does not significantly affect results, six models with a total of $800,1,184,1,514,6,260,10,492$, and 40,740 elements were constructed to study convergence of deformation and stress responses. Mesh size was the only parameter that changed in these models. Table 6-2 shows models used in this sensitivity analysis. Maximum rut depth and vertical stress on the top of the subgrade were used as responses, and these responses were predicted after 10,000 wheel passes, as shown in Figure 6-2 and Figure 6-3. Figure 6-4 shows the effect of the number of elements in the mesh on required computation time.

Table 6-2 Effect of number of elements on predicted responses

\begin{tabular}{||c|c|c|c|c|c|c||}
\hline & \multicolumn{3}{|c|}{$\begin{array}{c}\text { Maximum length of } \\
\text { elements (cm) }\end{array}$} & $\begin{array}{c}\text { Number } \\
\text { of } \\
\text { elements }\end{array}$ & $\begin{array}{c}\text { Rutting } \\
(\mathrm{mm})\end{array}$ & $\begin{array}{c}\text { Stress on top } \\
\text { of subgrade } \\
(\mathrm{kPa})\end{array}$ \\
\hline Model & HMA & Base & Subgrade & & & \\
\hline 1 & 10 & 25 & 51 & 800 & 8.6 & 50 \\
\hline 2 & 10 & 20 & 25 & 1,184 & 7.6 & 38 \\
\hline 3 & 5 & 20 & 20 & 1,514 & 7.1 & 37 \\
\hline 4 & 5 & 10 & 20 & 6,260 & 6.9 & 36 \\
\hline 5 & 5 & 10 & 10 & 10,492 & 6.9 & 36 \\
\hline 6 & 2.5 & 10 & 10 & 40,740 & 6.9 & 36 \\
\hline \hline
\end{tabular}




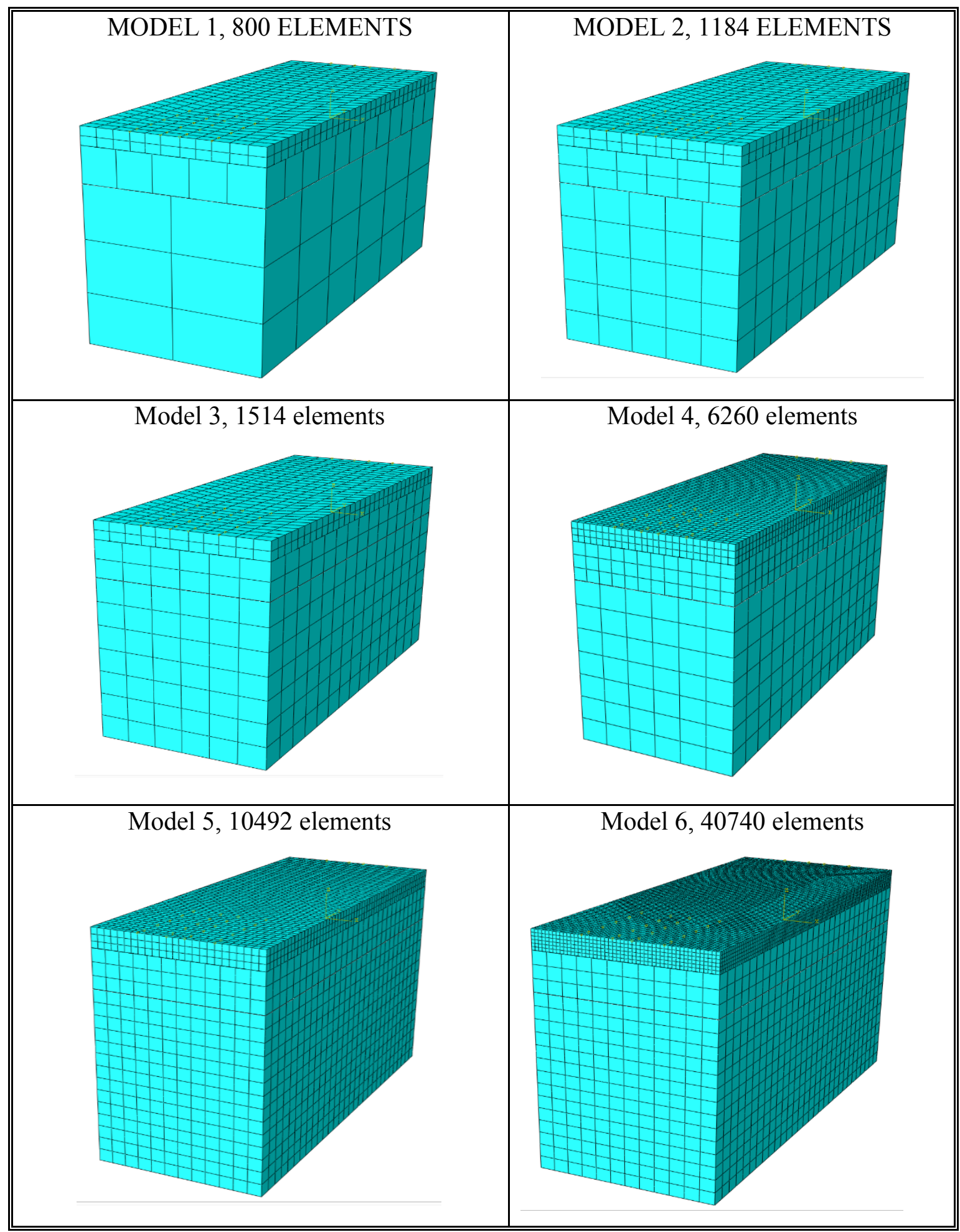

Figure 6-1 Sensitivity analysis for optimum mesh size 


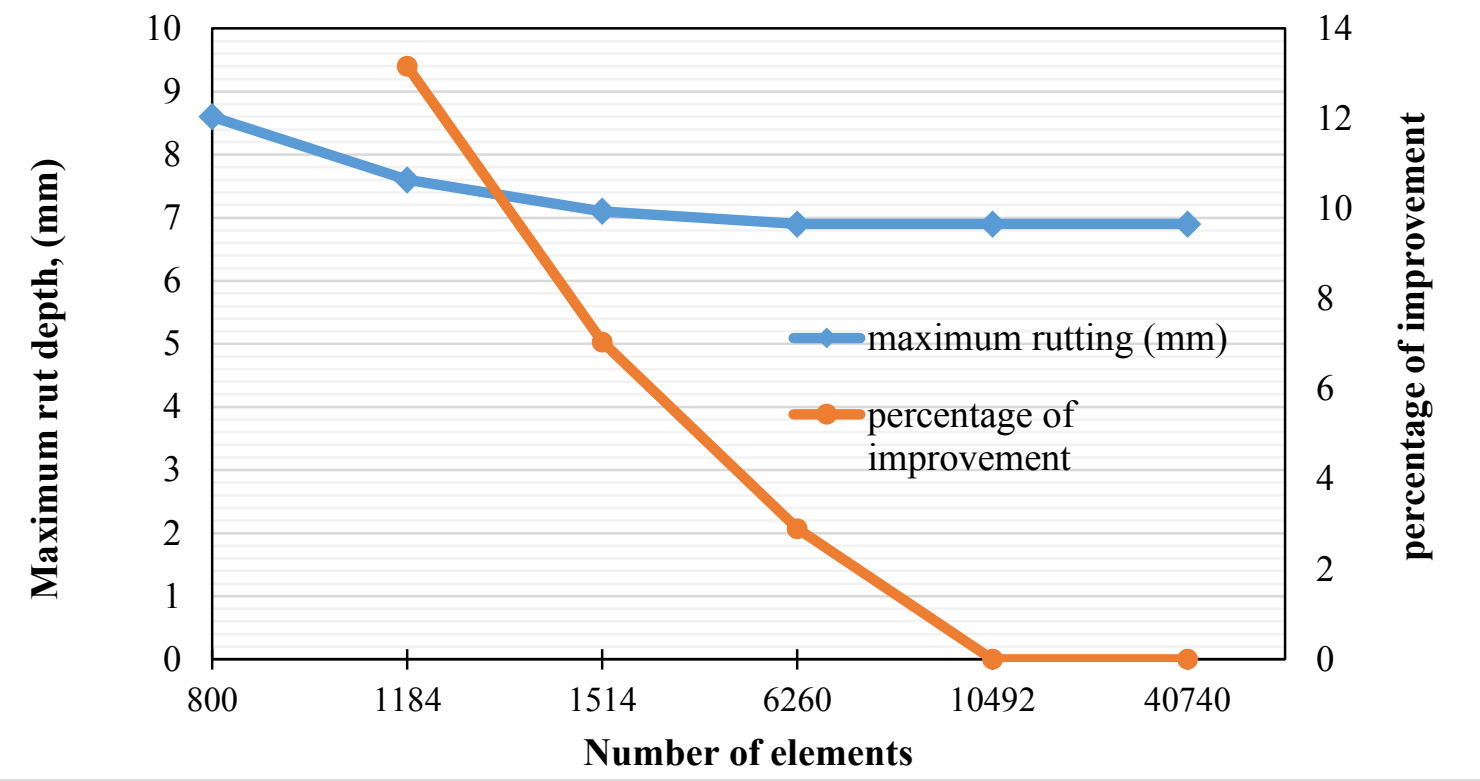

Figure 6-2 Effect of number of elements on predicted maximum rut depth after 10,000 wheel passes

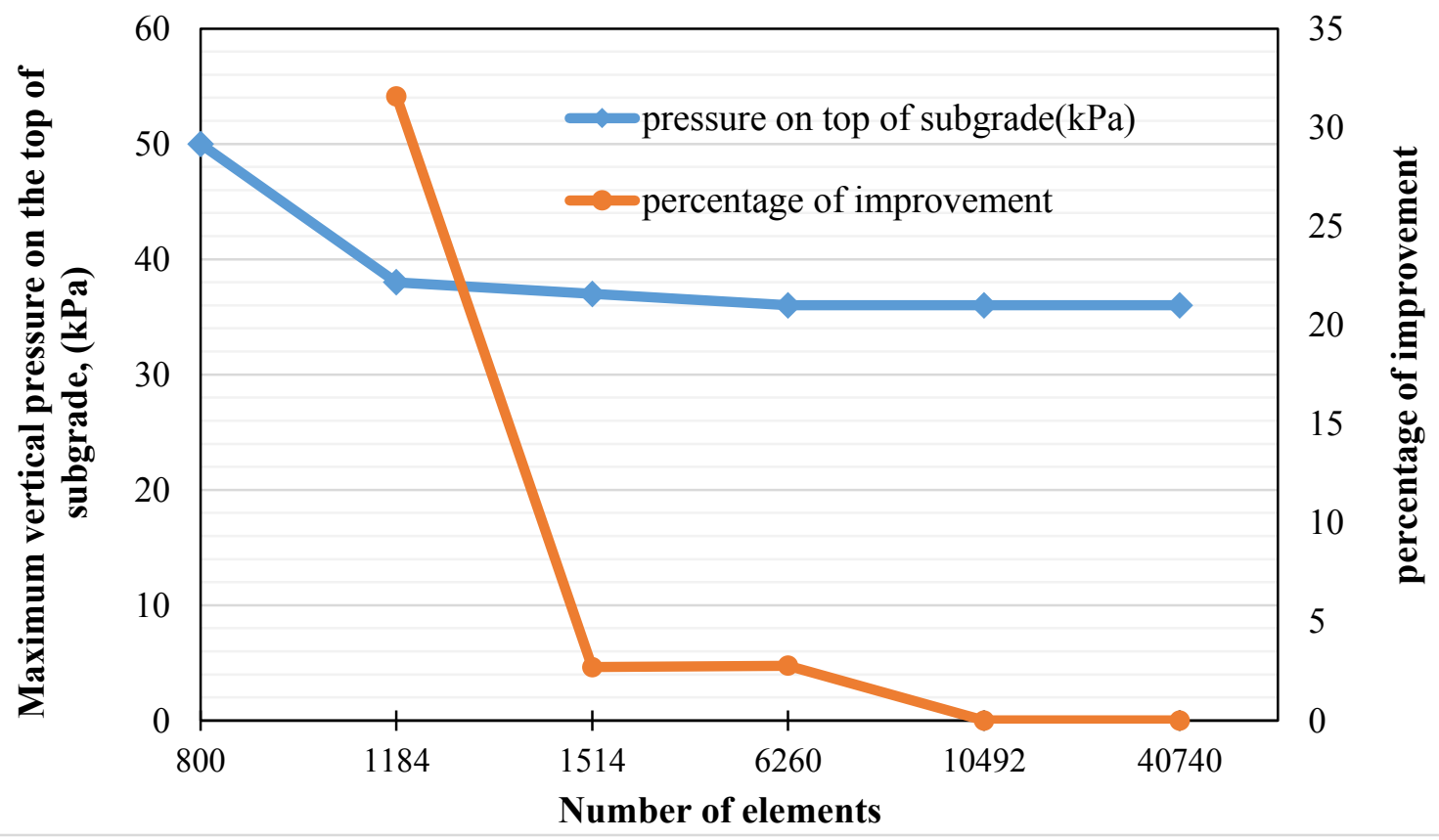

Figure 6-3 Effect of number of elements on predicted maximum pressure on top of subgrade after 10,000 wheel passes 


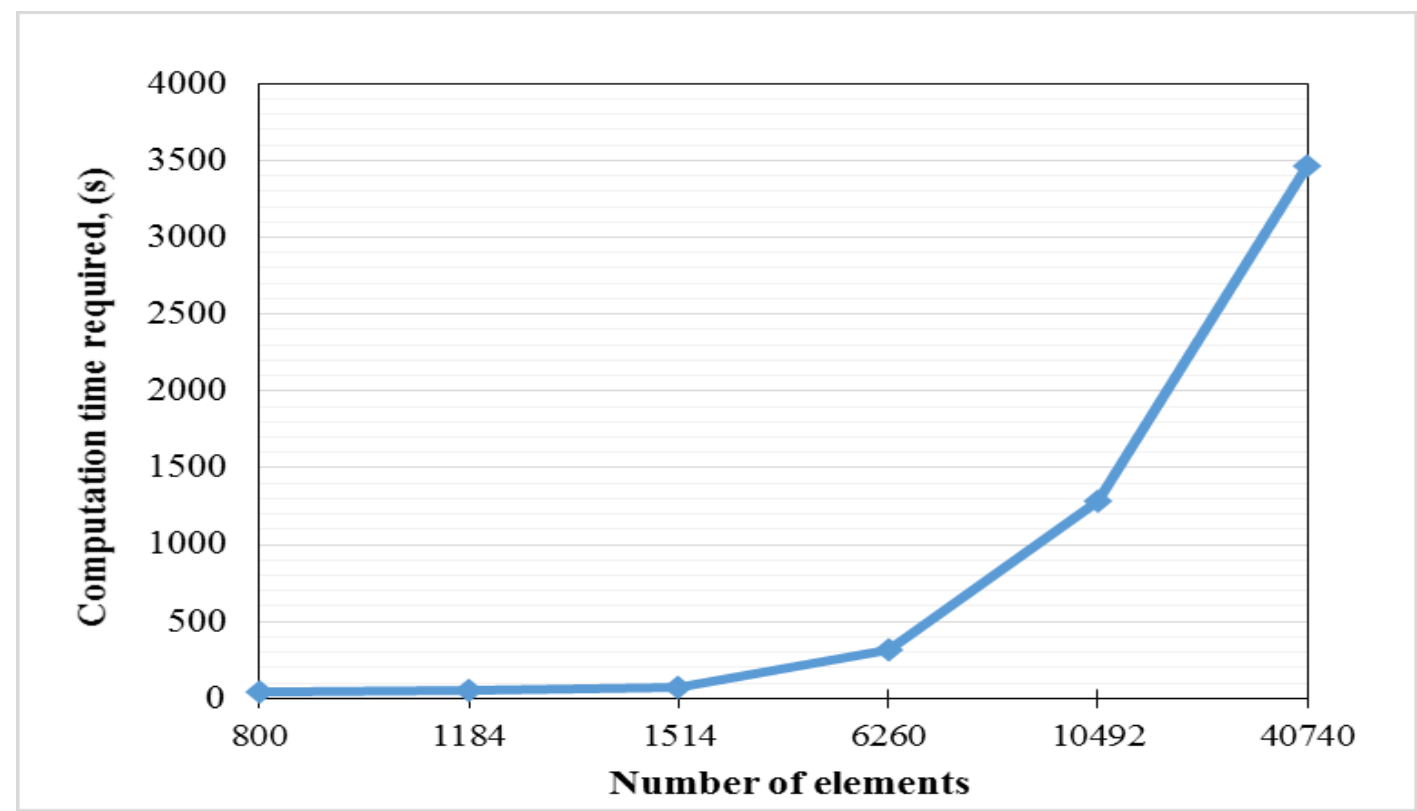

Figure 6-4 Effect of number of elements on computation time required for 10,000 wheel passes

Figure 6-2 and Figure 6-3 indicate that increasing the number of elements in the model from 1,514 to 6,260 changed the predicted maximum rut depth and vertical stress on the top of subgrade by $2.1 \%$ and $2.0 \%$, respectively, while computational time increased by $78 \%$. This shows that the number of elements in Model 5 is the optimum mesh size with desirable accuracy and reasonable computational time. Therefore, maximum element size of 5 (2 in.), 10 (4 in.), and 10 cm (4 in.) was selected for HMA, base and subgrade layer, respectively. Figure 6-5 shows the mesh pattern used for modeling. 


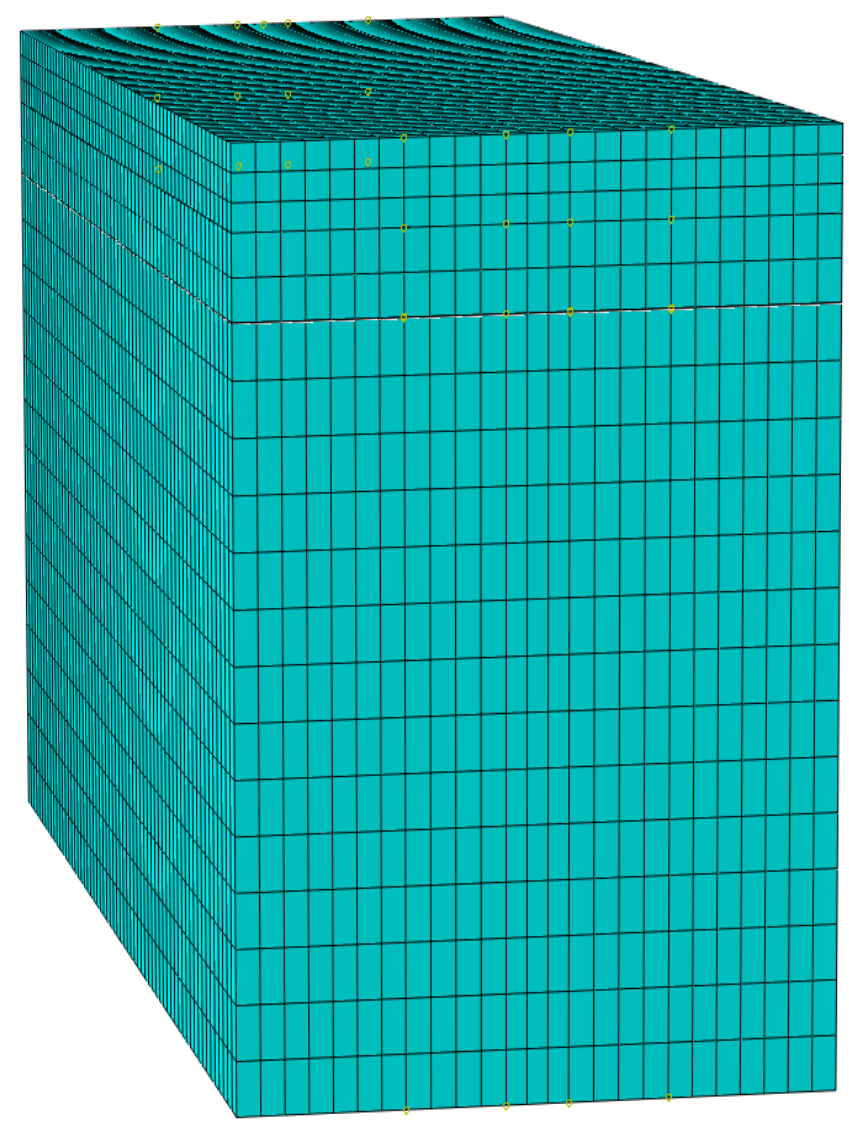

Figure 6-5 3-D FE mesh for test sections

\subsection{Material Properties}

An elastoplastic material model for the asphalt concrete layer is necessary to allow this layer to deform permanently. Permanent deformations in layers with only elastic properties are zero when the load was removed. Based on previous analysis, creep, Drucker Prager, and modified Drucker Prager material models were used for HMA, base, and subgrade layers, respectively.

\subsubsection{HMA Layer Properties}

Plastic behavior of the HMA layer was modeled using creep properties. The elastic modulus and Poisson's ratio were used to model elastic behavior of the HMA layer. Elastic layer moduli for each section were backcalculated from surface deflection data obtained in the FWD test. Poisson's ratios were estimated to be typical values because their effects on the backcalulation 
process were negligible. The creep model was defined by five material parameters which define time-dependent behavior of the HMA material: creep parameters, A, m, and $\mathrm{n}$. In order to obtain these parameters, flow test was conducted on samples compacted by the Superpave Gyratory compactor with loose asphalt samples from CISL test sections. The test was conducted following AMPT Flow Test Protocol developed in the NCHRP study (NCHRP-465, 2002).

\subsubsection{Creep / Flow Number Test}

This test was conducted to measure resistance of HMA material to tertiary deformation (asphalt flow). The test could be conducted in a uniaxial or triaxial state of compressive loading on a laboratory-prepared sample with diameter of $100 \mathrm{~mm}(4 \mathrm{in}$.) and height of $150 \mathrm{~mm}(6 \mathrm{in}$.) cored from Superpave gyratory-compacted plugs. The test applied repeated haversine loading with $0.1 \mathrm{~s}$ loading and $0.9 \mathrm{~s}$ unloading duration up to 10,000 cycles or until a specimen failed, whichever occurred first. Mixture response characteristics (elastic/plastic, viscoelastic/viscoplastic) were obtained from test results. Recommended test temperatures ranged from $25^{\circ} \mathrm{C}$ to $60^{\circ} \mathrm{C}\left(77^{\circ} \mathrm{F}\right.$ to $\left.141^{\circ} \mathrm{F}\right)$. Design stress levels ranged between 69 and $207 \mathrm{kPa}(10-30 \mathrm{psi})$ for unconfined tests and 483 to $966 \mathrm{kPa}$ (70-140 psi) for confined tests. Typical confinement levels ranged between 35 and $207 \mathrm{kPa}$ (5-30 psi) (NCHRP-465, 2002).

Primary and tertiary stages of creep have a nonlinear relationship between strain and time. In the secondary stage, the relationship between strain and time is linear, as shown in Figure 6-6. Model parameters used in the ABAQUS model were obtained using the linear portion of the relationship while plotted as $\log$ strain versus log time. 


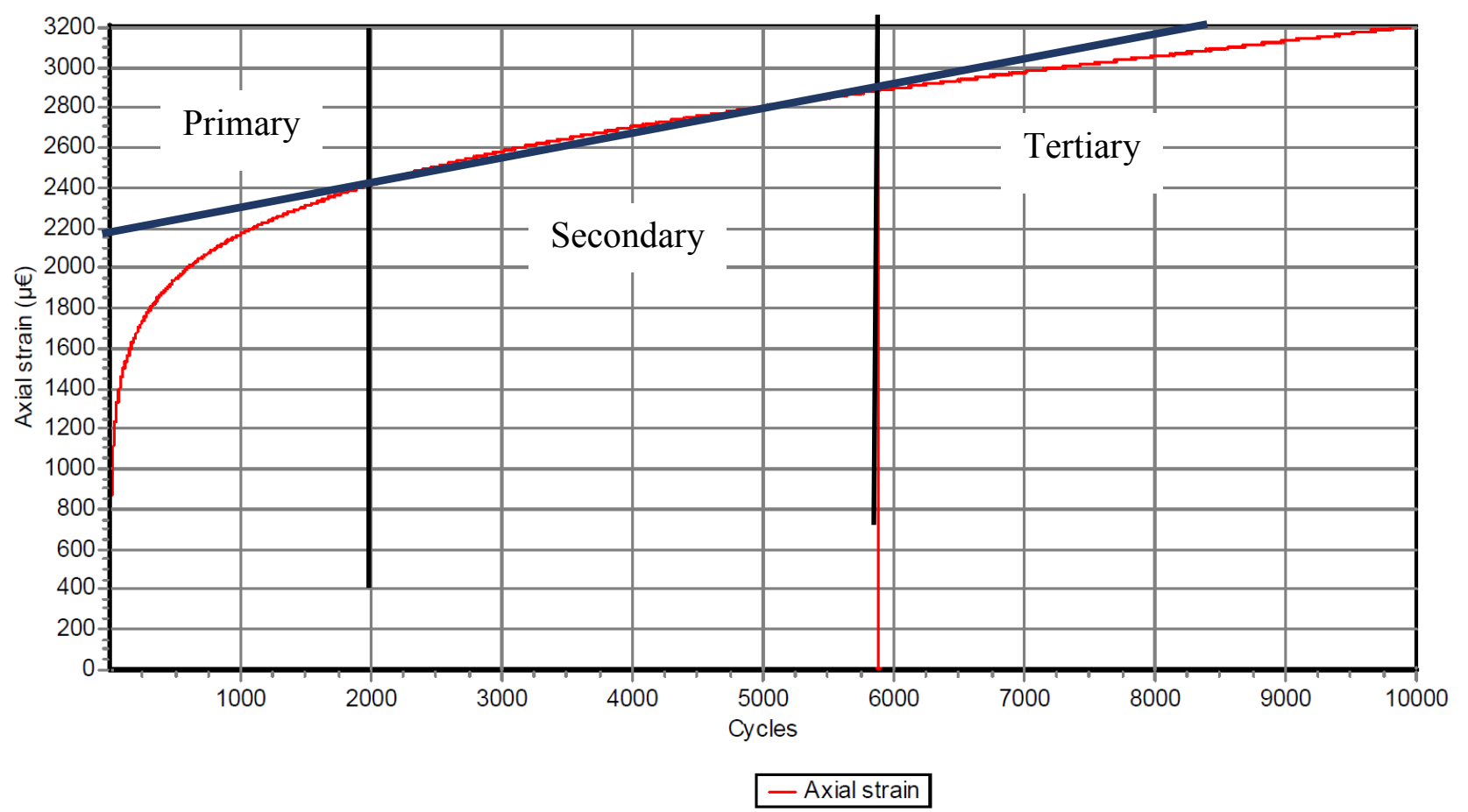

Figure 6-7 Creep test results

In this study, creep test was conducted on six samples (three samples from each experiment). Loose samples of asphalt mixture were sampled during paving of test sections at CISL. Cylindrical samples of $150 \mathrm{~mm}$ (6 in.) diameter and $150 \mathrm{~mm}$ (6 in.) height were compacted at $143-149^{\circ} \mathrm{C}\left(289-300^{\circ} \mathrm{F}\right)$ using a Superpave gyratory compactor. Cores with $100 \mathrm{~mm}(4 \mathrm{in}$.) diameter and $150 \mathrm{~mm}$ (6 in.) height were then taken from the compacted samples. Figure 6-8 shows creep test setup with an AMPT machine. All samples were tested at room temperature and at a deviatoric stress of $207 \mathrm{kPa}$ (30 psi). Tests were stopped after 10,000 cycles or a maximum plastic strain of 5,000 microstrain, whichever occurred first. 


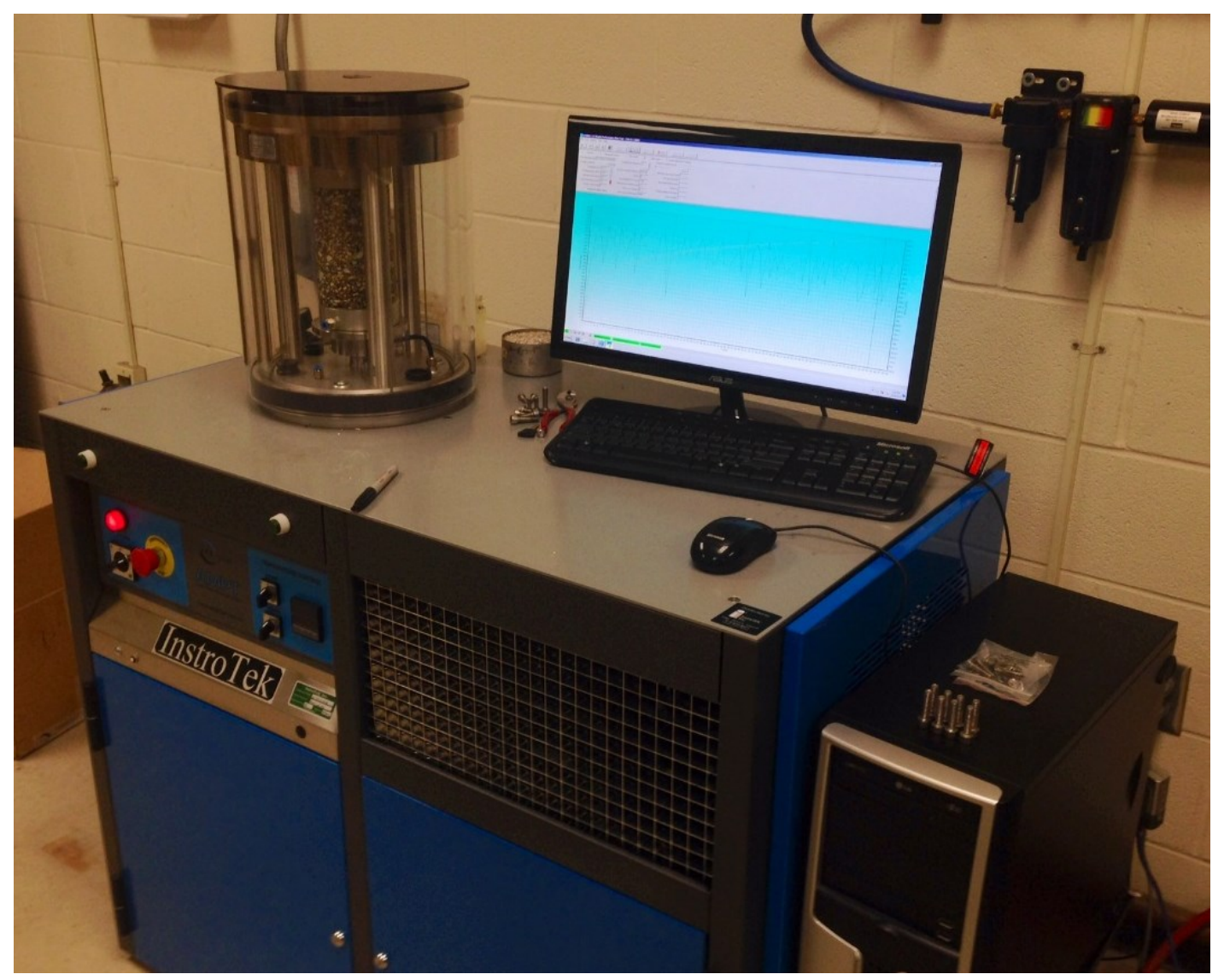

Figure 6-9 Creep test on HMA samples

Figure 6-10 shows typical outputs of axial strain versus loading cycle from the creep test, and Table 6-3 shows the creep parameters derived from creep test results. The $m$ value was set to -0.8 , but the $n$ value varied from 0.8489 to 1.1521 and the A value ranged from $3 \mathrm{E}-8$ to $4.1 \mathrm{E}-8$ with an average of $3.5 \mathrm{E}-8$. 

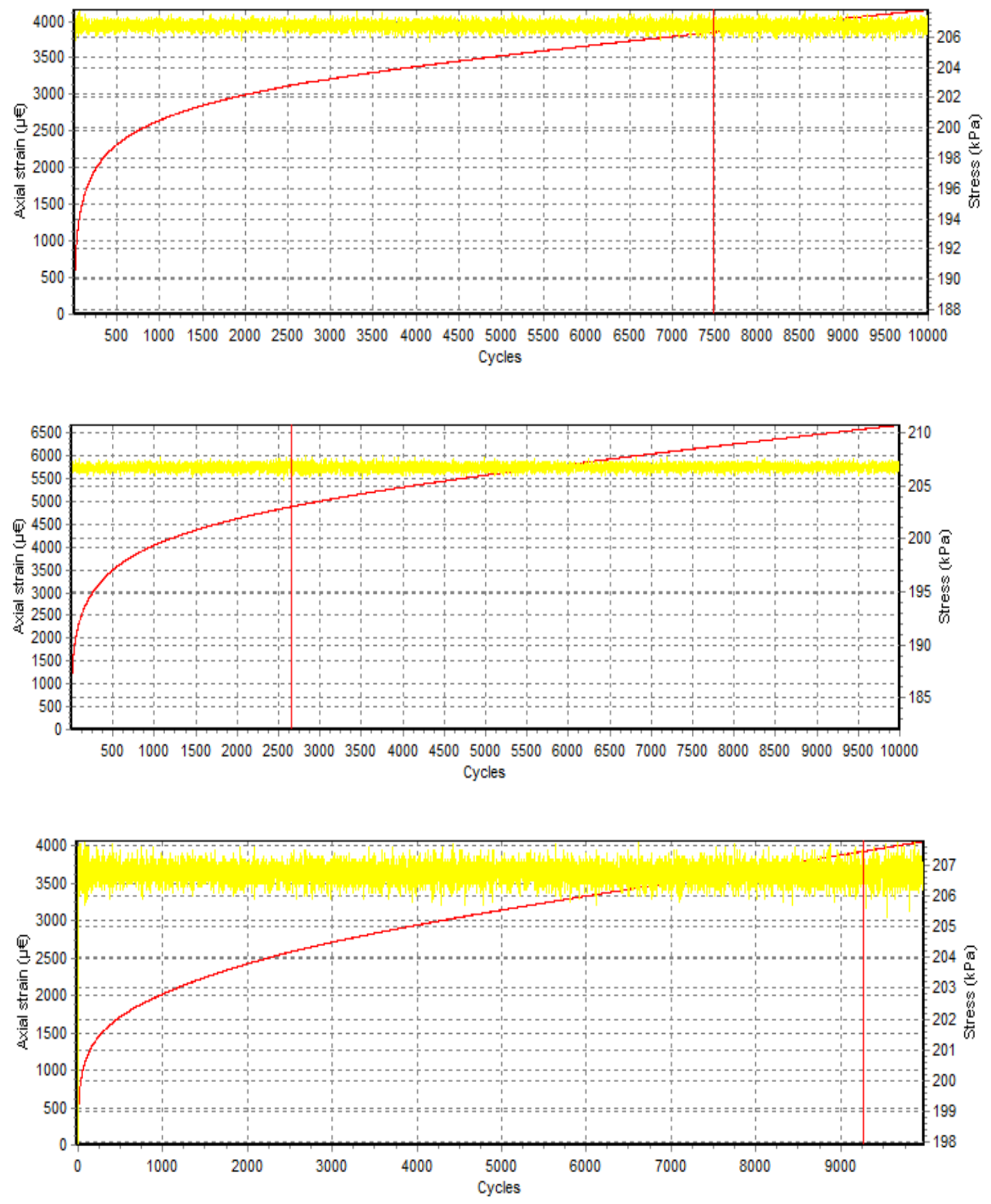


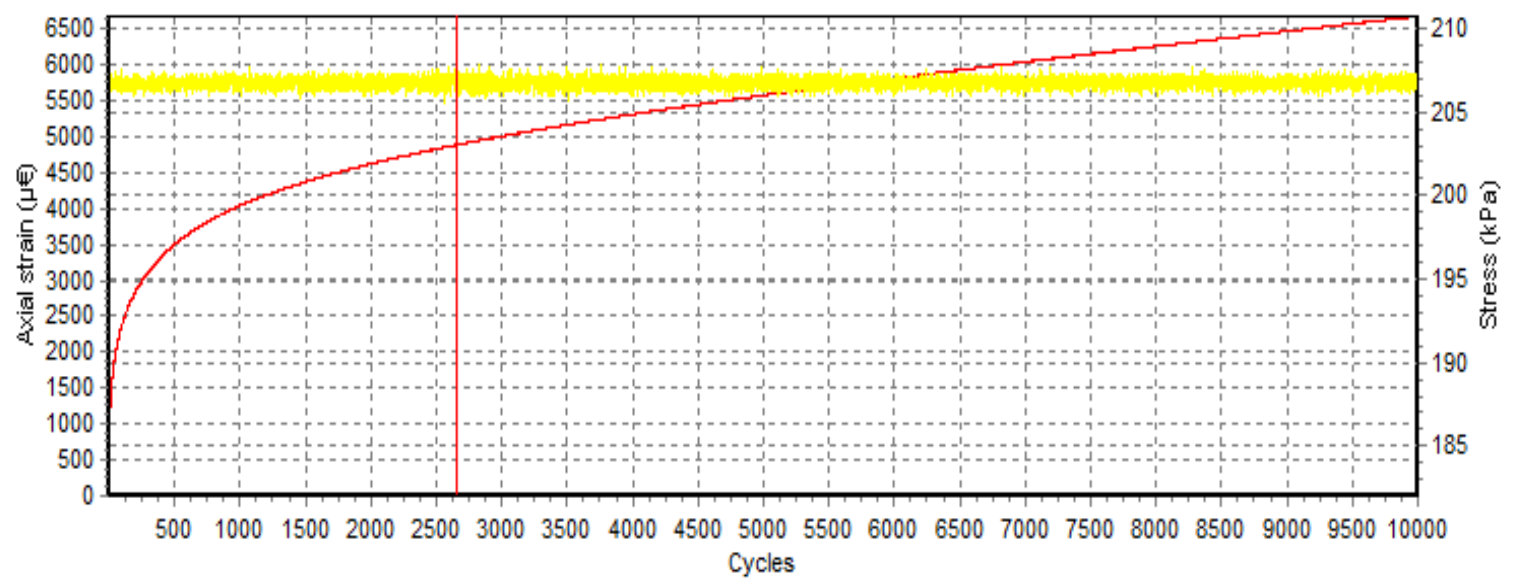

Figure 6-11 Creep test results 
Table 6-3 Creep parameters derived from creep test

\begin{tabular}{||c|c|c|c|c||}
\hline \multirow{3}{*}{ First Experiment } & $\begin{array}{c}\text { SAMPLE } \\
\text { NO. }\end{array}$ & $\mathbf{A}$ & $\mathbf{M}$ & $\mathbf{N}$ \\
\cline { 2 - 5 } & 1 & $3.1 \mathrm{E}-08$ & -0.8 & 0.8489 \\
\cline { 2 - 5 } & 2 & $3.0 \mathrm{E}-08$ & -0.8 & 0.9654 \\
\cline { 2 - 5 } Second Experiment & 3 & $3.7 \mathrm{E}-08$ & -0.8 & 0.9175 \\
& 1 & $4.1 \mathrm{E}-08$ & -0.8 & 1.1521 \\
\cline { 2 - 6 } & 2 & $3.9 \mathrm{E}-08$ & -0.8 & 1.1012 \\
\cline { 2 - 6 } & 3 & $3.7 \mathrm{E}-08$ & -0.8 & 1.0503 \\
\hline \multirow{3}{*}{ Average } & & $3.5 \mathrm{E}-8$ & -0.8 & 1.01 \\
\hline
\end{tabular}

\subsubsection{Base and Subgrade Layer Properties}

As mentioned, the DP model was selected to model plastic behavior of soil and granular materials. Elastic behavior of the base and subgrade materials was modeled by the elastic modulus and Poisson's ratio. Poisson's ratio of 0.35 was chosen for the base and subgrade layer. Elastic moduli were obtained by backcalculation.

Input parameters for the DP model, measured from the triaxial test, were angle of friction, flow stress ratio, and dilation angle. When creep behavior is defined, ABAQUS sets this value to 1.0. The angle of dilation $(\psi)$ controls the amount of plastic volumetric strain developed during plastic shearing and is assumed constant during plastic yielding. The angle of dilation for a cohesive material such as clay is close to zero. For sand and gravel with an angle of internal friction $\varphi>30^{\circ}$, the value of dilation angle can be estimated from Equation 6-1 
A negative value of dilation angle is acceptable only for loose sands; otherwise, negative value is considered zero. Results of laboratory tests conducted by Han et al. (2011) on identical materials as test sections at CISL were used as DP inputs.

In this study, creep behavior was added to the DP model to simulate creep behavior of subgrade. A creep test was conducted based on the method developed by Lai et al (2009). Three samples with density and moisture content similar to CISL test sections were prepared. Each sample had a diameter of $71 \mathrm{~mm}$ (2.78 in.) and height of $141 \mathrm{~mm}$ (5.56 in.). Constant compressive stress of $45 \mathrm{kPa}$ (6.5 psi) was applied on the samples, as shown in Figure 6-9. Compressive stress was set to $45 \mathrm{kPa}(6.5 \mathrm{psi})$ to be close to the pressure cell reading in the APT test. Regression was then conducted on the plastic strain rate to extract A, m, and $n$ values shown in Table 6-4.

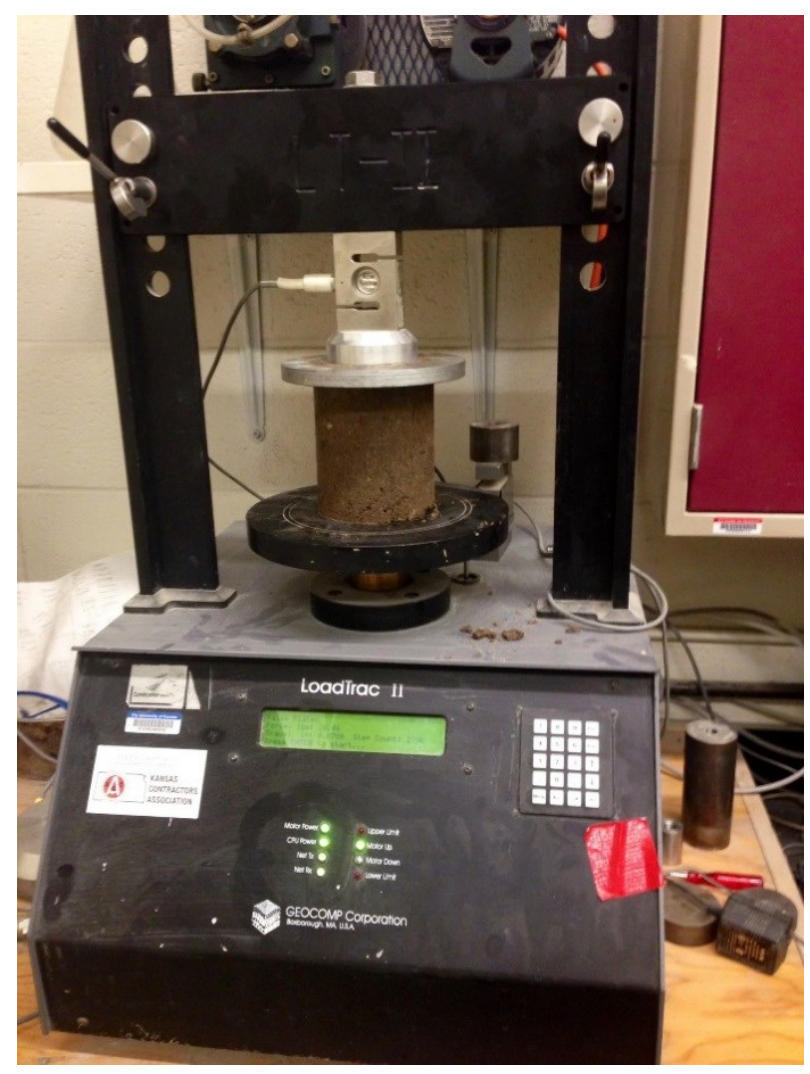

Figure 6-12 Creep test on subgrade sample 
Table 6-4 Creep test results

\subsection{Boundary Condition and Loading}

Because of the symmetrical condition, a quarter of the actual CISL test section was modeled to reduce computational time. Figure 6.10 shows boundary conditions and a moving wheel load. Boundary conditions were:

Front: symmetry $(\mathrm{U} 2=\mathrm{UR} 1=\mathrm{UR} 3=0)$

Right: symmetry $(\mathrm{U} 1=\mathrm{UR} 2=\mathrm{UR} 3=0)$

\begin{tabular}{||l|l|l|l||}
\hline & A & M & N \\
\hline Sample 1 & $4.22 \mathrm{E}-05$ & -0.58 & 0.82 \\
\hline Sample 2 & $5.40 \mathrm{E}-05$ & -0.58 & 0.57 \\
\hline Sample 3 & $6.16 \mathrm{E}-05$ & -0.58 & 0.51 \\
\hline Average & $5.26 \mathrm{E}-05$ & -0.58 & 0.63 \\
\hline \hline
\end{tabular}

Left: displacement $(\mathrm{U} 1=0)$

Back: displacement $(\mathrm{U} 2=0)$

Bottom: encastre

$(\mathrm{U} 1=\mathrm{U} 2=\mathrm{U} 3=\mathrm{UR} 1=\mathrm{UR} 2=\mathrm{UR} 3=0)$ 


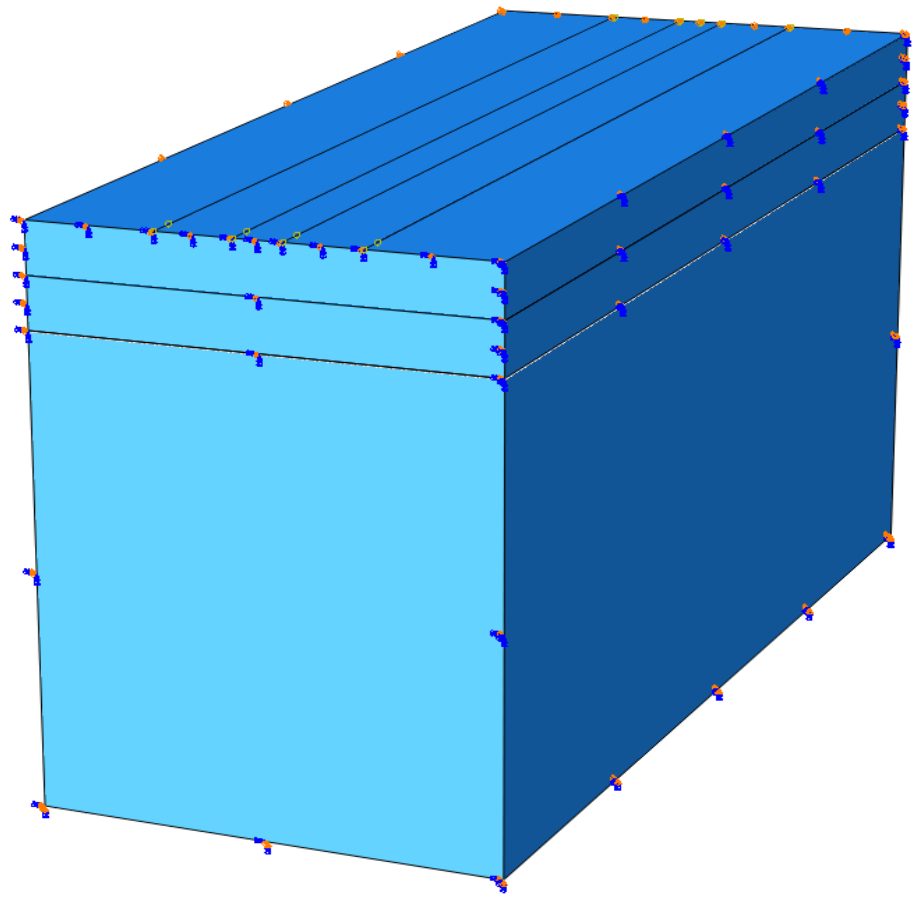

Figure 6-13 Boundary conditions

\subsection{Interaction}

Contact surfaces were defined in the interaction module. Two types of contacts were used for this model: tied (for perfectly bonded areas) and contact. Contact was used only when model convergence became an issue. In this study, three sets of interaction were defined:

1. HMA bottom/ Base Top (consider using Tie constraint)

2. Base Bottom/ Geosynthetic top (consider using Contact constraint)

3. Geosynthetic bottom/Subgrade top (consider using Contact constraint)

To simplify the model, interaction between the HMA bottom and base top was defined as Tie constraint. The assumption was made that no movement exists between these interfaces. To simulate friction between the geosynthetic material and the base or subgrade material, contact was used. 


\subsection{Loading}

State-of-the-art computer systems allow researchers to simulate complicated structures. Even with advanced computers, however, 3-D simulation of long-term performance of pavement subjected to hundreds of thousands of wheel loading cycles is impossible. Therefore, simplification should be done to model applied loading conditions.

Simplified assumption regarding loading can be considered in two parameters: loading duration and loading area. For loading duration, equivalent, pulse, and moving loading are the most common methods. Equivalent loading disregards the unloading period and applies load for the accumulative loading time. Pulse loading assumes that load is applied on a specific area (typically at the center of the top layer) for a specific loading time and then the load is removed to model unloading time. Moving load is closer to the real loading condition during CISL experiments. In this mode, load is applied on a set of elements at the beginning of a wheel path for a specific time. Then load is removed from the previous element set and reapplied on the next set of elements. This trend continues until it reaches the end of the section. Schematic diagrams of these loading modes are shown in Figure 6-11. For loading area, wheel load can be applied on the wheel area, entire wheel path, or equivalent circular/semicircular area. Seven loading modes can be considered by combining all loading time and loading area modes in 3-D modeling: pulse loading on one wheel, equivalent loading on one wheel, pulse loading on entire wheel path, equivalent loading on entire wheel path, pulse loading on circular/semicircular loading area, equivalent loading on circular/semicircular loading area, and moving load on one wheel.

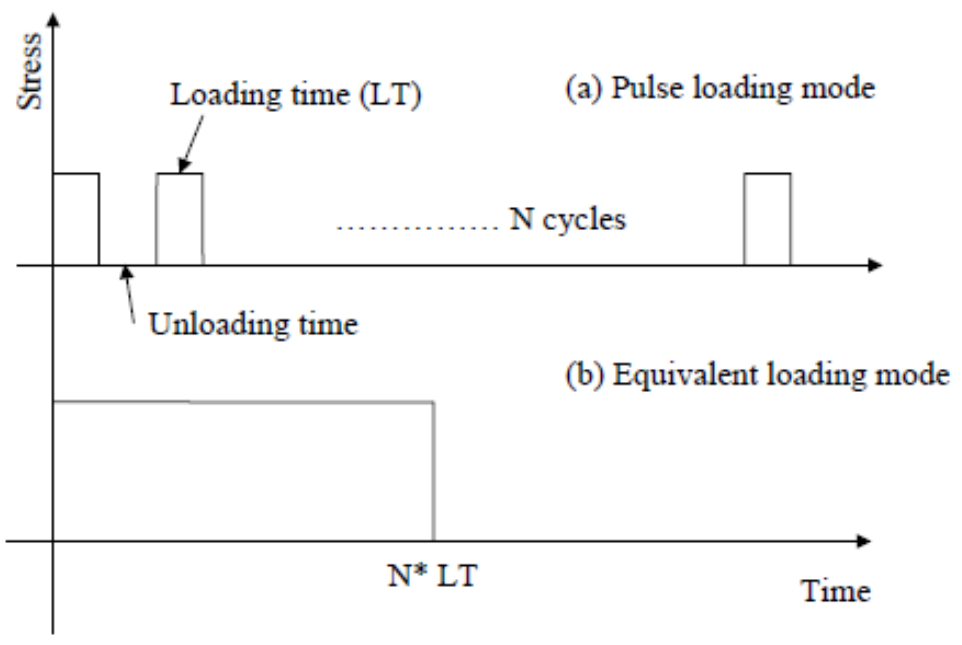

Figure 6-14 Schematic diagram of moving load 
In this study, sensitivity analysis was conducted on three loading modes: pulse loading on entire wheel path, equivalent loading on entire wheel path, and moving loading on one wheel. Figure 6-12 shows loading modes used in the sensitivity analysis.

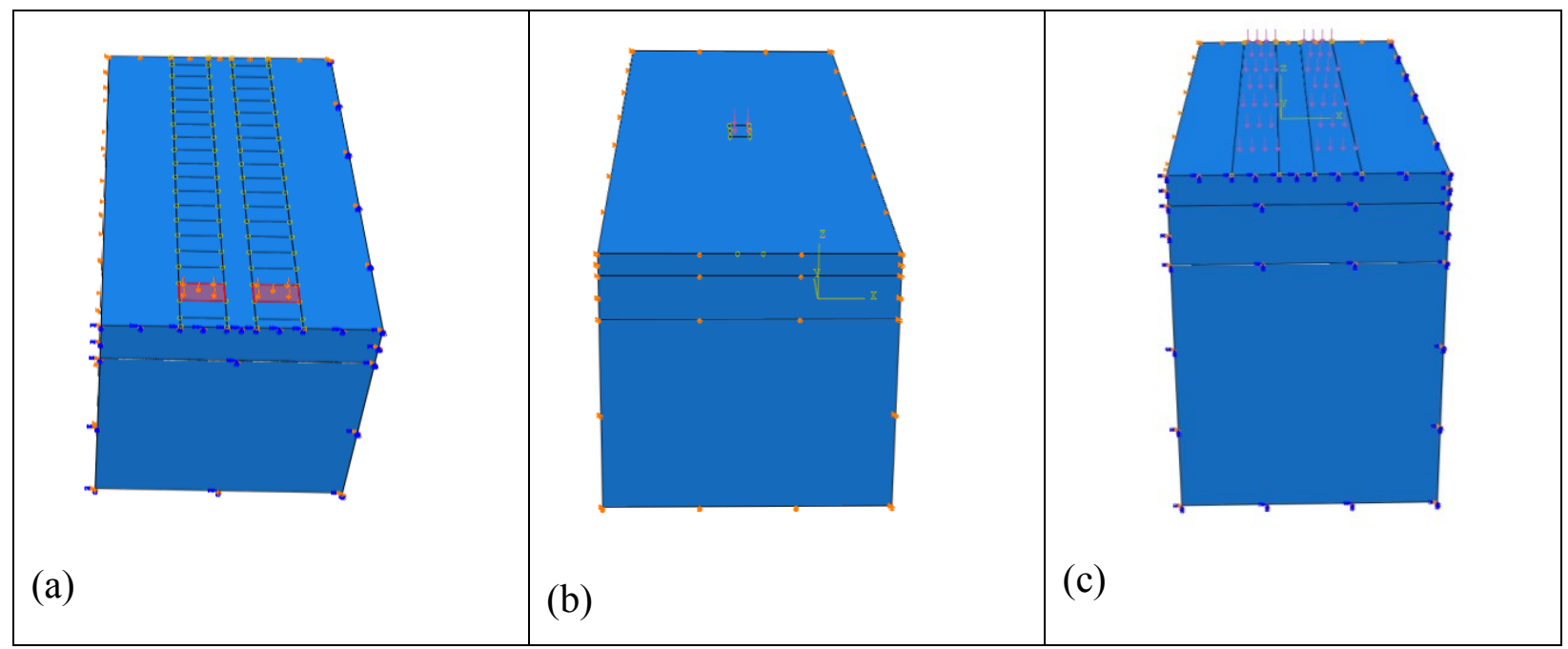

Figure 6-15 Loading modes

In the full-scale test at CISL, $80 \mathrm{kN}(18,000 \mathrm{lb})$ of axle load were applied on dual tires, as shown in Figure 6-16. Tire pressure was $620 \mathrm{kPa}(90 \mathrm{psi})$ and speed of the APT machine was $11 \mathrm{~km} / \mathrm{hr}$ (7 mph) in this study.

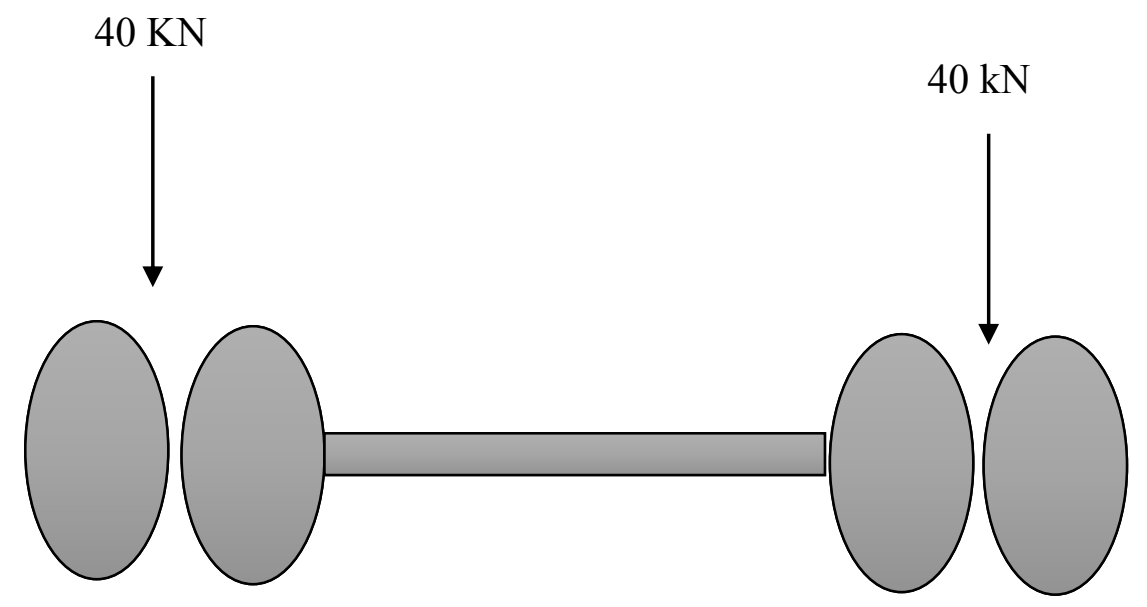

Figure 6-16 APT loading configuration 


\subsection{Sensitivity Analysis on Loading Mode and Material Model}

To determine the most accurate model for material modeling and loading mode, 10 combinations of three loading modes were considered, as shown in Table 6-5: equivalent loading on entire wheel path, equivalent loading on entire wheel path, and moving load on one wheel. A comparison was conducted for the material model. In the elastic model, layer behavior was simulated using elastic modulus, Poisson's ratio, and unit weight. The HMA layer was modeled as elastic, and elastoplastic and plastic behavior of the HMA layer was modeled using the creep model. Plasticity of the base and subgrade layers was modeled using DP, modified DP, and MC models. Modified DP model is similar to the DP model, but it considers the creep behavior of soil. Table 6-6 shows material properties used in the sensitivity analysis.

A rectangular-shaped tire imprint was used in the first three models. Tire pressure of 620 $\mathrm{kPa}(90 \mathrm{psi})$ applied on dual tires and tire width of $21 \mathrm{~cm}(8.2 \mathrm{in})$ was used to obtain a tire imprint with a length of $17 \mathrm{~cm}$ (6.7 in). Loading speed similar to the APT machine during accelerated pavement testing at CISL was used to calculate loading time. The APT machine speed of $11 \mathrm{~km} / \mathrm{hr}$ $(7 \mathrm{mph})$ translated to loading time of $0.05 \mathrm{~s}$ of tire imprint for one pass. To simulate a higher number of repetitions, loading times were multiplied to achieve the number of load repetitions. For example, in order to simulate 1,000 passes of wheel path, load applied on the tire imprint was for 50 seconds.

In Models $4-6$, load was applied on the $21 \mathrm{~cm}$ (8.2 in) width of each tire and the entire length of the section. In the quarter model, length of wheel path was $3.05 \mathrm{~m}$ (120 in.) based on axle speed and length of the loading area in order to simulate one pass of APT load at CISL. Consequently, load was applied on the entire wheel path for $0.05 \mathrm{~s}$.

Moving load was applied to Models 7 through 10. In these models, wheel path length was divided into 20 parts. In the first step, load was applied on the first part for the equivalent loading time. In the next step, load was removed from the previous part and applied to the next part. This continued until the load reached the end of the wheel path. To simulate higher number of traffic load, loading time in each step was multiplied to obtain the desired number of load repetitions. 
Table 6-6 Material properties used in sensitivity analysis

\begin{tabular}{|c|c|c|c|}
\hline & Parameter & Unit & Value \\
\hline \multirow{4}{*}{ HMA } & elastic modulus & $\mathrm{MPa}$ & 2068 \\
\cline { 2 - 4 } & Poisson ratio & - & 0.35 \\
\cline { 2 - 4 } & creep parameter A & & $1 \mathrm{E}-09$ \\
\cline { 2 - 4 } & $\mathrm{n}$ & & 0.9106 \\
\cline { 2 - 4 } & $\mathrm{m}$ & $\mathrm{MPa}$ & -0.807 \\
\hline \multirow{5}{*}{ Base } & elastic modulus & - & 186 \\
\cline { 2 - 4 } & Poisson ratio & $\mathrm{kPa}$ & 0.35 \\
\cline { 2 - 4 } & cohesion & Degree & 4.7 \\
\cline { 2 - 4 } & friction angle & & 47.2 \\
\cline { 2 - 4 } & angle of dilation & $\mathrm{MPa}$ & 17.2 \\
\hline Subgrade & elastic modulus & - & 39 \\
\cline { 2 - 4 } & Poisson ratio & $\mathrm{kPa}$ & 0.35 \\
\cline { 2 - 4 } & cohesion & degree & 104 \\
\cline { 2 - 4 } & friction angle & & 0 \\
\cline { 2 - 4 } & angle of dilation & & $0.26 \mathrm{E}-05$ \\
\cline { 2 - 4 } & creep parameter $\mathrm{A}$ & & 0.6 \\
\cline { 2 - 4 } & $\mathrm{n}$ & & -0.5814 \\
\cline { 2 - 4 } & m & & \\
\cline { 2 - 4 } & & & \\
\hline
\end{tabular}

Figure 6-4 shows that permanent deformation in models with only elastic parameters of the HMA layer (Models 1, 4, and 7) was very low. Predicted rut depths from Model 6 are closer to measured values from the APT test. In this model, behavior of HMA and subgrade was modeled using creep model and modified DP model, respectively. All models underpredict permanent deformation. However, compared to other models, higher permanent surface deformation in Model 6 was obtained because load was applied on the entire wheel path for a longer period of time. 
Table 66-7 Models developed for sensitivity analysis

\begin{tabular}{|c|c|c|c|c|}
\hline Model & Loading Mode & HMA layer & Base layer & Subgrade \\
\hline 1 & & Creep & Elastic & Elastic \\
\hline 2 & & Elastic & DP & DP \\
\hline 3 & & Creep & DP & Modified DP \\
\hline 4 & & Creep & Elastic & Elastic \\
\hline 5 & & Elastic & DP & DP \\
\hline 6 & & Creep & DP & Modified DP \\
\hline 7 & & Creep & Elastic & Elastic \\
\hline 8 & & Elastic & DP & DP \\
\hline 9 & & Creep & DP & Modified DP \\
\hline 10 & & Creep & $\mathrm{MC}$ & $\mathrm{MC}$ \\
\hline
\end{tabular}




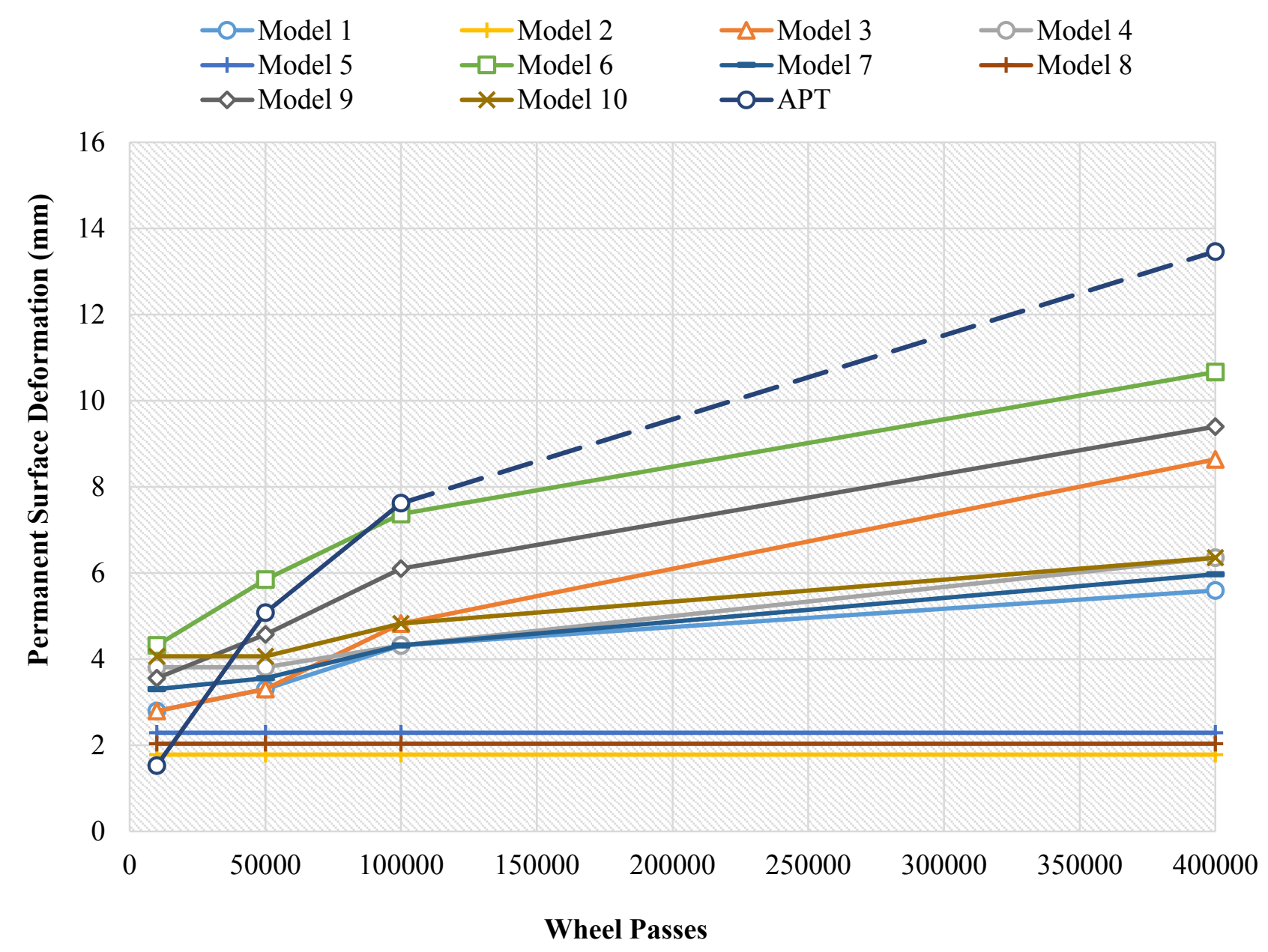

Figure 6-14 Effects of loading mode and material property model on rutting 


\section{Chapter 7 - Finite Element Model Analysis Results}

\subsection{Comparison of the FE Model Results with Full-scale Test Results}

To verify FE model analysis results, a comparison was made between responses measured from the full-scale test described in Chapter 4 and ABAQUS model results. Six FE models were developed with similar material properties and layer thicknesses to model the test sections. Predicted permanent deformation and stress and strain responses from FE models were then compared to full-scale test measurements.

\subsubsection{Permanent Deformation}

Figure 7-1 and Figure 7-2 illustrate permanent surface deformations versus load cycle applied to each test section. The FE model underpredicted permanent deformation of the test sections, but it is capable of showing long-term performance of the test sections. The trends are similar to what were observed in the APT. In the first experiment, thinner section (Section D) showed higher deformation and Section B with152 mm (6 in.) HMA layer experienced lower deformation. In the second experiment, predicted permanent deformation on the reinforced sections (Section H and F) was less than that on the unreinforced section (Section E) with similar layer thickness. 
$\rightarrow-$ Section A $\quad-\circ-$ Section B $\quad-0-$ Section C $\quad-0-$ Section D

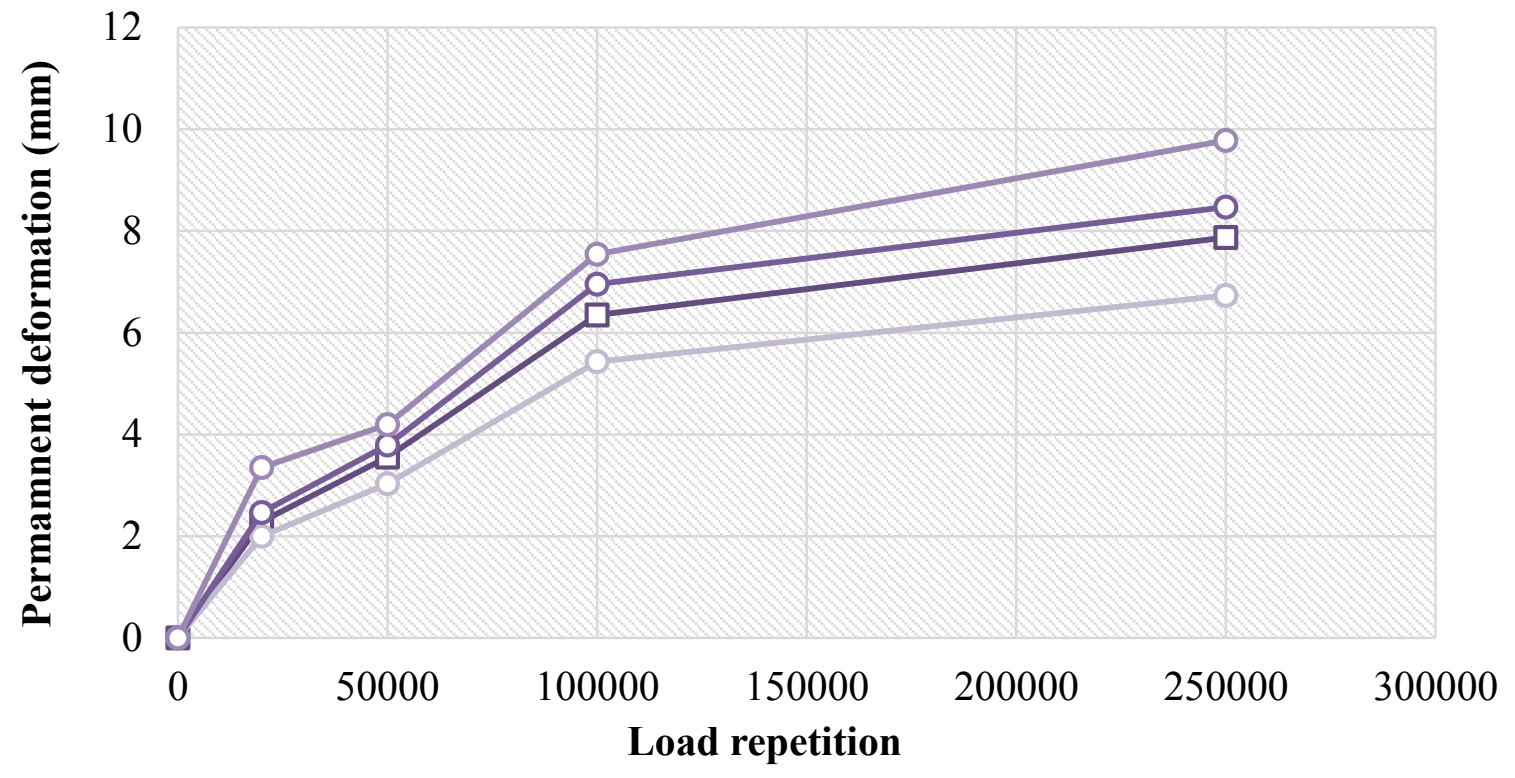

Figure 7-2 Permanent surface deformation versus load cycle applied first experiment

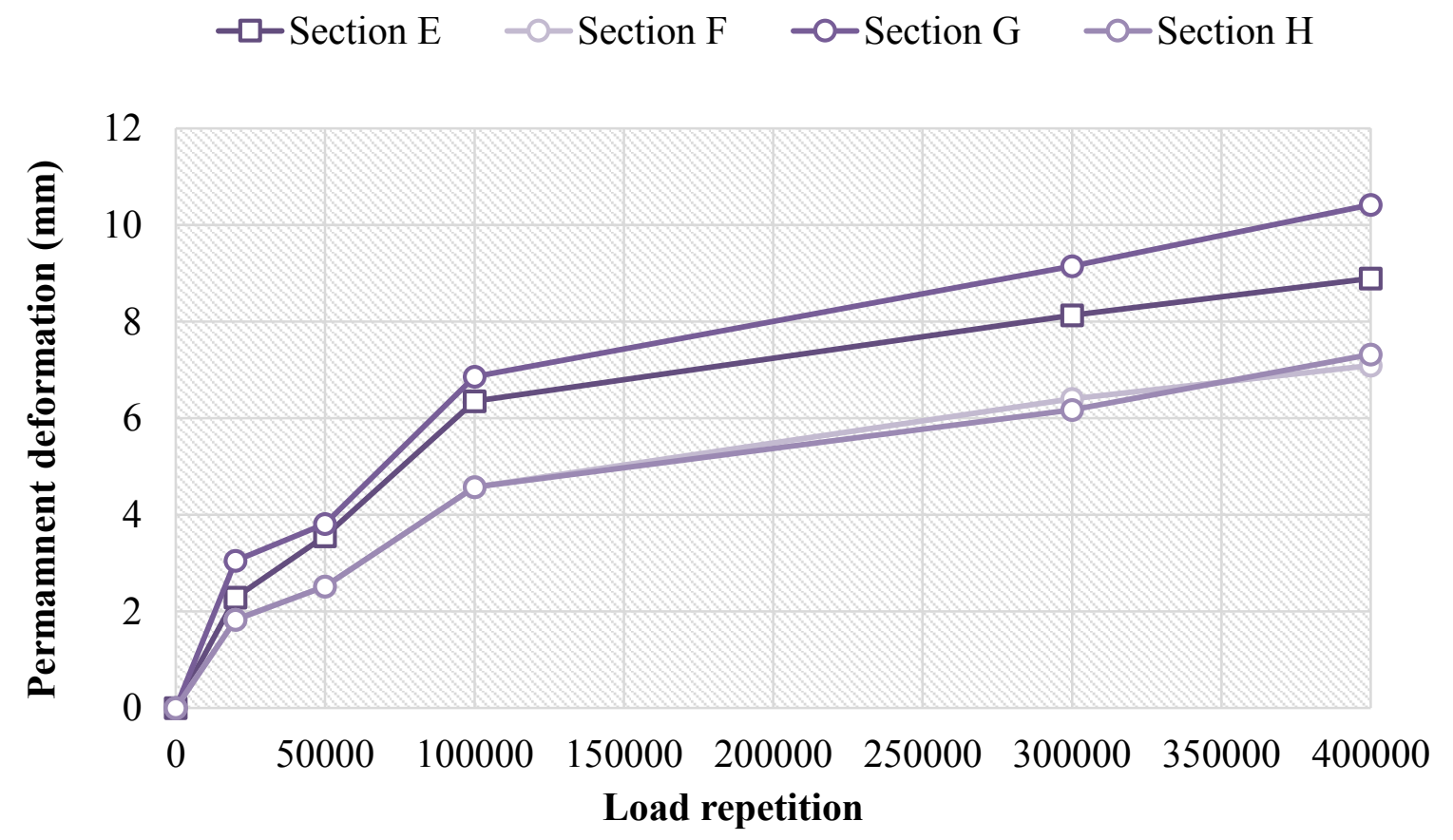

Figure 7-3 Permanent surface deformation versus load cycle applied second experiment 


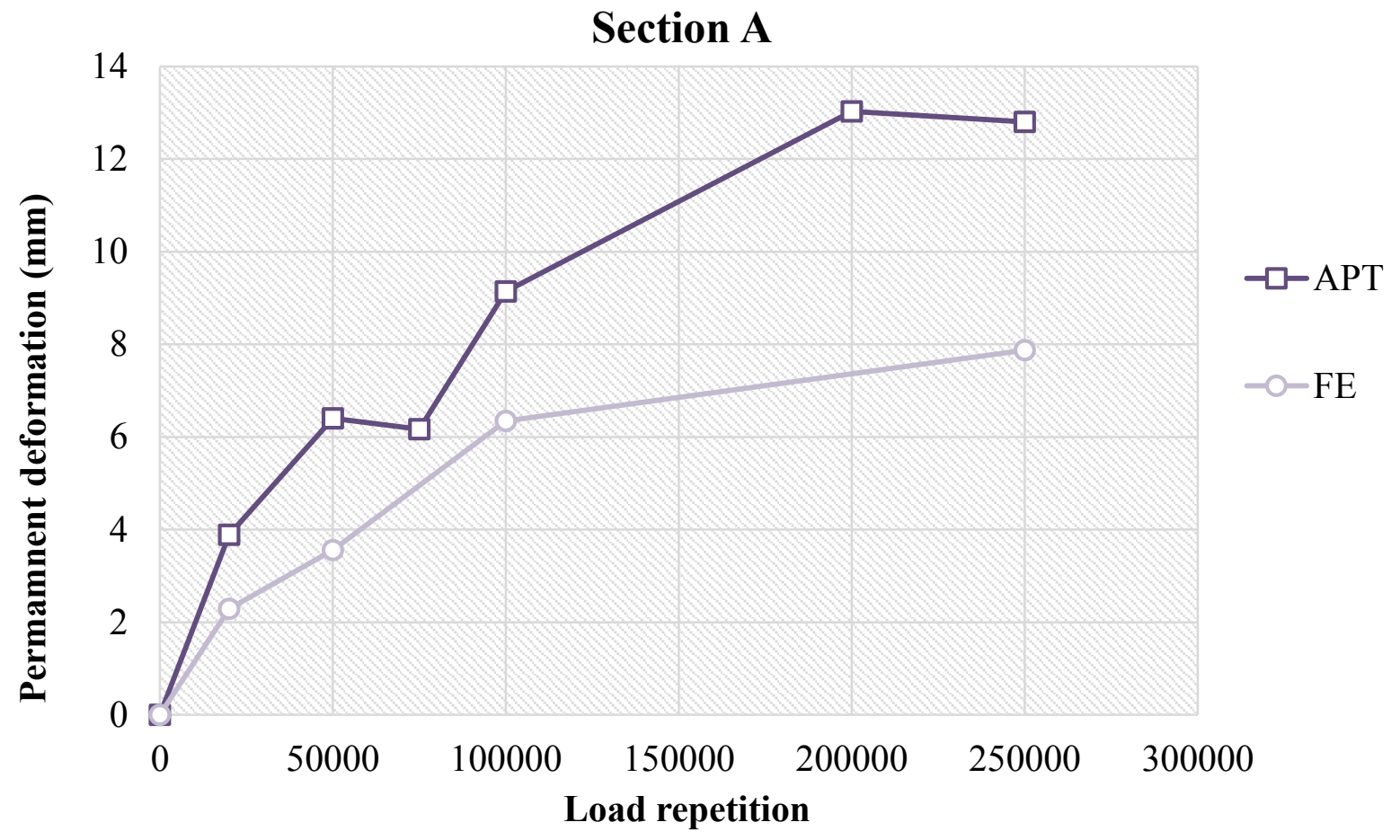

Figure 7-4 Permanent surface deformation versus load cycle applied Section A

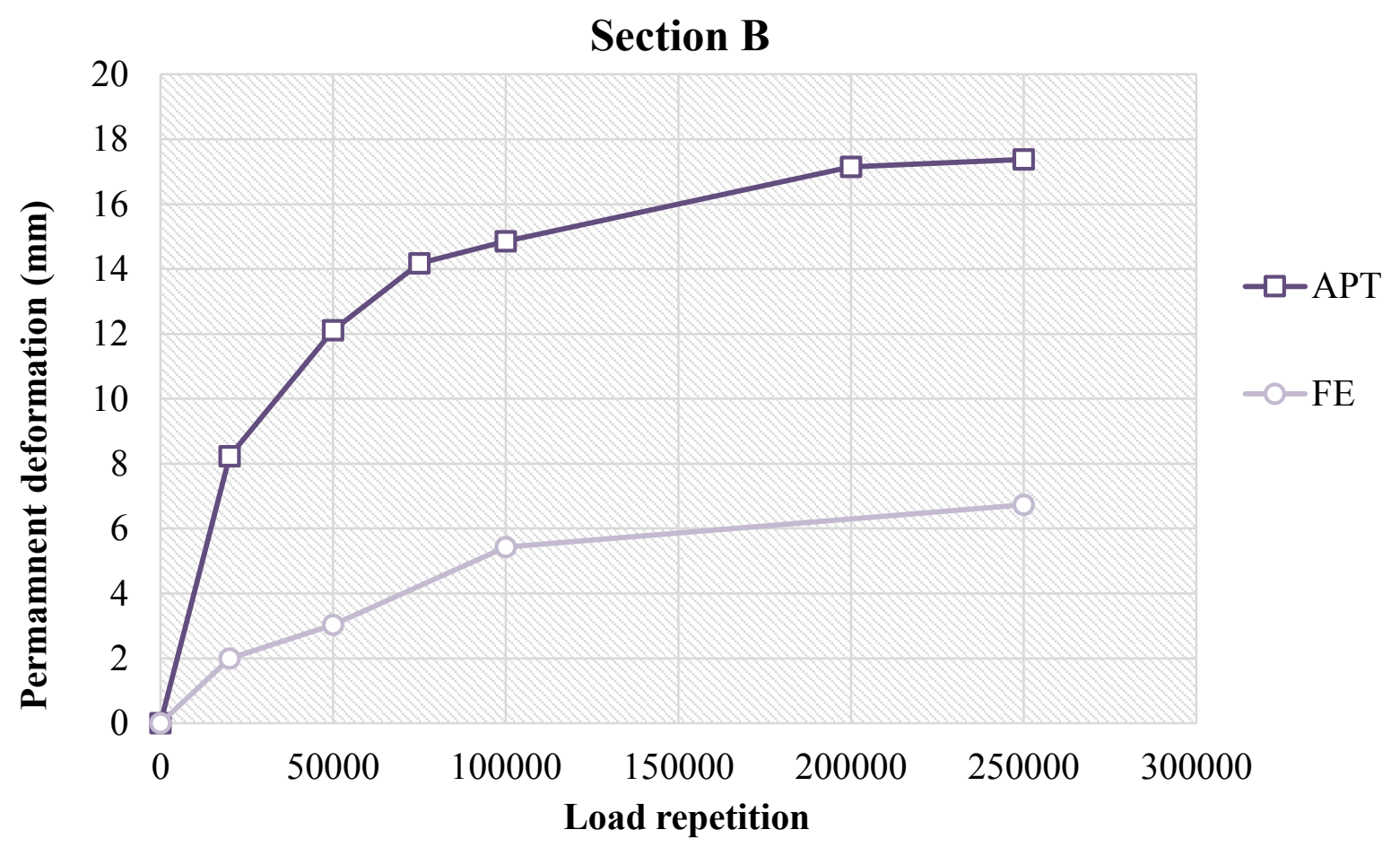

Figure 7-5 Permanent surface deformation versus load cycle applied Section B 


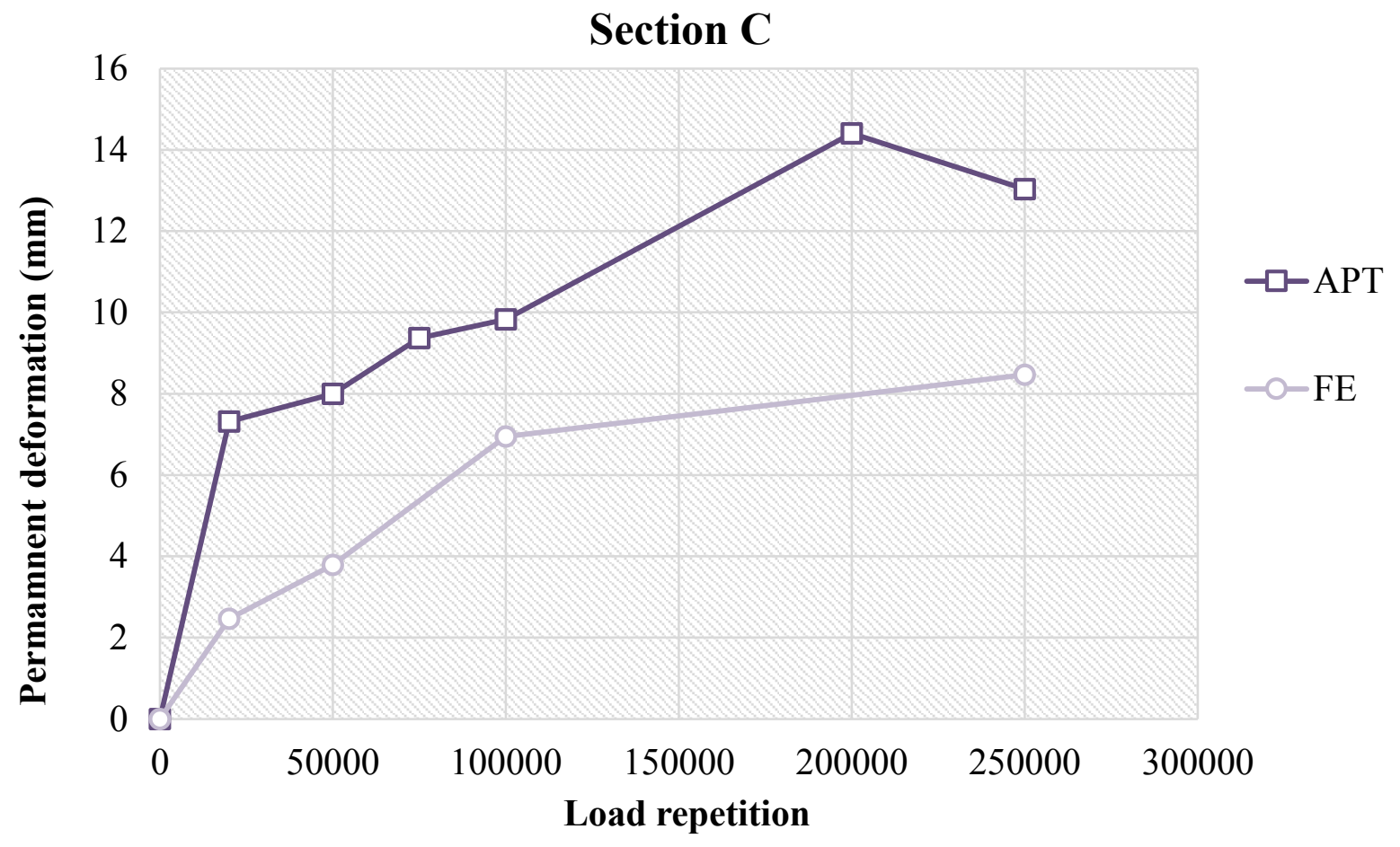

Figure 7-6 Permanent surface deformation versus load cycle applied Section C

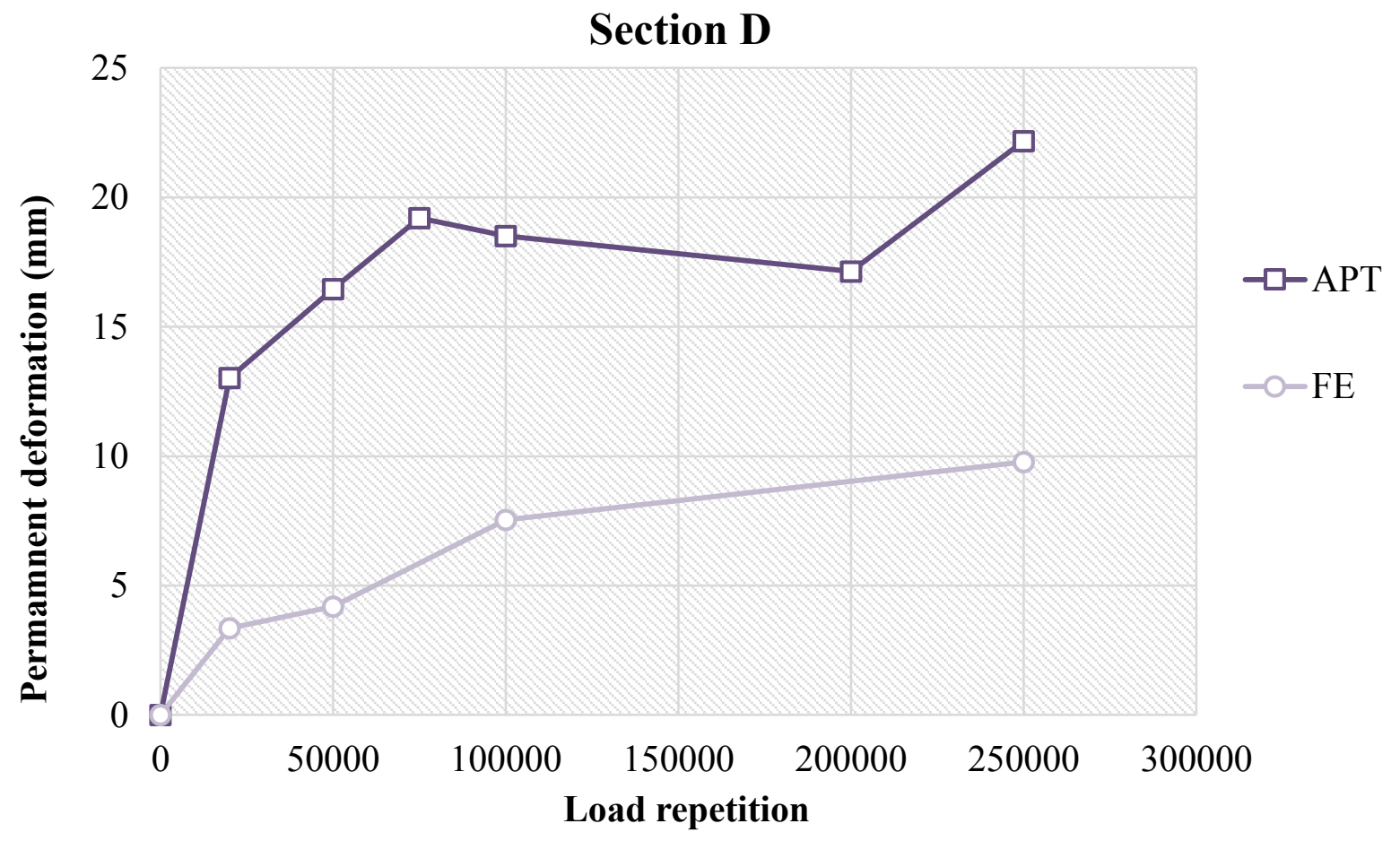

Figure 7-7 Permanent surface deformation versus load cycle applied Section D 


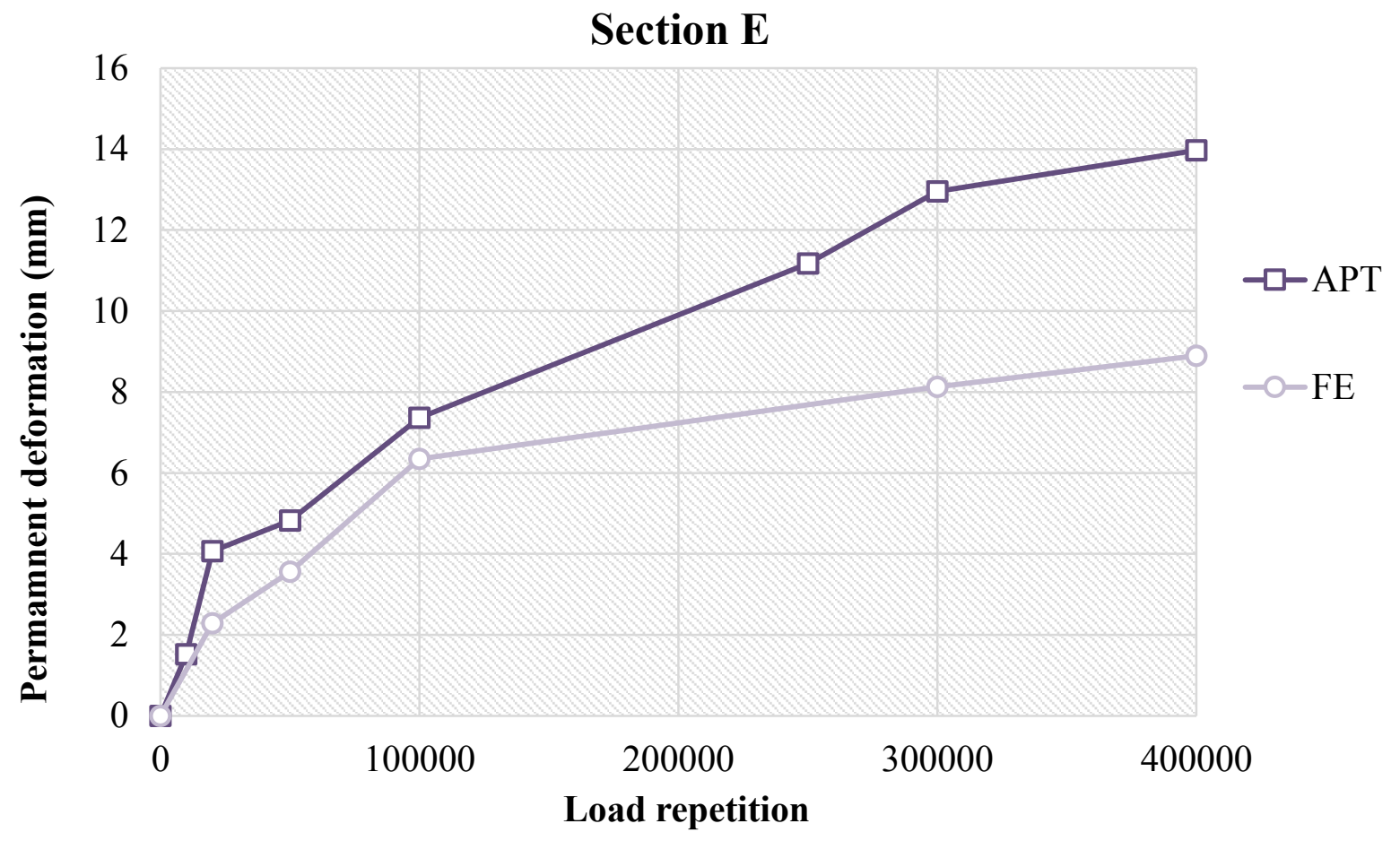

Figure 7-8 Permanent surface deformation versus load cycle applied Section D

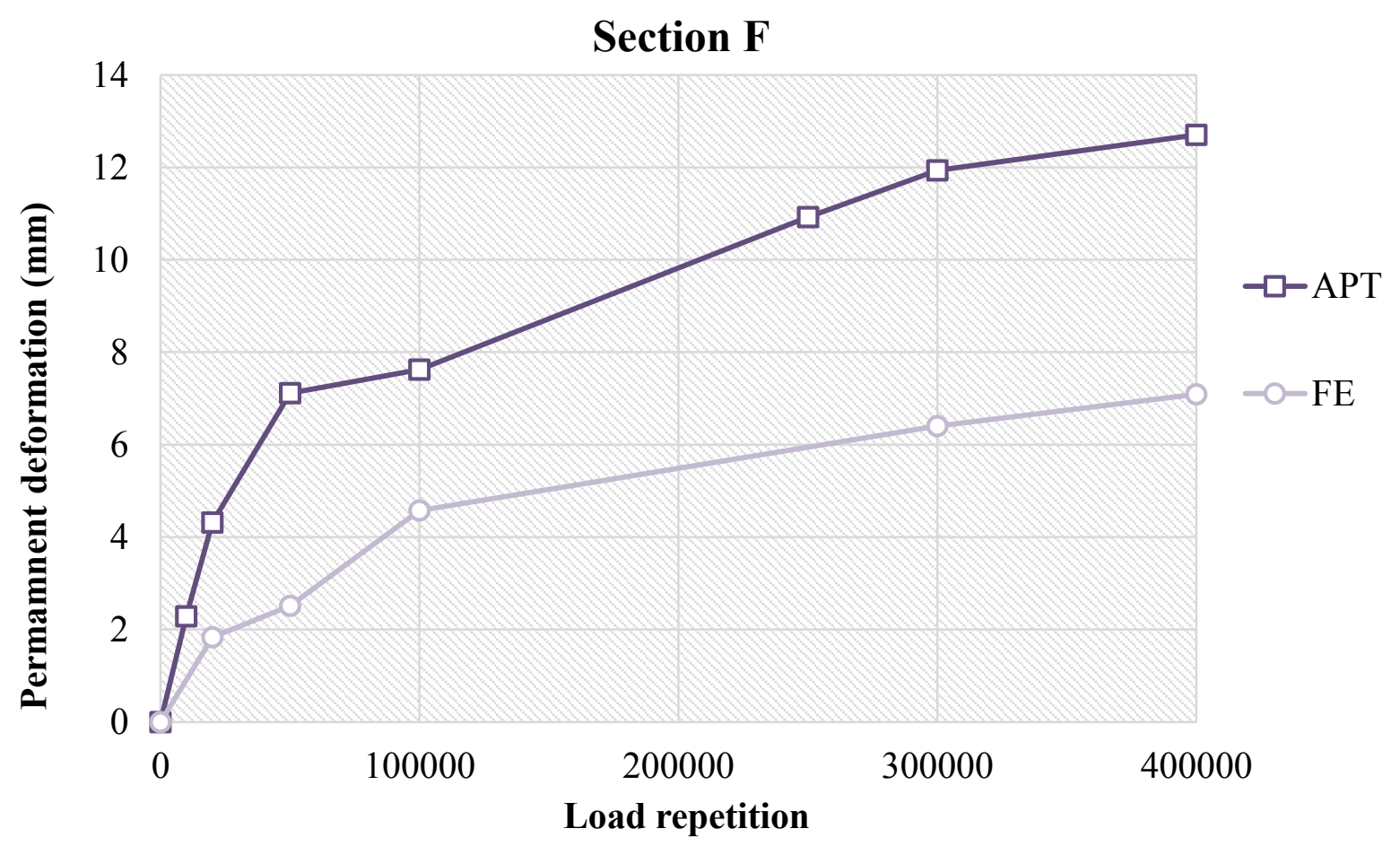

Figure 7-9 Permanent surface deformation versus load cycle applied Section F 


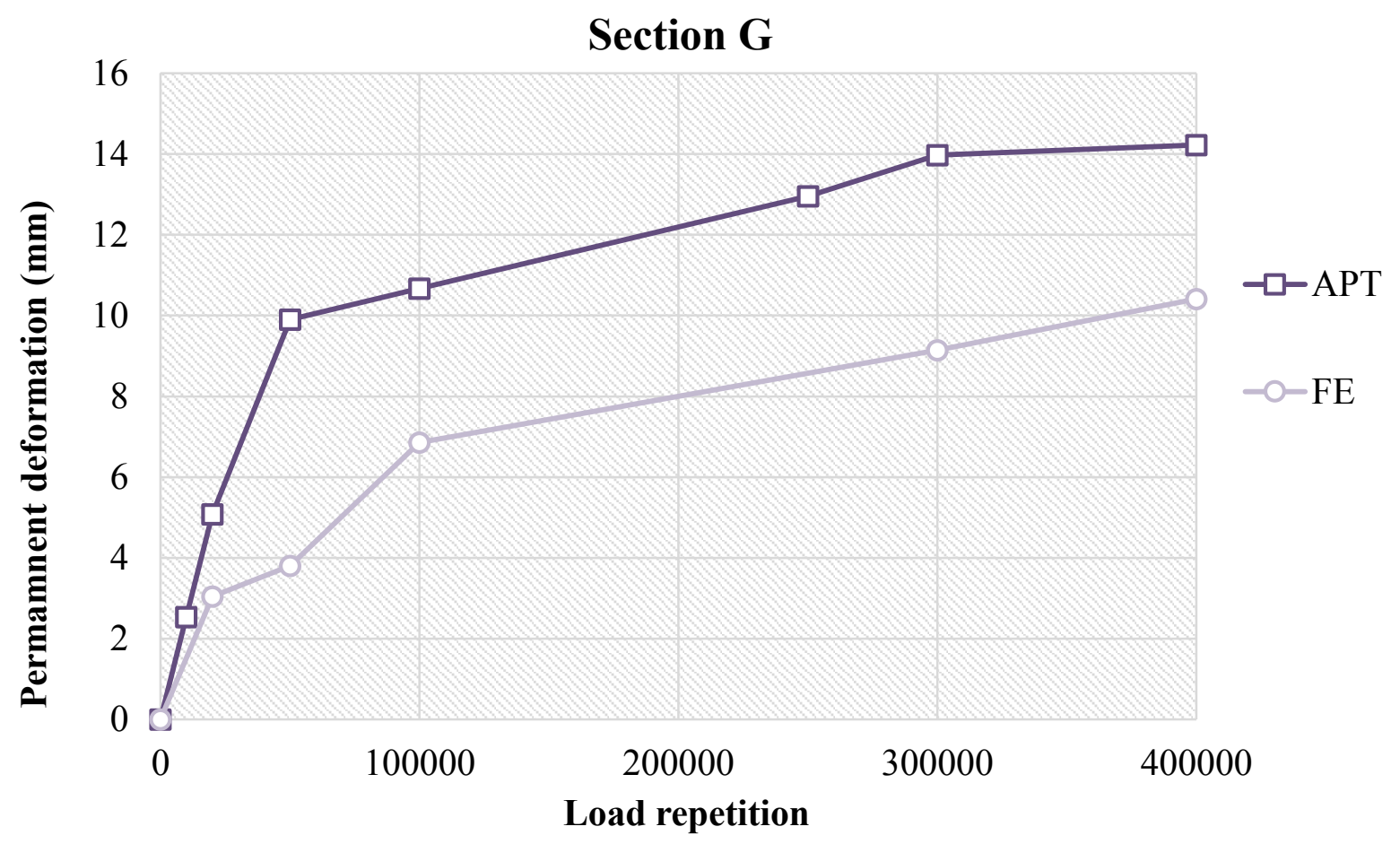

Figure 7-10 Permanent surface deformation versus load cycle applied Section G

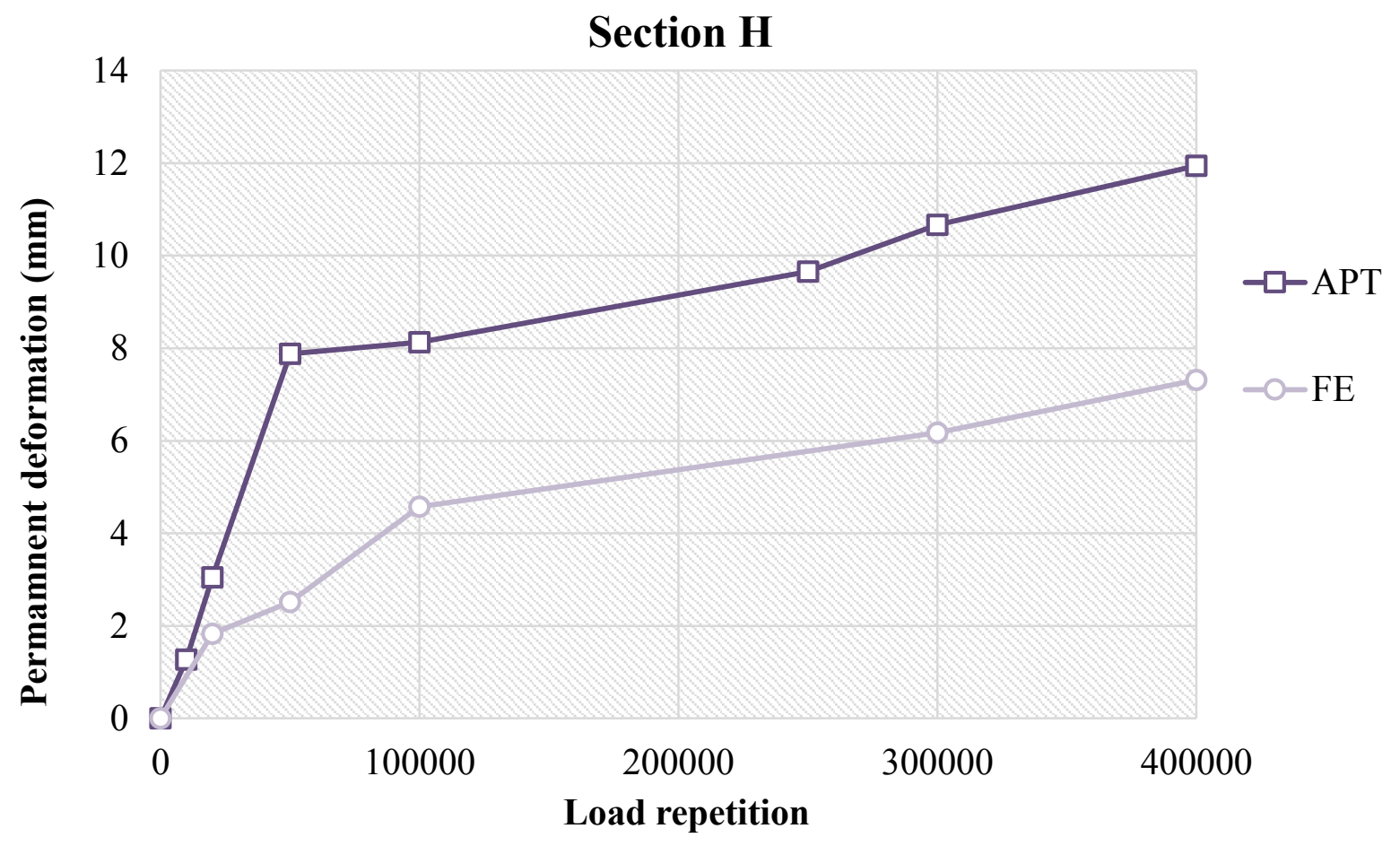

Figure 7-11 Permanent surface deformation versus load cycle applied Section $H$ 


\subsubsection{Vertical Stress on the Top of Subgrade}

Vertical stress on the top of subgrade is an important factor in mechanistic pavement design. Studies have shown a strong correlation between permanent deformation and pressure on top of the subgrade (Huang, 2008). Higher pressure causes decreased pavement life due to rutting failure. Maximum pressure for the test sections is shown in Figure 7-12and Figure 7-13. Among the first four test sections, unreinforced section (Section A) showed lower pressure on top of the subgrade compared to the reinforced sections. Total thickness of the pavement layer on top of the subgrade in the unreinforced section (Section A) was $102 \mathrm{~mm}$ (4 in.) more than Sections B, C, and D. However, reinforced sections with $152 \mathrm{~mm}$ (6 in.) HMA layer and $305 \mathrm{~mm}$ (12 in.) base layer performed better than unreinforced sections (A and E) in terms of vertical pressure on top of the subgrade.

Comparison between predicted pressure from the ABAQUS model and full-scale test measurements is depicted in Figure 7-14 toFigure 7-21. Initially, measured pressure values fluctuated due to consolidation of the HMA and base layers. FE model was unable to model this fluctuation, but after approximately 100,000 repetitions, when results were ordered and showed a

clear trend. Although quantitatively there are some differences between the predicted results and the actual measurements, the trends are similar. 


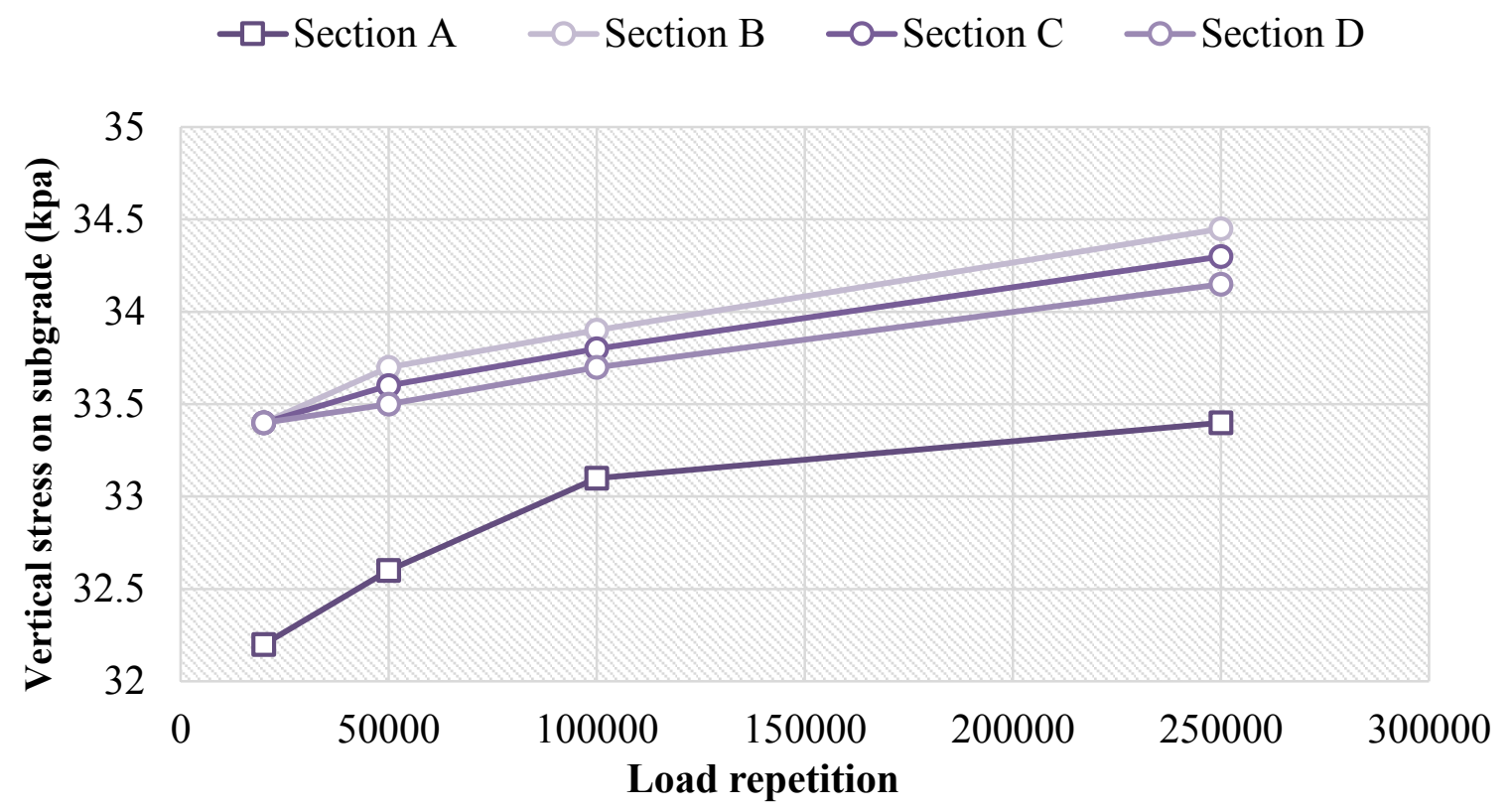

Figure 7-12 Predicted vertical stress on subgrade-Section A-D

$-\square-$ Section E $\quad-0-$ Section $F \quad-0-$ Section $G \quad-0-$ Section H

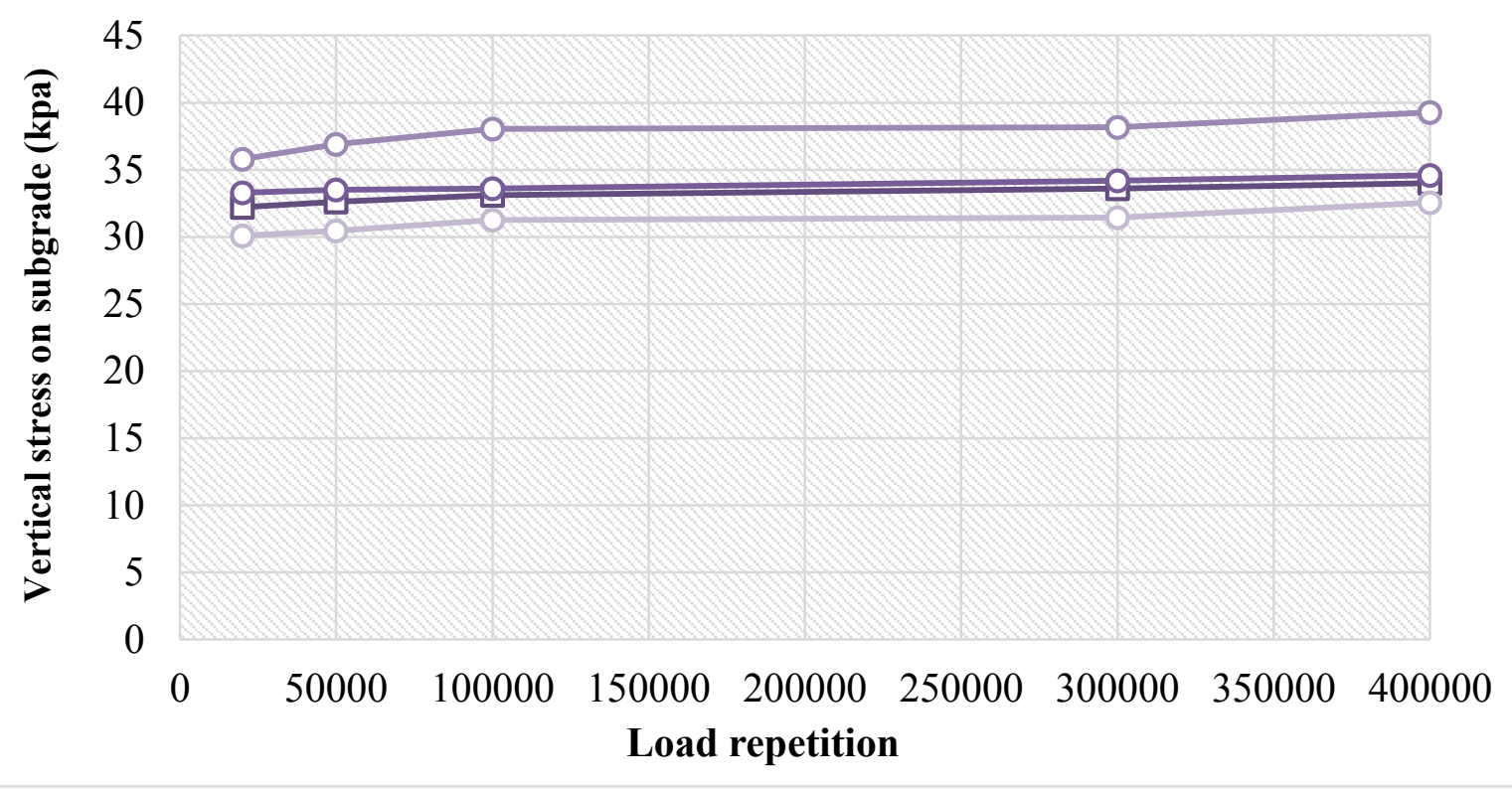

Figure 7-13 Predicted vertical stress on subgrade-Section E-H 


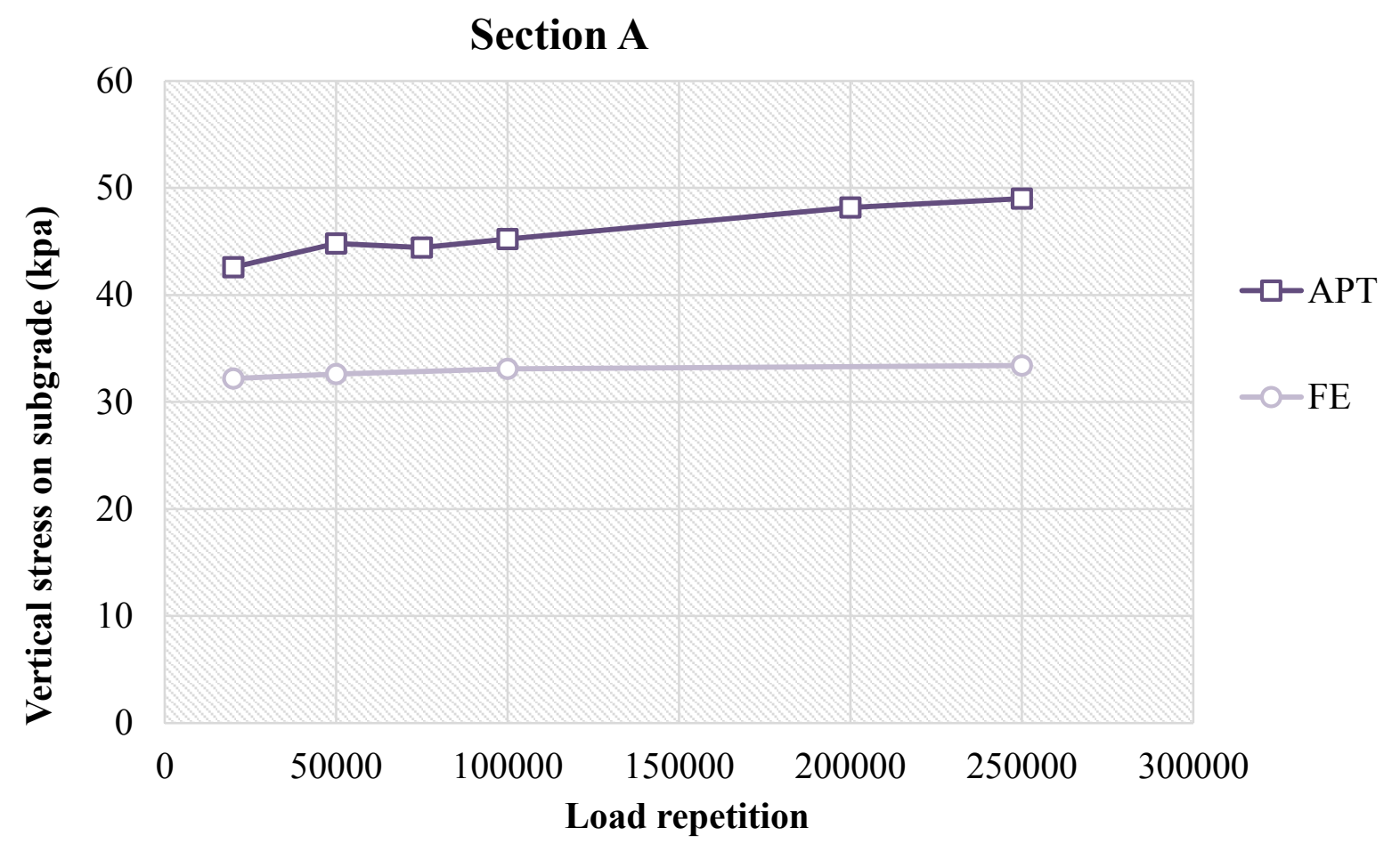

Figure 7-14 Vertical pressure on top of subgrade- Section A

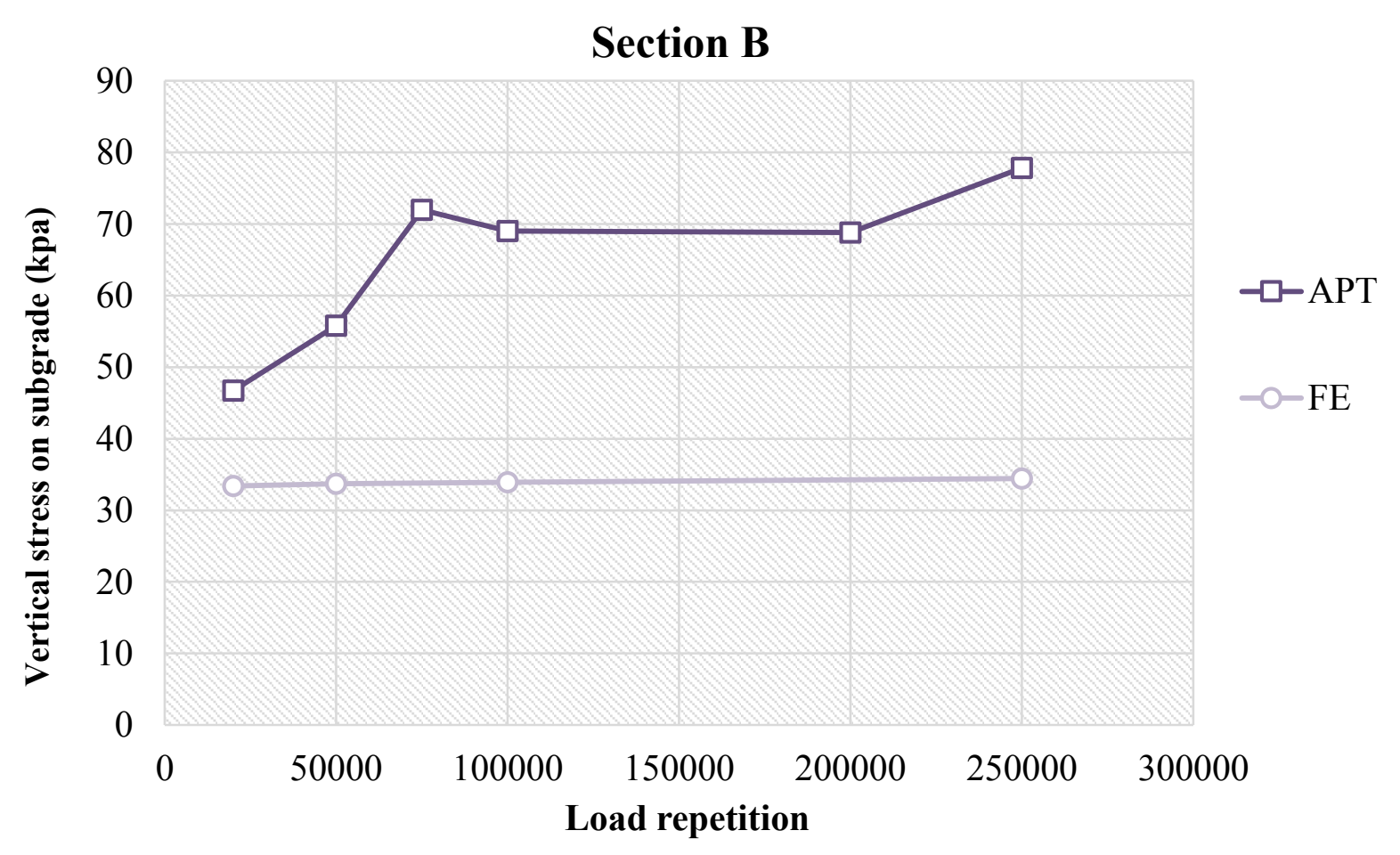

Figure 7-15 Vertical pressure on top of subgrade- Section B 


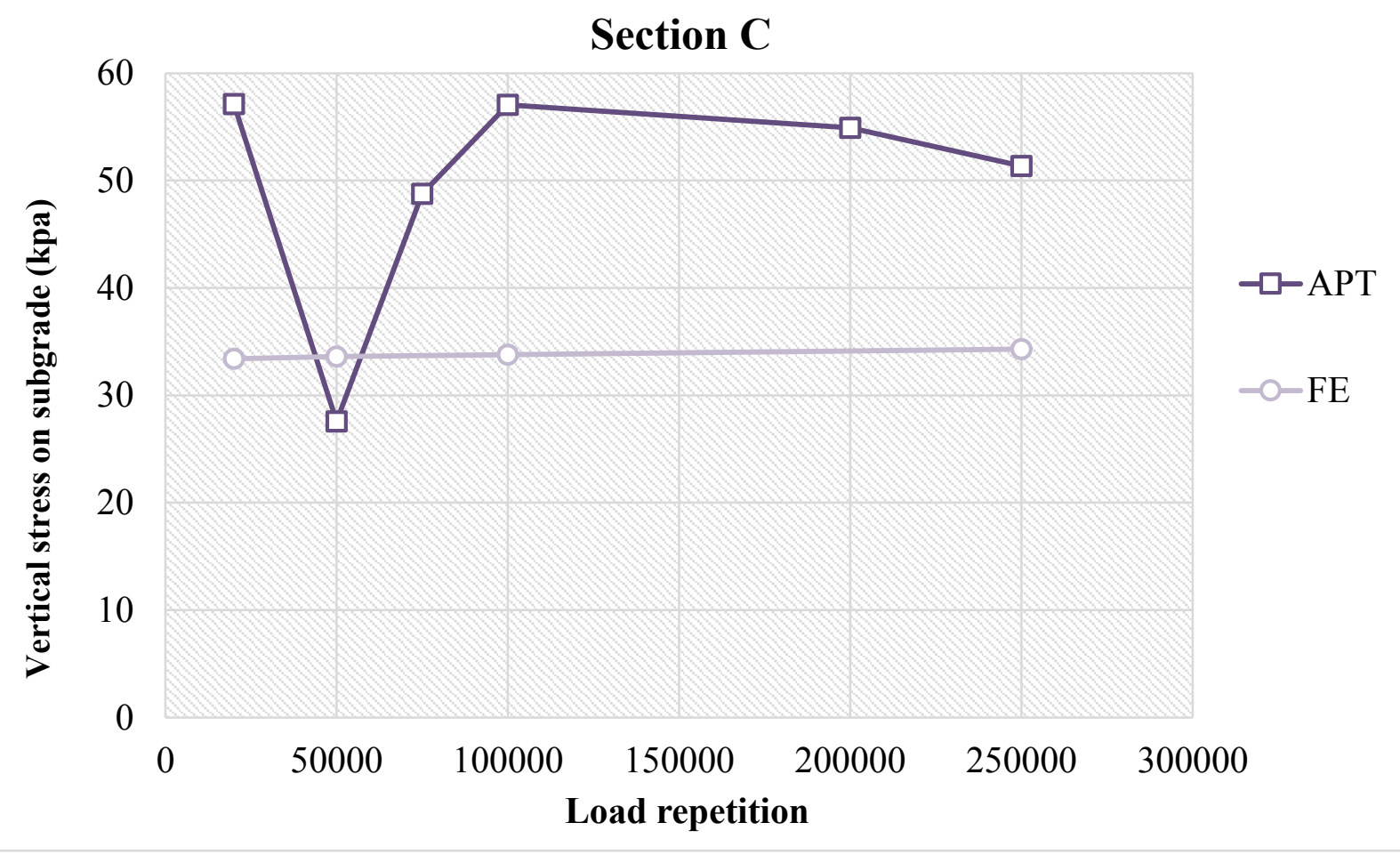

Figure 7-16 Vertical pressure on top of subgrade- Section C

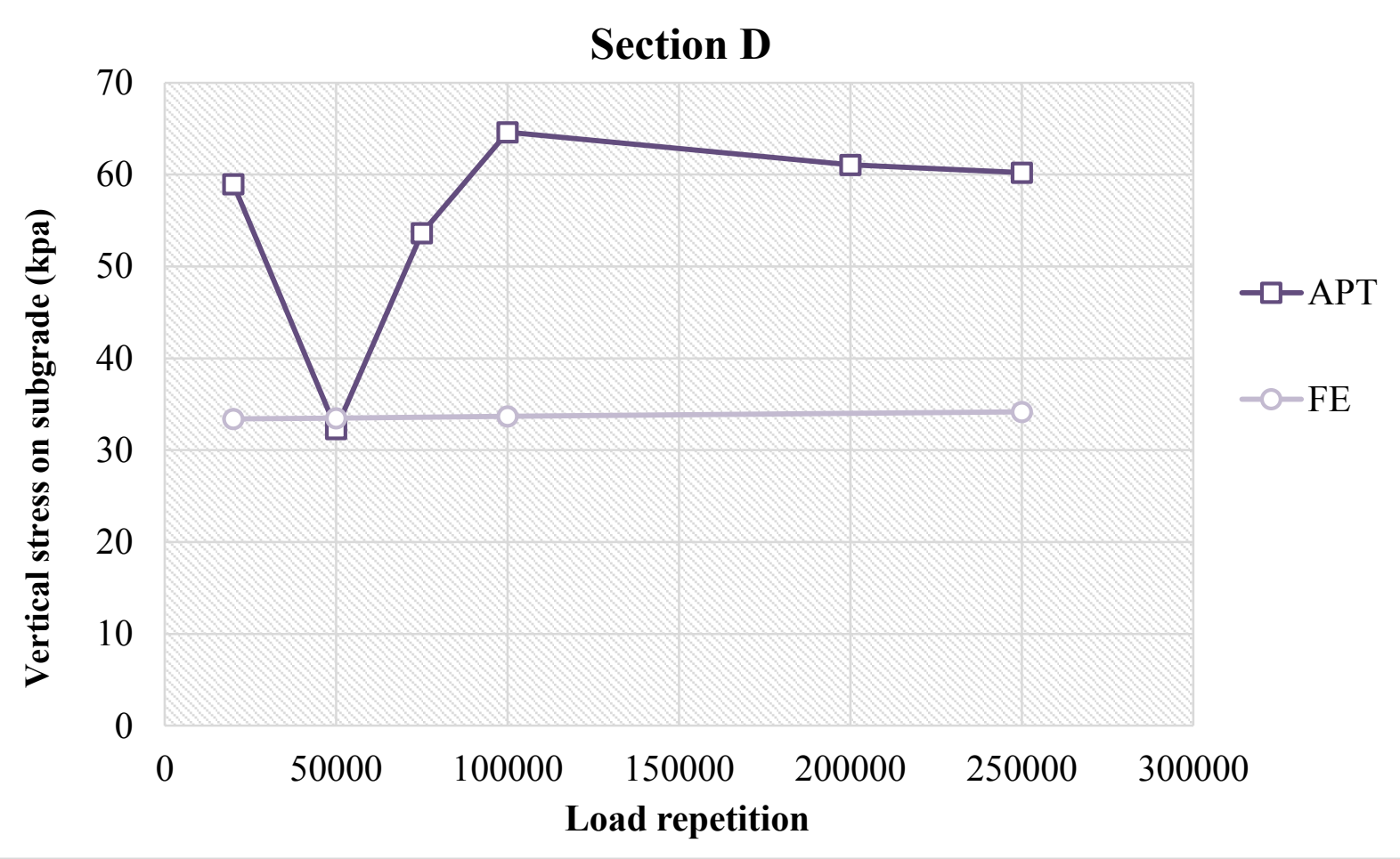

Figure 7-17 Vertical pressure on top of subgrade- Section D 


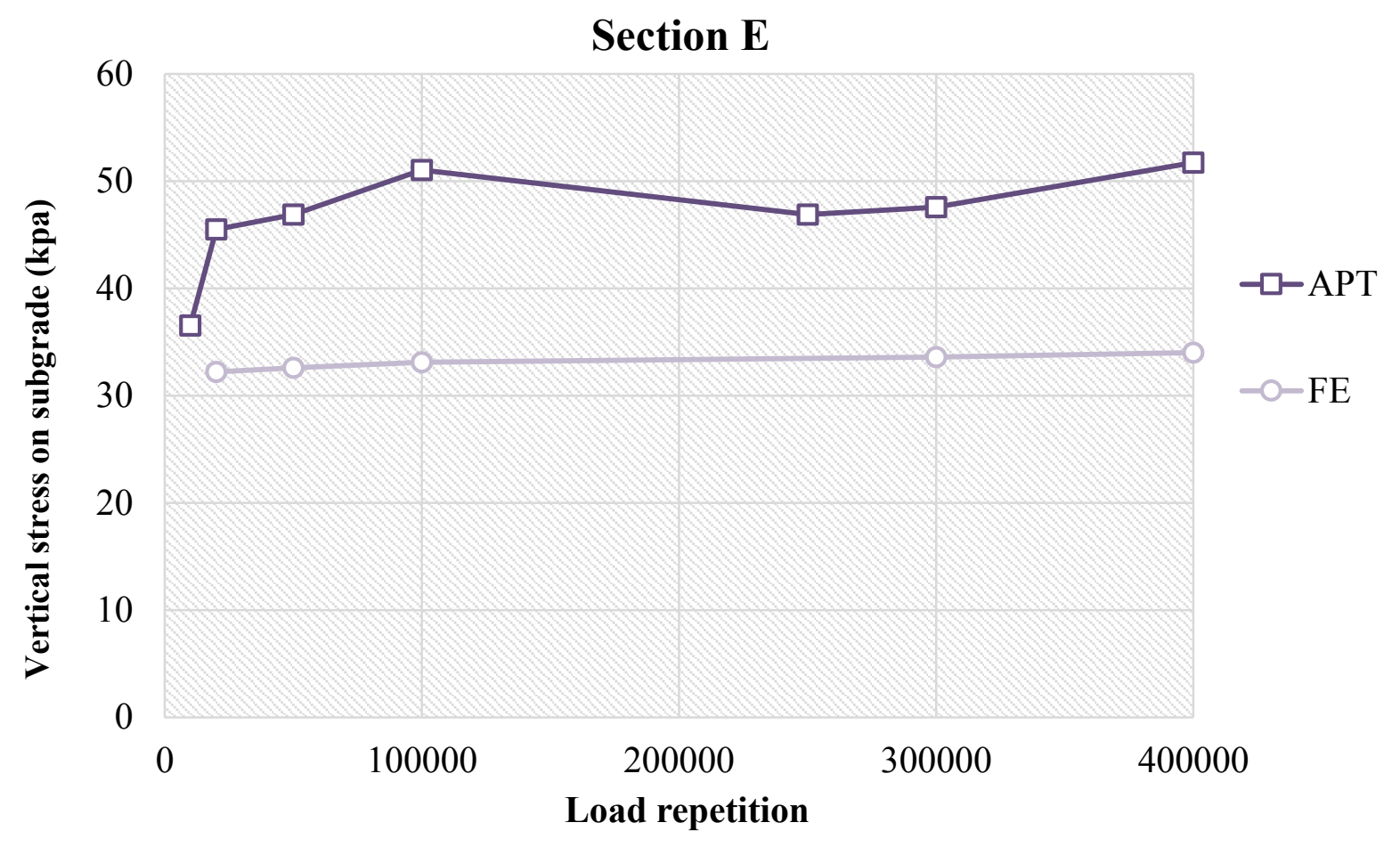

Figure 7-18 Vertical pressure on top of subgrade- Section $\mathbf{E}$

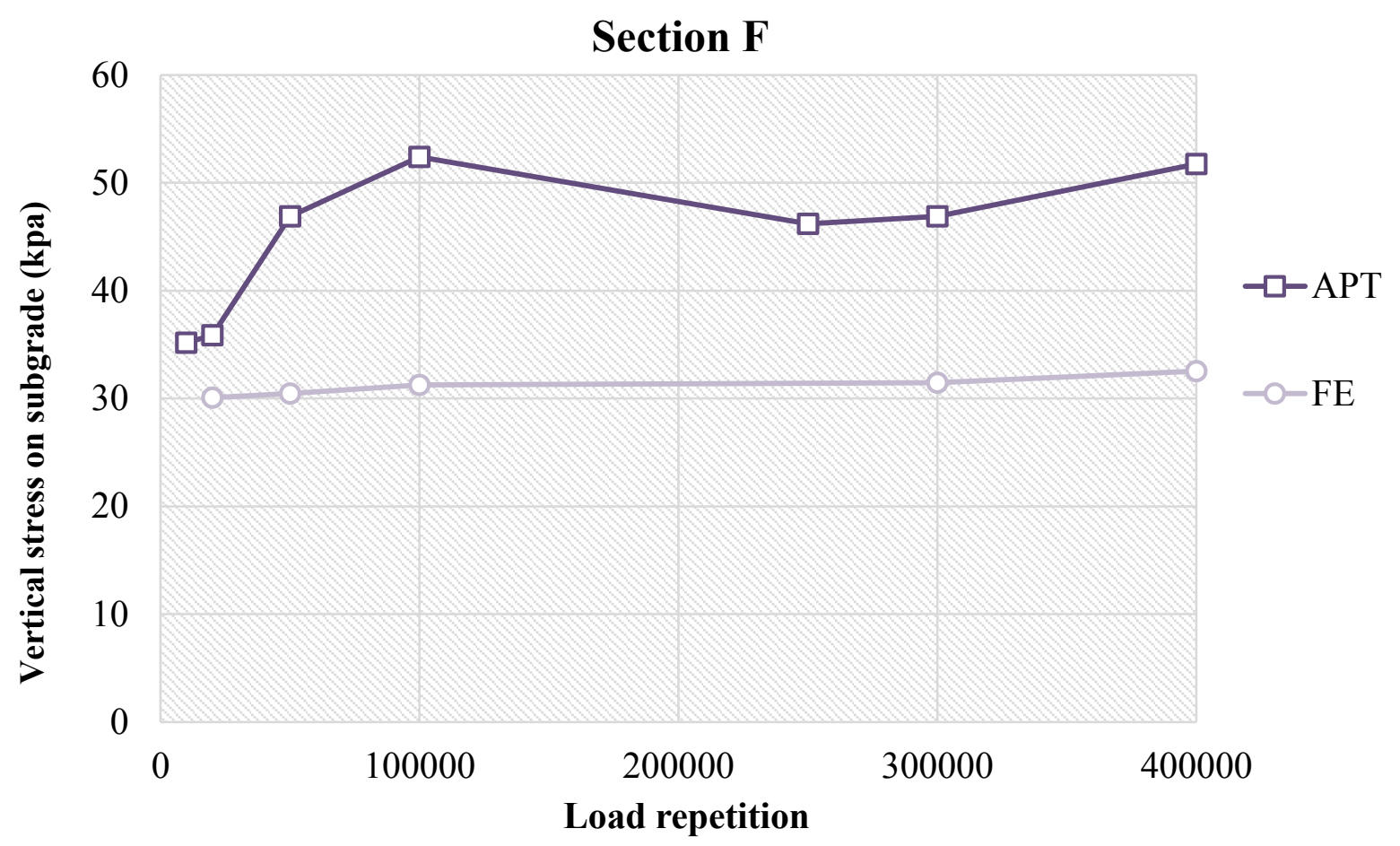

Figure 7-19 Vertical pressure on top of subgrade- Section F 


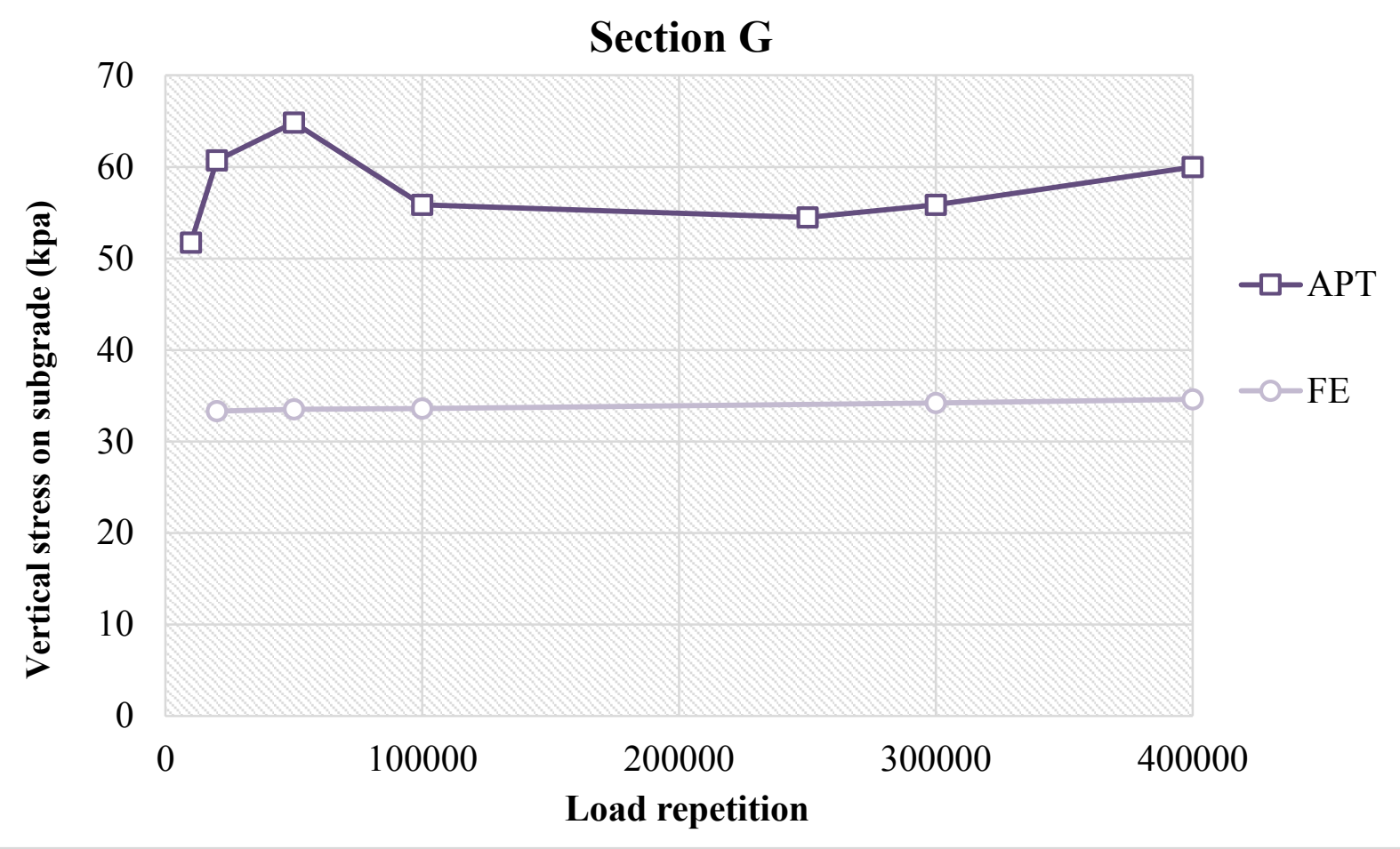

Figure 7-20 Vertical pressure on top of subgrade- Section G

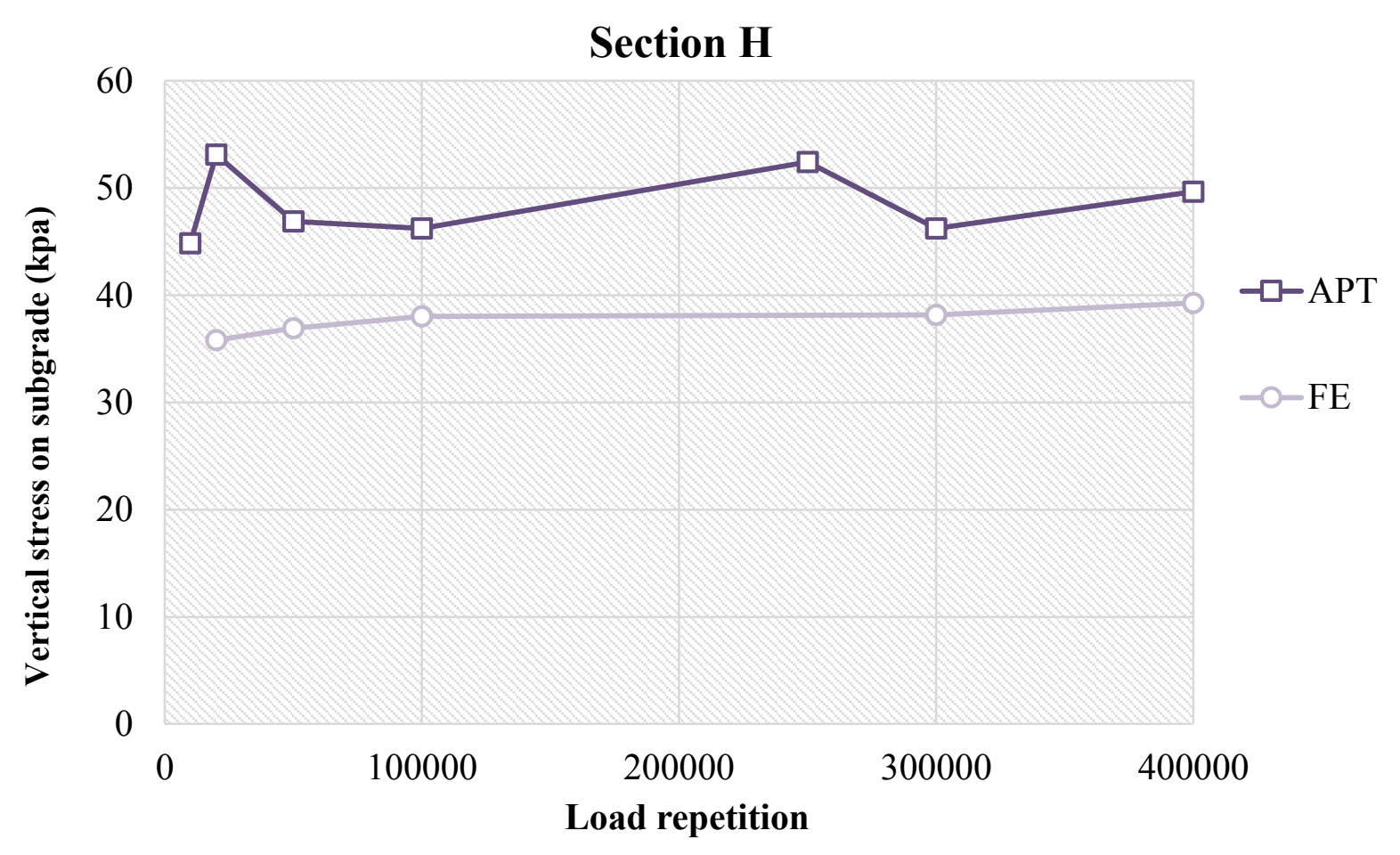

Figure 7-21 Vertical pressure on top of subgrade- Section $\mathbf{H}$ 


\subsubsection{Horizontal Strain at the Bottom of HMA Layer}

As explained in Chapter 5, strain at the bottom of the HMA layer is related to fatigue performance of pavements. Higher horizontal tensile strain at the bottom of the HMA layer decreases remaining life of the pavement based on fatigue failure criterion. FEM results confirmed the measured responses. FE analysis showed that the magnitude of strains at the bottom of HMA layer demonstrates a strong correlation to thickness of the layer, and the strains are higher in thinner sections. Values for reinforced and control sections with similar thickness of HMA layer were almost similar. This also shows that existence of the reinforcement layer does not significantly affect the horizontal tensile strain at the bottom of the HMA layer.

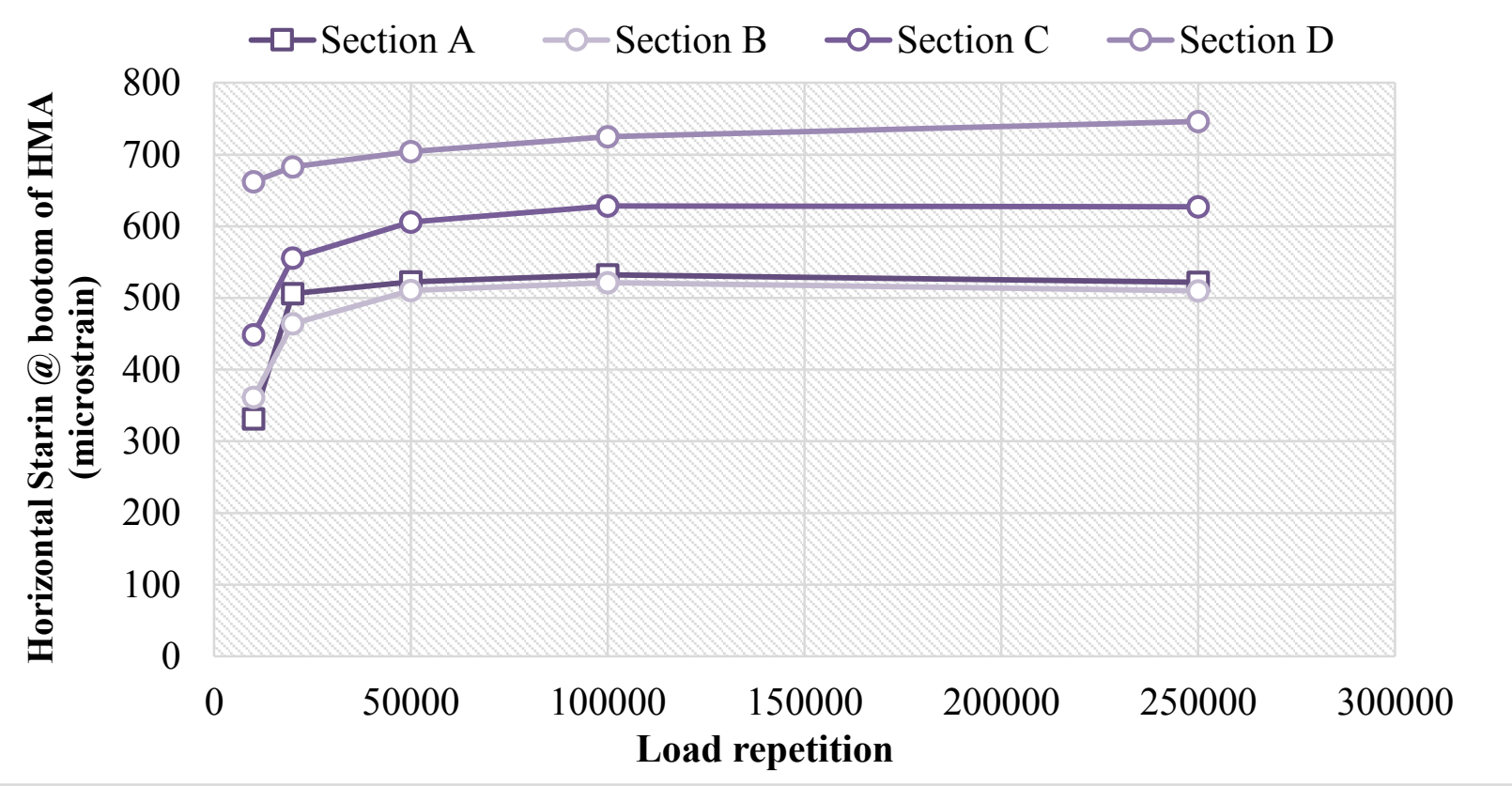

Figure 7-22 Predicted horizontal strain at the bottom of AC layer- Sections A-D 


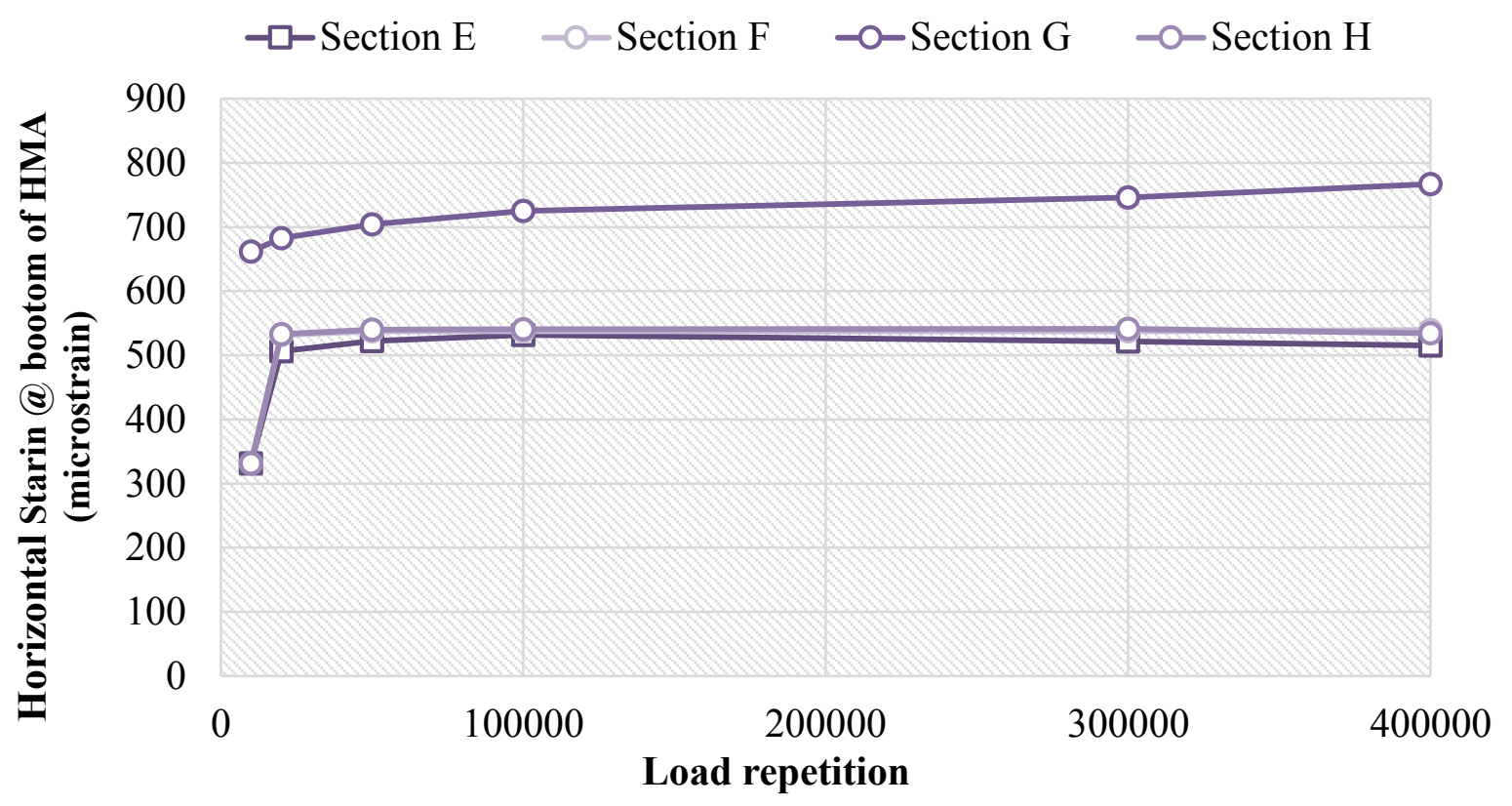

Figure 7-23 Predicted horizontal strain at the bottom of AC layer- Sections E-H

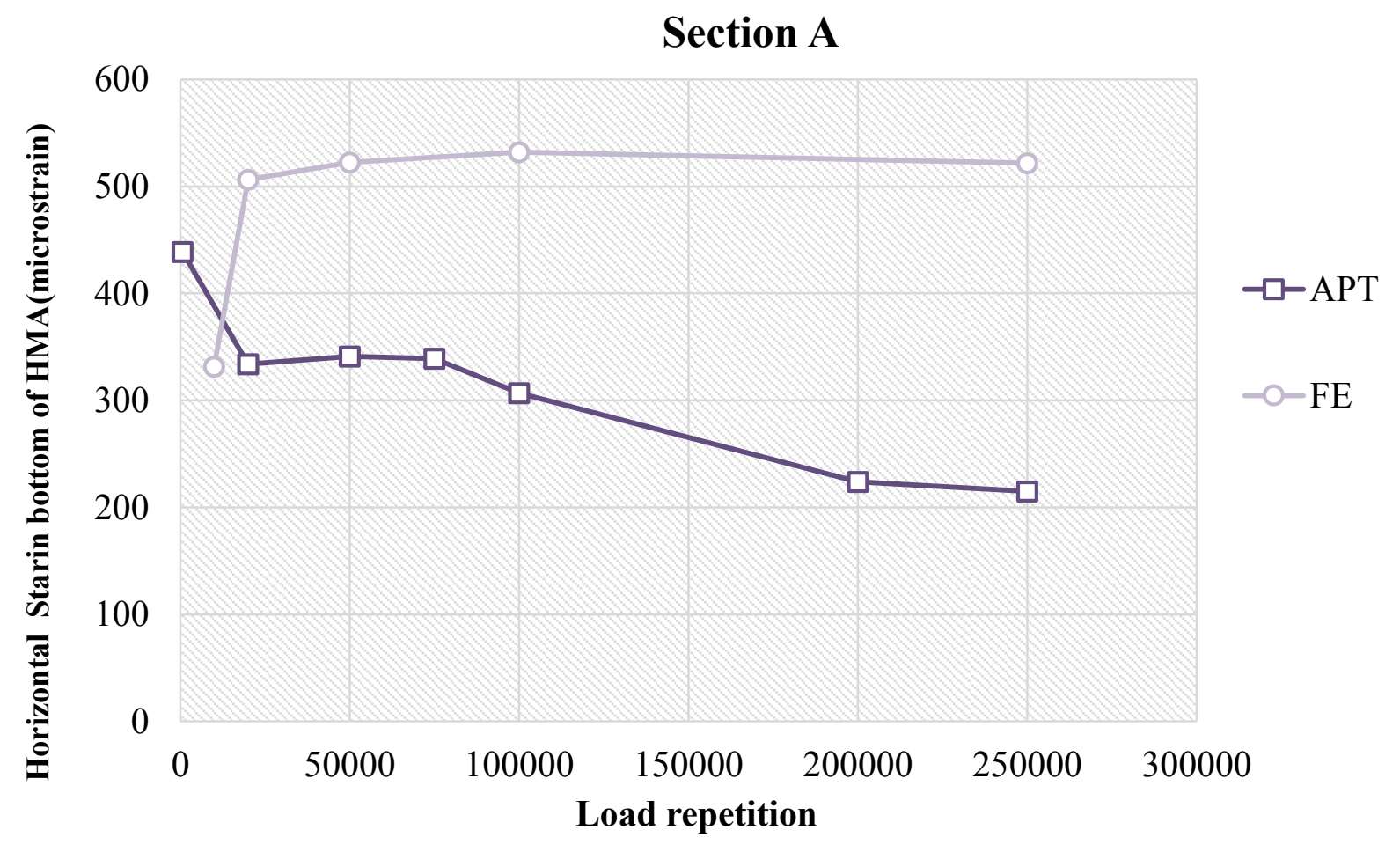

Figure 7-24 Horizontal strain at the bottom of AC layer-Section A 


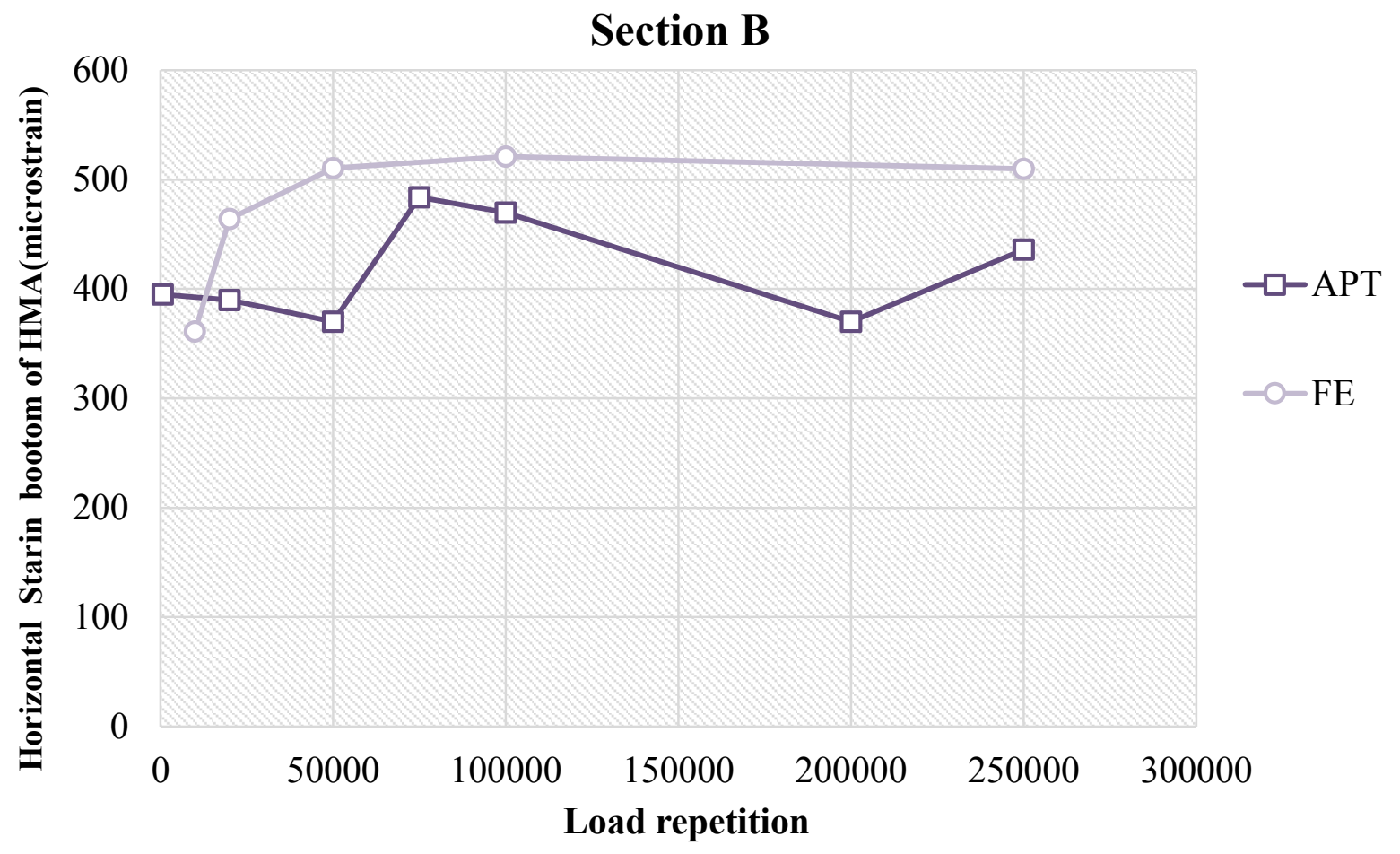

Figure 7-25 Horizontal strain at the bottom of AC layer- Section B

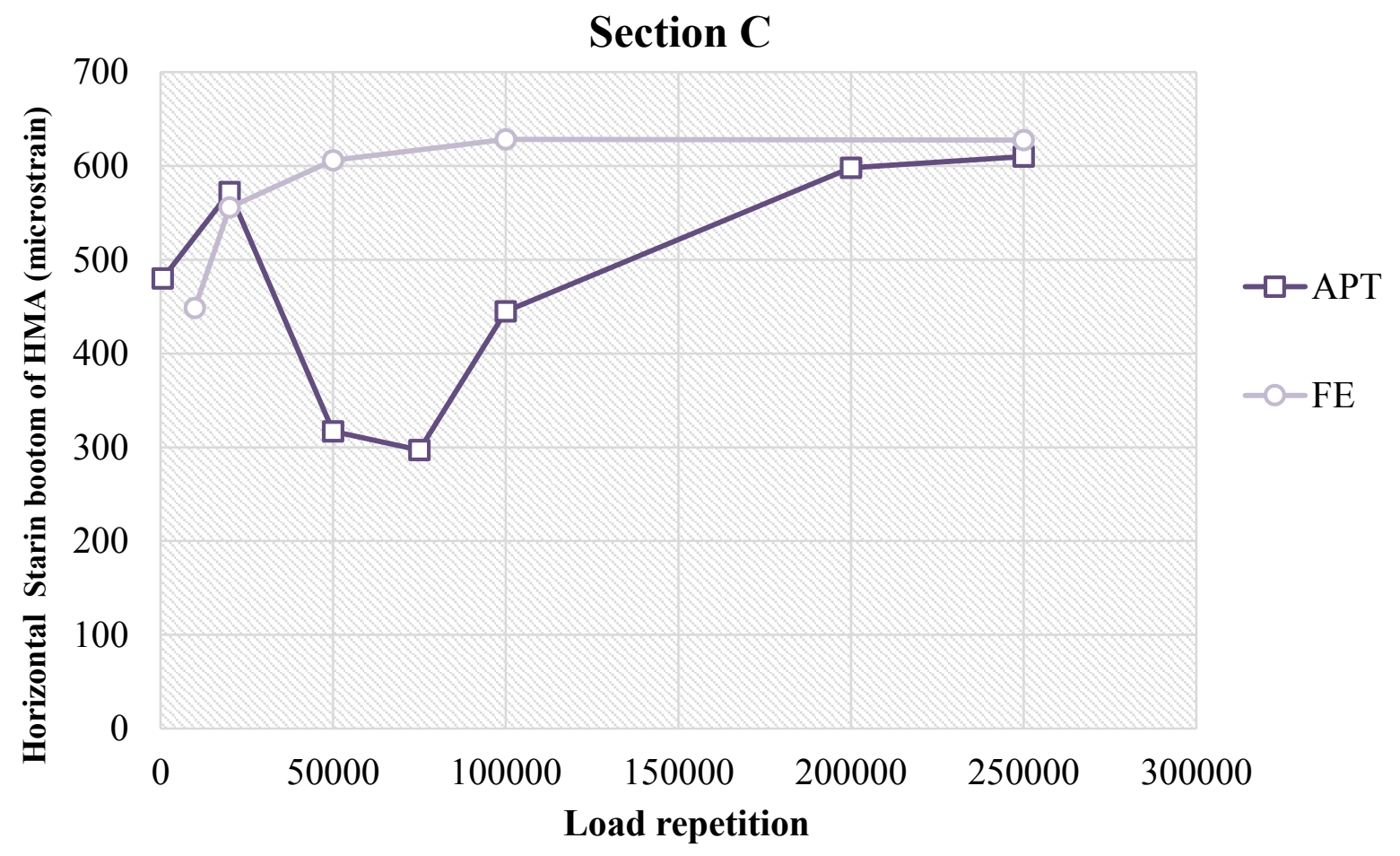

Figure 7-26 Horizontal strain at the bottom of AC layer-Section C 


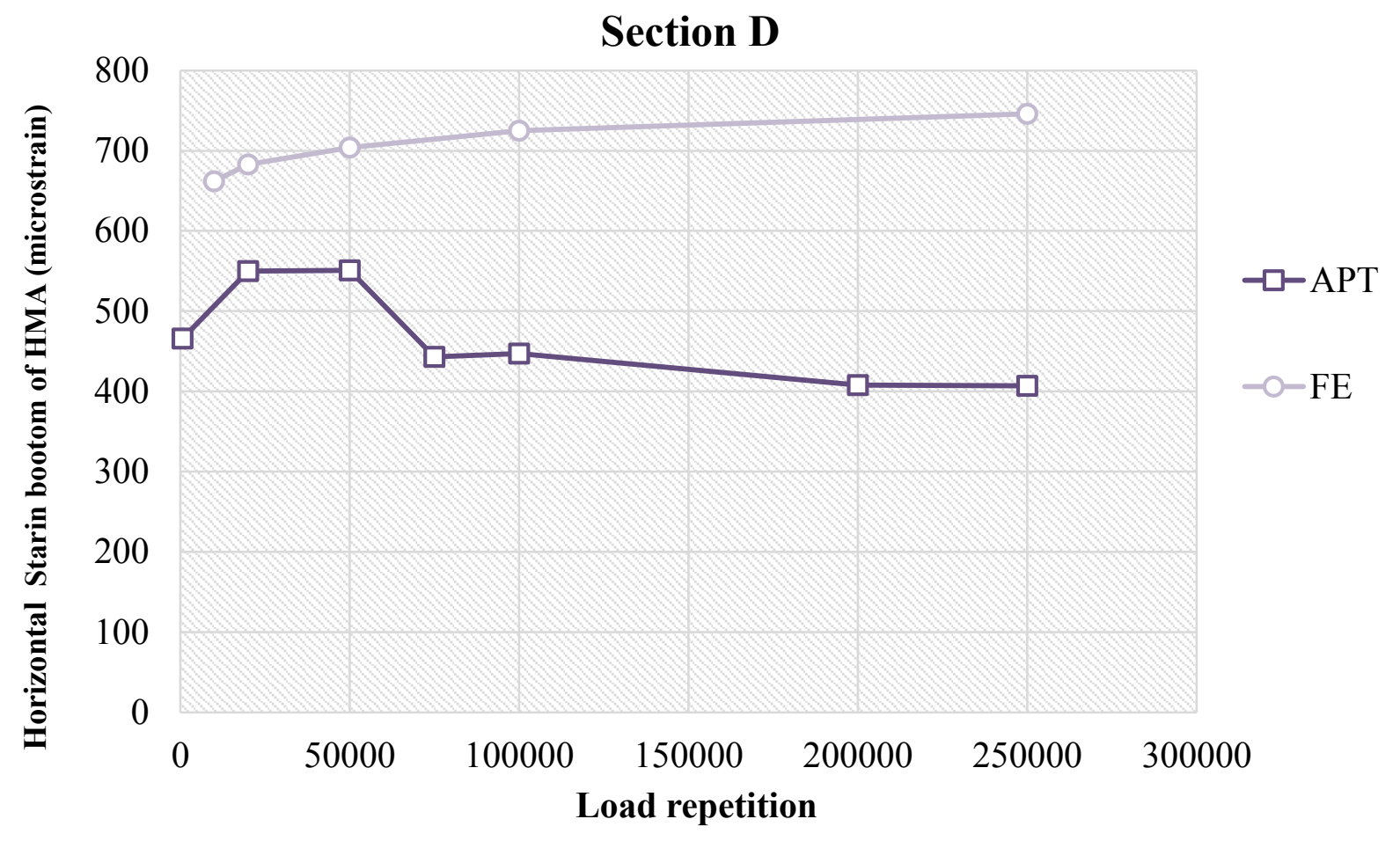

Figure 7-27 Horizontal strain at the bottom of AC layer- Section D

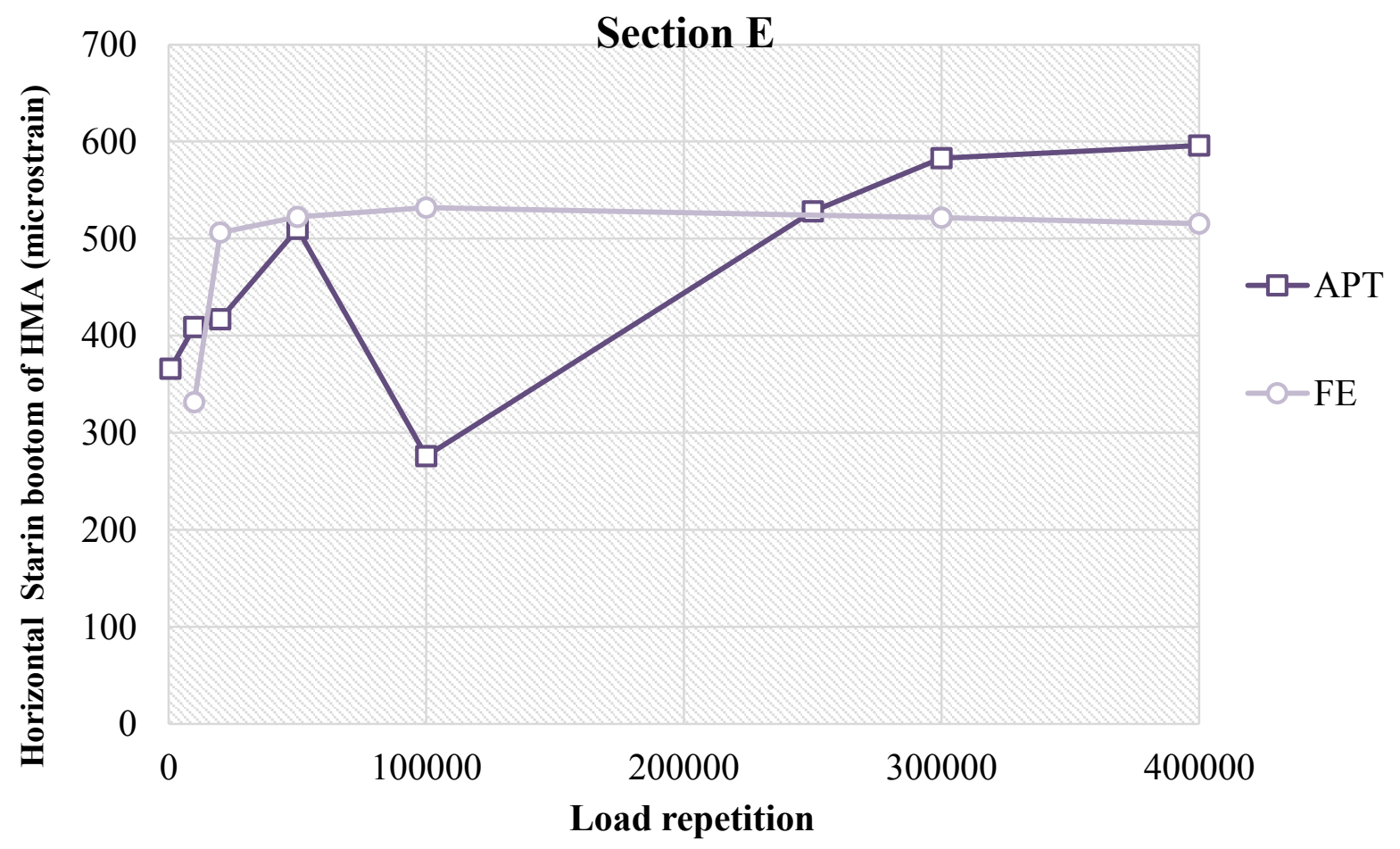

Figure 7-28 Horizontal strain at the bottom of AC layer- Section E 


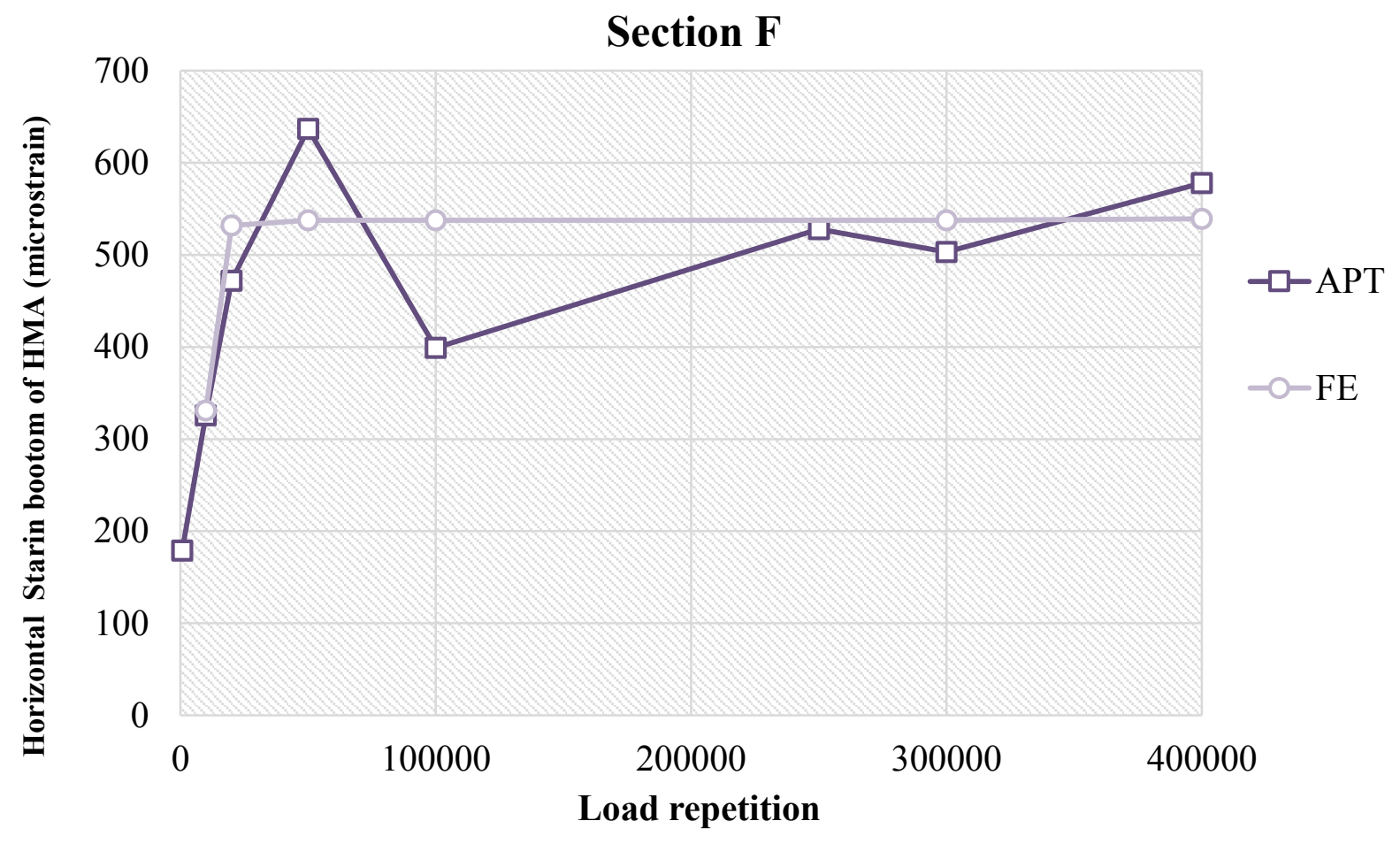

Figure 7-29 Horizontal strain at the bottom of AC layer- Section F

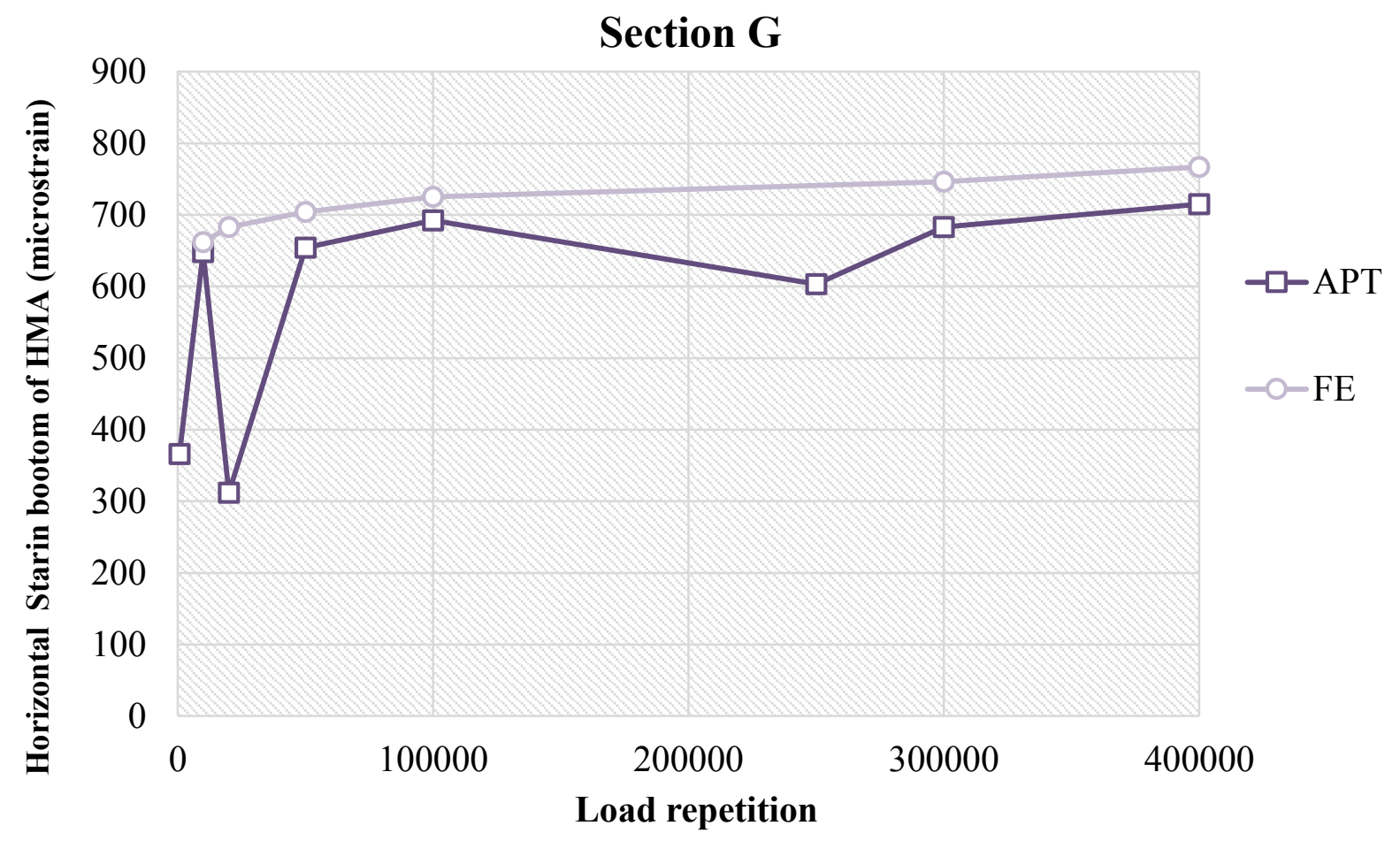

Figure 7-30 Horizontal strain at the bottom of AC layer-Section G 


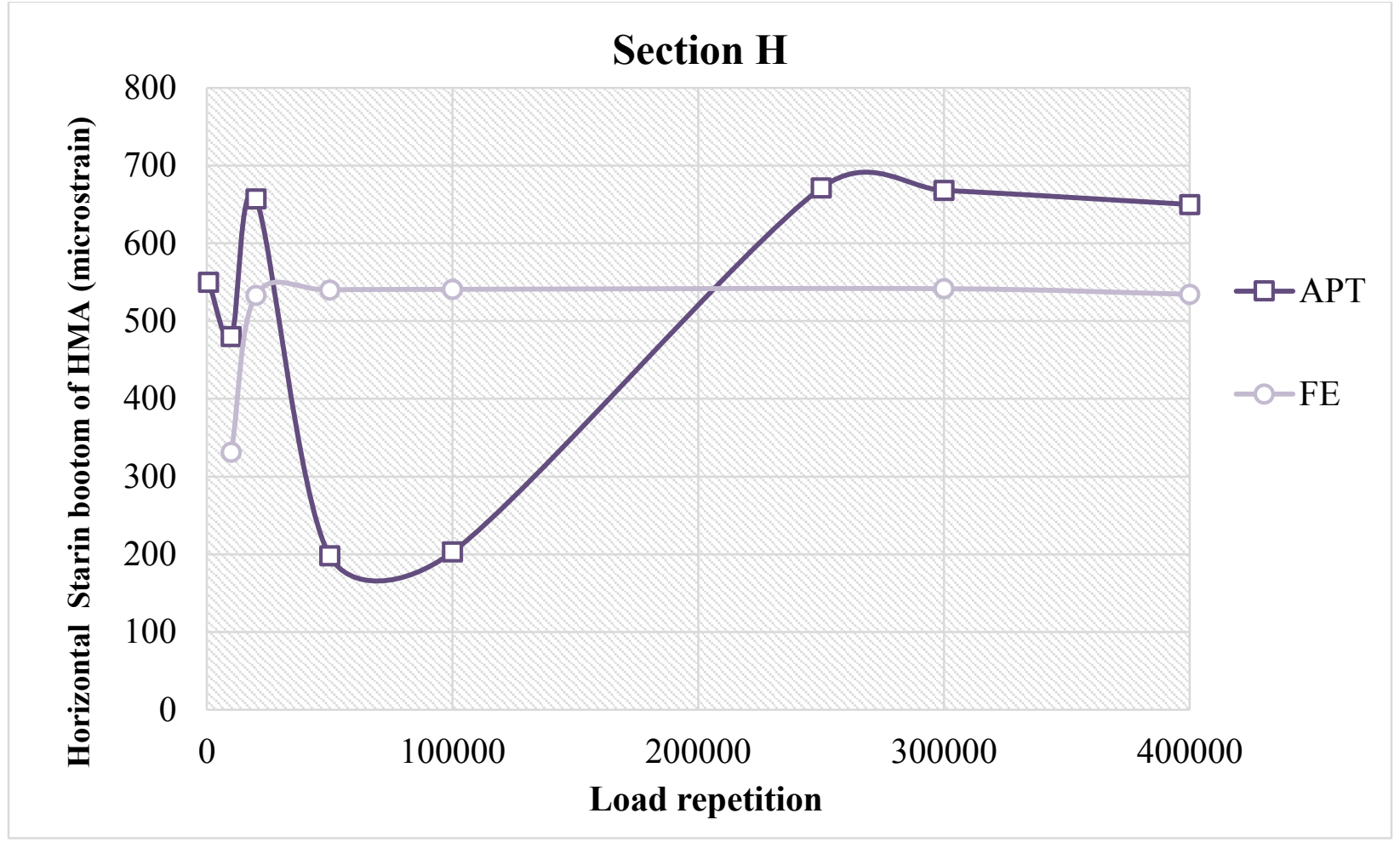

Figure 7-31 Horizontal strain at the bottom of AC layer-Section H

\subsection{Effect of Geotextile Properties}

To obtain optimum properties of geosynthetic reinforcement, various stiffness and bonding conditions at the geosynthetic-base and geosynthetic-subgrade interfaces were studied. Analysis focused on investigating how stiffness of the geotextile and interface friction properties impact pavement responses. Table 7-1 tabulates predicted pavement responses for various geotextile moduli after simulation of 250,000 wheel load repetitions. 
Table 7-1 Effects of geosynthetic modulus on pavement responses

\begin{tabular}{|c|c|c|c|}
\hline E (Mpa) & $\begin{array}{c}\text { Vertical } \\
\text { deformation at } \\
\text { surface (mm) }\end{array}$ & $\begin{array}{c}\text { Horizontal strain at } \\
\text { bottom of AC (micro) }\end{array}$ & $\begin{array}{c}\text { Vertical stress at top } \\
\text { of subgrade (kPa) }\end{array}$ \\
\hline unreinforced & 10 & 530 & 38.2 \\
\hline 69 & 9 & 531 & 37.4 \\
\hline 207 & 8 & 520 & 34.6 \\
\hline 345 & 8 & 510.9 & 33.7 \\
\hline 483 & 7 & 499 & 32.6 \\
\hline 620 & 7 & 496 & 30.3 \\
\hline 670 & 7 & 490 & 29.7 \\
\hline 827 & 6 & 487 & \\
\hline
\end{tabular}

As shown in Table 7-1, the benefit of reinforcement can be increased by using stiffer geotextile. Increasing geotextile stiffness from $69 \mathrm{MPa}(10,000 \mathrm{psi})$ to $483 \mathrm{MPa}(70,000 \mathrm{psi})$ reduces rutting and pressure on top of the subgrade by $19.4 \%$ and $12.8 \%$, respectively.

Table 7-2 shows effects of the friction coefficient between the geotextile and base/subgrade layer on pavement responses. Results indicated that better interface bond between the reinforced layer and base/subgrade improves pavement performance. However, this improvement is not significant. Improving interface bonding from $\mu=0.7$ to 1 decreases surface displacement by only $2 \%$.

Table 7-2 Effects of geosynthetic interface friction on pavement responses

\begin{tabular}{|c|c|c|c|c|c|}
\hline Pavement Responses & \multirow{2}{*}{ Unreinforced } & \multicolumn{4}{|c|}{ Friction coefficient } \\
\cline { 3 - 6 } & & 0.7 & 0.8 & 0.9 & 1 \\
\hline $\begin{array}{c}\text { Surface Vertical } \\
\text { Displacement (mm) }\end{array}$ & 9.91 & 9.40 & 9.40 & 9.14 & 9.14 \\
\hline $\begin{array}{c}\text { Horizontal strain at } \\
\text { bottom of AC (micro) }\end{array}$ & 530 & 525 & 524 & 523 & 523 \\
\hline $\begin{array}{c}\text { Vertical stress at top of } \\
\text { subgrade (kPa) }\end{array}$ & 38.2 & 37.1 & 36.9 & 36.8 & 36.7 \\
\hline
\end{tabular}




\subsection{Traffic Benefit Ratio}

A primary benefit of using reinforcement in pavements is the reduction of the quantity of pavement material (that is using thinner layers) without sacrificing pavement performance. This improvement can be measured in terms of Traffic Benefit Ratio (TBR). TBR is defined as the ratio of number of wheel passes required to reach a given level of rutting in the reinforced section divided by the number of cycles required in the unreinforced section with similar layer thickness and material properties to reach the same level of rutting. In this study, TBR value was calculated based on $12.5-\mathrm{mm}(0.5 \mathrm{in})$ rut depth. Also, the properties of geotextile G2 were used in this study. TBR values for the test sections are shown in Table 7-3.

Higher TBR indicates that the reinforcement layer has more influence on pavement performance. Based on the numerical analysis, TBR values for the thinner sections were higher than the thicker sections. For example, TBR for the section with $152 \mathrm{~mm}$ (6 in.) asphalt layer and $305 \mathrm{~mm}$ (12 in.) base course was 1.08. TBR value for the thinner section with $102 \mathrm{~mm}$ (4 in.) AC and $203 \mathrm{~mm}$ ( 8 in.) base layer was 1.14, meaning that more benefit is derived from reinforcement in thinner pavements. 
Table 7-3 Traffic benefit ratio

\begin{tabular}{|c|c|c|c|}
\hline \multirow{2}{*}{ Section } & \multicolumn{2}{|c|}{ No. of Cycles to Failure } & \multirow{2}{*}{ TBR } \\
\cline { 2 - 3 } & Unreinforced & Reinforced & \\
\hline $\begin{array}{c}152 \mathrm{~mm} \mathrm{AC}-305 \\
\mathrm{~mm} \text { Base }\end{array}$ & 510,000 & 550,000 & 1.08 \\
\hline $\begin{array}{c}152 \mathrm{~mm} \mathrm{AC}-254 \\
\mathrm{~mm} \text { Base }\end{array}$ & 490,000 & 530,000 & 1.08 \\
\hline $\begin{array}{c}152 \mathrm{~mm} \text { AC- } 203 \\
\mathrm{~mm} \text { Base }\end{array}$ & 450,000 & 510,000 & 1.13 \\
\hline $\begin{array}{c}127 \mathrm{~mm} \text { AC- } 305 \\
\mathrm{~mm} \text { Base }\end{array}$ & 500,000 & 550,000 & 1.10 \\
\hline $\begin{array}{c}127 \mathrm{~mm} \text { AC- } 10 " \\
\text { Base }\end{array}$ & 490,000 & 550,000 & 1.12 \\
\hline $\begin{array}{c}127 \mathrm{~mm} \mathrm{AC}-8 " \\
\text { Base }\end{array}$ & 450,000 & 510,000 & 1.13 \\
\hline $\begin{array}{c}102 \mathrm{~mm} \text { AC- } 305 \\
\mathrm{~mm} \text { Base }\end{array}$ & 480,000 & 530,000 & 1.10 \\
\hline $\begin{array}{c}102 \mathrm{~mm} \text { AC- } 254 \\
\mathrm{~mm} \text { Base }\end{array}$ & 460,000 & 515,000 & 1.12 \\
\hline $\begin{array}{c}102 \mathrm{~mm} \text { AC- } 203 \\
\mathrm{~mm} \text { Base }\end{array}$ & 440,000 & 500,000 & 1.14 \\
\hline
\end{tabular}




\section{Chapter 8 - Conclusions and Recommendations}

\subsection{Summary}

This dissertation investigated potential benefits of using geotextile as reinforcement in flexible pavements. These benefits can be obtained by improving structural capacity of the pavement. Geosynthetics in pavements have three specific roles: separation, lateral confinement, and tension membrane effect. As a separator layer, geotextile prevents interlayer mixing of the base and subgrade materials. Frictional force between the geosynthetic and base/subgrade may limit lateral movement of the base layer and increase confinement. Existence of the reinforcement layer at the base-subgrade interface results in lower vertical pressure on the underlying layer (subgrade) due to wider distribution of load from truck traffic.

To investigate performance of geotextile-reinforces base for paved roads, eight full-scale test sections were constructed and fully instrumented. Mechanistic responses such as pressure on top of the subgrade, strain at the bottom of the HMA layer and strain on the geotextile body were monitored when test sections were loaded by the APT machine.

In the next part of this study, a 3-D FE model was developed to study structural behavior of geotextile-reinforced pavements. This model was calibrated by full-scale test measurements. Good agreement existed between predicted and measured responses. Sensitivity analysis of the effects of geotextile properties on pavement responses was done using the FE model.

\subsection{Conclusions}

The following conclusions can be drawn from analysis of performance and response monitoring data from full-scale tests and numerical simulation of these tests:

(1) In the first test, one geotextile reinforced section (Section C) outperformed the control section in terms of rutting. However, this improvement was not observed for other 
reinforced sections (Sections B and D). Visual observation after excavation showed geotextile in Section B, which had the lowest strength, ruptured during loading; geotextile in Section D did not stretch in some parts.

(2) In the second test, two reinforced sections (Sections F and H) performed better than the control section in terms of rutting and pressure on subgrade.

(3) Pressure and strains in the reinforced sections did not change much until approximately 100,000 wheels passes, after which strength of the geotextiles was mobilized and these parameters changed considerably.

(4) Predicted fatigue lives of the test sections were calculated using transverse and longitudinal strains at the bottom of the HMA layer and the Asphalt Institute and Shell models. HMA fatigue life did not increase due to geotextile-reinforced base.

(5) FE analysis showed that benefits of reinforcement are more noticeable when stiffer geotextiles are used. Calculated traffic benefit ratio from FE analysis indicated that geotextile improves pavement life in terms of rutting. This benefit is greater for pavements with thin HMA layer and base course.

\subsection{Recommendations for Future Work}

The following are recommendations for future work.

1. In this study, eight full-scale sections were tested due to cost constraint. Additional tests on pavements with varying thickness and material properties are suggested to be conducted.

2. Tests on sections with more than one layer of reinforcement are also suggested to be conducted.

3. Laboratory tests need to be conducted on geotextile-base and geotextile-subgrade interface properties for increased accuracy of FE modeling

4. Cost-benefit ratio of the geotextiles should be studied in details. 


\section{References}

1. AASHTO. (2008). "Mechanistic-empirical pavement design guide: A manual of practice." Publication No. MEPDG-1, American Society of State Highway and Transportation Officials, Washington, D.C.

2. ABAQUS (2006). User's Manual. Version 6.6. Providence, RI.

3. Abu Al-Rub, R. K., Darabi, M. K., Huang, C. W., Masad, E. A., and Little, D. N. (2012). "Comparing finite element and constitutive modelling techniques for predicting rutting of asphalt pavements." International Journal of Pavement Engineering, 13(4), 322-338.

4. Al-Qadi, I. L., and Bhutta, S. A. (1996). "In situ measurements of secondary road flexible pavement response to vehicular loading." Transportation Research Record: Journal of the Transportation Research Board, No. 1652, Transportation Research Board of the National Academies, Washington, D.C., pp. 206-216.

5. ASTM (Annual Book of ASTM Standards). (1986). "Tensile properties of geotextiles by the wide-width strip method, D 4595." ASTM, Philadelphia, PA.

6. Barksdale, R. D. (1971). "Compressive stress pulse times in flexible pavements for use in dynamic testing.", Transportation Research Record 345 , Transportation Research Board, Washington DC, 32-44.

7. Barksdale, R. D., Brown, S. F., and Chan, F. (1989). "Potential benefits of geosynthetics in flexible pavement systems" NCHRP Report 315, Transportation Research Board, National Research Council, Washington, DC.

8. Bayomy, F. M., Al-Shaikh, A. M., and Abduljauwad, S. N. (1996). "Effect of geotextile on permanent deformation in salt-encrusted subgrade soils." Transportation Research Record: Journal of the Transportation Research Board, No. 1534, Transportation Research Board, Washington, D.C., pp. 40-49.

9. Bhutta, S. A. (1998). "Mechanistic-empirical pavement design procedure for geosynthetically stabilized flexible pavements." Ph.D. dissertation, Virginia Tech., Blacksburg, VA.

10. Brandon, T. L., Al-Qadi, I. L., Lacina, B. A., and Bhutta, S. A. (2005). "Construction and instrumentation of geosynthetically stabilized secondary road test sections." . 
Transportation Research Record: Journal of the Transportation Research Board, No. 1534, Transportation Research Board, Washington, D.C., pp. 50-57.

11. Duncan, J.M., Monismith, C.L. and Wilson, E.L. (1968). "Finite element analysis of highway pavements." Highway Research Record 228, Highway Research Board, Washington, D.C., pp. 18-33.

12. Ericks, H., and Drescher, A. (2001). "The use of geosynthetics to reinforce low volume roads." Report No. MN/RC-2001-15, Minnesota Department of Transportation, St. Paul.

13. FAA, Federal Aviation Administration. (1994) "Geogrid reinforced base course." Engineering Brief No. 49.

14. Gray, B.E. (1939). "Present design practice and construction developments in flexible pavements," Proceedings, Highway Research Board, Washington, D.C.

15. Gregory, G. H., and Bang, S. (1994). "Design of flexible pavement subgrades with geosynthetics." Proceedings of the 30th Symposium on Engineering Geology and Geotechnical Engineering, Boise, Idaho, pp. 569-582.

16. Hadi, M. N. S and Bodhinayake, B. C. (2003). "Non-linear finite element analysis of flexible pavements." Advances in Engineering Software, Vol. 34, pp. 657-662.

17. Henry, K. S., Clapp, J., Davids, W., and Humphrey, D. (2009). "Structural improvements of flexible pavements using geosynthetics for base course reinforcement." Final Report No. ERDC/CRREL TR-09-11, U.S. Army Corps of Engineers, Engineering Research and Development Center, Cold Regions Research and Engineering Laboratory, Hanover, New Hampshire, October 2009.

18. Huang, Y. H. (2003). "Pavement analysis and design ." $2^{\text {nd }}$ Edition, Pearson Education, Upper Saddle River, NJ.

19. Kelly, D., Fairfield, C., and Sibbald, A. (1995). "Geosynthetics for the improvement of unpaved roads." Highways \&Transportation, Vol. 42, No. 07/08, pp. 13-15.

20. Kwon, J., Tutumluer, E., and Kim, M. (2005). "Development of a mechanistic model for geosynthetic-reinforced flexible pavements." Geosynthetics International, 12(6), pp. 310320 .

21. Lai, X., Wang, S., Qin, H., and Liu, X. (2010). "Unsaturated creep tests and empirical models for sliding zone soils of Qianjiangping landslide in the Three Gorges." Journal of Rock Mechanics and Geotechnical Engineering, 20(2), pp.49-54. 
22. Lewis, P. (2008). "Lessons Learned From the Operations Management of an Accelerated Pavement Testing Facility." Proceedings of the $3^{\text {rd }}$ Intl. Confc. On Accelerated Pavement Testing, Madrid, Spain.

23. Marchionna, A., Cesarini, M., Fornaci, M. C., and Malgarini, M. (1985). "Pavement elastic characteristics measured by means of tests conducted with the falling weight deflectometer." Transportation Research Record 1007,Transportation Research Board, Washington D.C., pp. 46-53.

24. Maxwell, S., W. Kim, T. B., and Benson C. H. (2005). "Effectiveness of geosynthetics in stabilizing soft subgrades." Wisconsin Highway Research Program 0092-45-15, Wisconsin Department of Transportation, Madison, WI.

25. Nazzal, M. D., Abu-Farsakh, M. Y., and Mohammad, L. N. (2010). "Implementation of a critical state two-surface model to evaluate the response of geosynthetic reinforced pavements." International Journal of Geomechanics, 10(5), 202-212.

26. Onyango, M. (2009). "Verification of mechanistic prediction models for permanent deformation in asphalt mixes using accelerated pavement testing." Ph.D. Dissertation, Kansas State University, Manhattan, KS.

27. Pavement Interactive. (2008). $\quad$ Retrieved from http://www.pavementinteractive.org/article/pavement-history/

28. Perkins, S. W. (2001). "Numerical modeling of geosynthetic reinforced flexible pavements" FHWA/MT-01-003/99160-2, Western Transportation Institute, Department of Civil Engineering, Montana State University, Bozeman, MT.

29. Perkins, S.W. (1999). "Geosynthetic reinforcement of flexible pavements: laboratory based pavement test sections." Report No. FHWA/MT-99/8106-1, Montana Department of Transportation, Helena, MT.

30. Perkins, S.W. (1999). "Mechanical response of geosynthetic-reinforced flexible pavements," Geosynthetics International, Vol. 6, No. 5, pp. 347-382.

31. Perkins, S.W. and Cortez, E.R. (2005). "Evaluation of base-reinforced pavements using a heavy vehicle simulator." Geosynthetics International, Vol. 12, No. 2, pp. 86-98.

32. Perkins, S.W., and Ismeik, M. (1997). "A synthesis and evaluation of geosyntheticreinforced base layers in flexible pavements: part I," Geosynthetics International, Vol. 4, No. 6, pp. 549-604. 
33. Pokharel, S.K., Han, J., Manandhar, C., Yang, X.M., Leshchinsky, D., Halahmi, I., and Parsons, R.L. (2011). "Accelerated pavement testing of geocell-reinforced bases over weak subgrade." Transportation Research Record: Journal of the Transportation Research Board, No. 2204, Transportation Research Board of the National Academies, Washington, D.C., pp. 67-75.

34. Raad, L. J. and Figueroa, L.(1980). Load response of transportation support systems. ASCE Transportation Engineering Journal, Vol. 106, American Scociety of Civil Engineers, Ruston, VA.

35. Rao, C.S. (1991). "Finite element method for structural design of heavy duty granular pavements." Journal of Computers and Structures, Vol. 40, No. 5, pp. 1223-1233.

36. Sivaneswaran, N., Pierce, L.M., and Mahoney, J.P. (2001). Everseries Pavement Analysis Programs: Everstress, Evercalc and Everpave. Washington State Department of Transportation, Olympia, WA.

37. Tang, X. A (2007). "Study of permanent deformation behavior of geogrid reinforced pavement using small scale accelerated pavement testing." Ph.D. Dissertation, Pennsylvania State University, State College, PA.

38. Tingle, J. S, and Jersey, S. R. (2005). "Cyclic plate load testing of geosynthetic-reinforced unbounded aggregate roads." Transportation Research Record: Journal of the Transportation Research Board, No. 1936, Transportation Research Board of the National Academies, Washington, D.C., pp. 60-69.

39. Vishay Precision Group (2010). "External Bridge Completion for Strain Gauge Circuits”, Application Note VMM-5. Rev. 1, April.

40. Vischer, W. "Low-volume road flexible pavement design with geogrid-reinforced base." Transportation Research Record No. 1819, Transportation Research Board, Washington D.C, 2003.

41. Warren, K.A. and Howard. I.L. (2007). "Sensor selection, installation, and survivability in a geosynthetic-reinforced flexible pavement." Geosynthetics International, Vol. 14, pp. $298-315$

42. Webster, S. L. (1991). "Geogrid reinforced base courses for flexible pavements for light aircraft." Report No. gl-93-6, Report for US Department of Transportation/Federal Aviation Administration/Department of the Army, US Army Corps of Engineers Waterways Experiment Station, Vicksburg, MS. 
43. Webster, S. L. (1992). "Geogrid reinforced base courses for flexible pavements for light aircraft: literature review and test section design." Miscellaneous Paper GL-92-6. U.S. Army Corps of Engineers Waterways Experiment Station, Vicksburg, MS.

44. Webster, S. L., and Alford, S. J. (1978). "Investigation of construction concepts for pavements across soft ground." Technical Report S-78-6. U.S. Army Corps of Engineers Waterways Experiment Station, Vicksburg, Miss.

45. Yang, X. (2010). "Numerical analyses of geocell-reinforced granular soils under static repeated loads." Ph.D. Dissertation, University of Kansas, Lawrence, KS.

46. Zhang, Y. (2007). "Investigation of geosynthetic-soil confinement using asphalt pavement analyzer." MSc. thesis, University of Kansas, Lawrence, KS. 